Nelson Gaspar Dip Júnior

\title{
Análise de expressão de micro RNA em carcinoma urotelial de bexiga
}

\author{
Tese apresentada à Faculdade de Medicina \\ da Universidade de São Paulo para obtenção \\ do Título de Doutor em Ciências \\ Programa de Urologia \\ Orientador: Prof. Dra. Kátia Ramos Moreira \\ Leite
}

São Paulo

2012 
Dados Internacionais de Catalogação na Publicação (CIP)

Preparada pela Biblioteca da

Faculdade de Medicina da Universidade de São Paulo

Creprodução autorizada pelo autor

\section{Dip Júnior, Nelson Gaspar}

Análise de expressão de micro RNA em carcinoma urotelial de bexiga / Nelson Gaspar Dip Júnior. -- São Paulo, 2012.

Tese(doutorado)--Faculdade de Medicina da Universidade de São Paulo.

Programa de Urologia.

Orientadora: Kátia Ramos Moreira Leite.

Descritores: 1.Neoplasias da bexiga urinária 2.Micro RNAs 3.Diagnóstico 4.Prognóstico

USP/FM/DBD-173/12 
“Dedico este trabalho à minha mãe Luiza e a meus irmãos Luís Fernando e Ana Cristina pela incansável força e incentivo constante ao meu crescimento pessoal e profissional" 


\section{Agradecimentos}

A Deus em primeiro lugar, porque sem Ele nada disso seria possível.

À Prof. Dra. Kátia, minha orientadora, por ter me recebido de braços e coração abertos, pelo carinho e compreensão e pela paciência materna em ensinar cada um de nós com rigor e dedicação. São pessoas como você que fazem um mundo melhor. Muito obrigado por sua inesquecível passagem em minha vida.

À minha grande "irmã" Sabrina Thalita dos Reis, pela sua amizade e paciência, pela sua ousadia em crescer cada vez mais, por me ensinar os melhores caminhos dessa difícil jornada. Sá, aqui não cabem palavras para expressar o quão importante é você na minha vida! Muito obrigado mesmo!

Ao Prof. Dr. Miguel Srougi, chefe do serviço de Urologia, por seu imenso espírito de liderança, simplicidade e valorização do ser humano. Muito obrigado por me aceitar nesse programa de pós-graduação e por me mostrar que sempre é possível dar um passo adiante.

Ao Prof. Dr. Marcos Francisco Dall'Oglio, chefe da Uro-oncologia, pelo exemplo de competência e determinação, e pelo apoio à minha formação e crescimento profissional.

Aos Dr. Carlos Alberto Lenzi, pelo incentivo constante ao meu sucesso, pela forma simples de ser, por ter me recebido como um filho. Sem você, tudo seria muito mais difícil. Obrigado!

Daniel Abe e Endric Hasegawa, amigos de todas as horas, com os quais pude contar em todos os momentos de alegrias e dificuldades. Sou eternamente grato a tudo que me ensinaram e por me fazerem uma pessoa melhor a cada dia.

Ao meu eterno amigo Rodrigo Alessandro Parreira, pela parceria direta, pelo ombro amigo e pela força incessante que sempre me deu. Não tenho palavras para te agradecer!

Ao Prof. Dr. Homero, coordenador da Comissão de Pós-Graduação da Disciplina de Urologia da USP, pela seriedade com que conduz esse programa e por estar sempre acessível a solucionar todas as minhas dificuldades. 
Aos médicos e amigos do Laboratório de Investigação Médica LIM-55, José Pontes Junior, Alberto Azobel Antunes, Iran, Camila, Nayara, Caio, Denis, Luciana, Manuel, Michele e Cláudia, por todo auxílio e por todo carinho que me deram. Saibam que sem vocês esse aprendizado não seria possível.

Às secretárias da Urologia Elisa, Tereza e lones, pela atenção dada, pelo tempo desprendido e pela presteza em me ajudar sempre.

Por fim, agradeço aos membros da Urologia do HCFMUSP: médicos, pósgraduandos, residentes e funcionários pelo apoio a mim desprendido. 
"Não há modo de ensinar mais forte e suave que o exemplo: persuade sem retórica, impele sem violência, convence sem debate, desata todas as dúvidas e corta caladamente todas as desculpas. Pelo contrário, fazer uma coisa e aconselhar outra é querer endireitar a sombra da vara torcida".

Manuel Bernardes 
Esta tese está de acordo com as seguintes normas, em vigor no momento desta publicação:

Referências: adaptado de International Committe of Medical Journals Editors (Vancouver).

Universidade de São Paulo. Faculdade de Medicina. Divisão de Biblioteca e Documentação. Guia de apresentação de dissertações, teses e monografias. Elaborado por Anneliese Carneiro da Cunha, Maria Julia de A. L. Freddi, Maria Fazanelli Crestana, Marinalva de Souza Aragão, Suely Campos Cardoso, Valéria Vilhena. 3ạ Ed, São Paulo: Divisão de Biblioteca e Documentação, 2011.

Abreviaturas dos títulos dos periódicos de acordo com List of Journals Indexed in Index Medicus. 
SUMÁRIO

Lista de abreviaturas, símbolos e siglas

Lista de figuras

Lista de tabelas

Resumo

Summary

1.Introdução

1.1 Considerações Gerais

1.2 Epidemiologia do Câncer de Bexiga

1.2.1 Fatores de risco ambientais 4

1.3 Manejo do Câncer de Bexiga 6

1.3.1 Tipos histológicos 6

1.3.2 Estadiamento e graduação tumoral 7

1.3.2.1 Estadiamento TNM 7

1.3.2.2 Graduação histológica 9

1.3.3 Métodos diagnósticos 10

1.3.4 Tratamento 11

1.4 Biologia Molecular do Câncer de Bexiga 13

1.4.1 Alterações genéticas do CUB não invasivo 13

1.4.2 Alterações genéticas do CUB invasivo 16

1.4.3 Epigenética do CUB 19

1.4.4 Micro RNA 20

1.4.4.1 Biogênese de miRNA 20

1.4.4.2 Funções de micro RNA 21

2. Objetivos 23

3. Métodos 25

$\begin{array}{ll}3.1 \text { Pacientes } & 26\end{array}$

3.2 Exame macro e microscópico___ $\quad 27$

$\begin{array}{ll}\text { 3.3 Processamento do RNA } & 28\end{array}$ 
3.3.1 Isolamento do miRNA 28

$\begin{array}{ll}\text { 3.3.2 Síntese do cDNA___ } 28 & 28\end{array}$

$\begin{array}{ll}\text { 3.3.3 Amplificação do miRNA___ } 29 & 29\end{array}$

3.4 Análise dos resultados___ 31

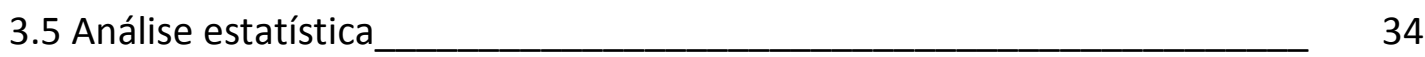

4. Resultados__ 36

4.1 Padrão de expressão geral em carcinoma urotelial de bexiga____ 37

4.2 Perfil de expressão de miRNA nos carcinomas de baixo grau, pTa e $\begin{array}{ll}\text { carcinomas de alto grau, pT2-3___ } & 37\end{array}$

4.3 Perfil de expressão de miRNA, recidiva e sobrevida câncer-específica____ $\quad 41$

$\begin{array}{ll}\text { 5. Discussão___ } & 44\end{array}$

5.1 Considerações finais___ 56

6. Conclusões__

$\begin{array}{ll}\text { 7. Anexos__ } & 60\end{array}$

8. Referências Bibliográficas____ 69

Apêndices 
Lista de Siglas

AcB RT112 - Linhagem celular tumoral de bexiga

AJCC - Junta Americana Contra o Câncer

AKT - Serina-Treonina Quinase de 60 kDa

BCG - Bacilo de Calmett-Guerin

$\mathrm{CaB}$ - Câncer de Bexiga

CDK2 - Quinase Ciclina-dependente tipo 2

CDK4 - Quinase Ciclina-dependente tipo 4

CDKN1A - Inibidor de Quinase Ciclina-dependente tipo 1A

cDNA - Ácido Desoxirribonucléico complementar

Cis - Carcinoma in situ

CUB - Carcinoma Urotelial de Bexiga

FGF - Fator de Crescimento Fibroblástico

FGFR3 - Gene do Receptor do Fator de Crescimento Fibroblástico tipo 3

HPB - Hiperplasia Prostática Benigna

ISUP - Sociedade Internacional de Patologia Urológica

MAPK - Proteína Quinase Mitogênica Ativada

miRNA - micro RNA

mTOR - Gene Alvo da Rapamicina de Mamíferos

NUBPM - Neoplasia Urotelial de Baixo Potencial de Malignidade

p53RE - Elemento de Resposta de p53

PCR - Reação de Polimerase em Cadeia

PET-CT - Tomografia com Emissão de Pósitrons

PI3K - Fosfatidilinositol 3 quinase

PTEN - Gene Homólogo da Fosfatase e Tensina

qRT-PCR - Quantificação do produto da PCR em Tempo Real

QT - Quimioterapia

RAS - Gene do Sarcoma de Rato

RB1 - Gene do Retinoblastoma 
Re-RTU - Re-ressecção Transuretral

RISC - Complexo Silenciador Induzido por RNA

RNM - Ressonância Nuclear Magnética

RTU - Ressecção Transuretral

R-X - Raio-X

scFv - Anticorpo anti-FGFR3 de cadeia simples

STAT - Transdutor de Sinal e Ativador de Transcrição

TC - Tomografia Computadorizada 
Figura 1 - Vias de carcinogênese do carcinoma urotelial de bexiga 14

Figura 2 - Esquema demonstrando a biogênese de miRNA 21

Figura 3 - Síntese do DNA complementar 29

Figura 4 - Amplificação do miRNA pelo método TaqMan ${ }^{\circledR}$ 30

Figura 5 - Esquema metodológico do estudo 34

Figura 6 - Perfil de expressão dos 14 miRNA nos tumores de baixo grau, pTa_ 39

Figura 7 - Perfil de expressão dos 14 miRNA nos tumores de alto grau, pT2-3 40

Figura 8 - Curva de Kaplan-Meyer demonstrando a diferença de sobrevida livre de recidiva de tumores pTa de baixo grau em relação à expressão de miR-21

Figura 9 - Curva de Kaplan-Meyer demonstrando as diferenças de sobrevida livre de recidiva e câncer-específica para o miR-10a em tumores de alto grau pT2-3

Figura 10 - Curva de Kaplan-Meyer demonstrando as diferenças de sobrevida livre de recidiva em tumores de alto grau pT2-3 em relação à expressão do miR-145 
Lista de Tabelas

Tabela 1 - Classificação TNM/AJCC 2010

8

Tabela 2 - Prognóstico das neoplasias uroteliais segundo Desai et al., 2000

10

Tabela 3 - Características demográficas dos grupos estudados

26

Tabela 4 - Micro RNA analisados e seus possíveis genes-alvo 32

Tabela 5 - Especificações dos micro RNA estudados

Tabela 6 - Níveis de expressão dos 14 miRNA conforme grau e estádio 


\section{RESUMO}

Dip Júnior NG. Análise de Expressão de Micro RNA em Carcinoma Urotelial de Bexiga [tese]. São Paulo: Faculdade de Medicina, Universidade de São Paulo; 2012.

Introdução: O câncer de bexiga é a segunda neoplasia maligna mais frequente do trato urinário, com 386.000 casos estimados e 150.000 mortes para 2011 no mundo. Noventa e cinco por cento são carcinomas uroteliais (CUB) papilíferos não músculo-invasivos de baixo grau, que apresentam altas taxas de recidiva, mas raramente progridem. Tumores invasivos de alto grau representam $10-20 \%$ dos diagnósticos, são altamente agressivos levando à mortalidade elevada. 0 conhecimento das vias moleculares envolvidas na carcinogênese dessa neoplasia é importante para a identificação de novos marcadores para diagnóstico, acompanhamento, prognóstico e desenvolvimento de novas terapias alvo. Micro RNA (miRNA) são pequenas sequências não codificantes de RNA que regulam a expressão dos genes inibindo a tradução da proteína ou promovendo a degradação do RNA mensageiro, estando atualmente envolvidos em vários processos celulares fisiológicos e patológicos, incluindo o câncer. Objetivos: Caracterizar o perfil de expressão de miRNA no CUB, relacionando-o com os parâmetros prognósticos clássicos para a doença: grau histológico e estadiamento. Além disso, relacionar esse padrão de comportamento dos miRNA com a recidiva tumoral e sobrevida câncer-específica em pacientes tratados cirurgicamente para CUB. Material e Métodos: Catorze miRNA (miR-100, miR-10a, miR-21, miR-205, miR-let7c, miR125b, miR-143, miR-145, miR-221, miR-223, miR-15a, miR-16-1, miR-199a e miR452) foram isolados de espécimes cirúrgicos de 60 pacientes divididos em 2 grupos: 30 pacientes com CUB não invasivo ( $\mathrm{pTa}$ ) de baixo grau submetidos à RTU de bexiga, 30 com CUB invasivo (pT2-3) de alto grau submetidos à cistectomia radical. $O$ grupo controle é representado por cinco pacientes portadores de bexiga normal sem CUB que realizaram tratamento cirúrgico aberto para tratamento da hiperplasia prostática benigna (HPB). O processamento dos miRNA envolveu três fases: (1) extração do miRNA com kit específico, (2) geração do DNA complementar e (3) amplificação do miRNA por PCR quantitativo em tempo real (qRT-PCR). A expressão de cada miRNA foi obtida através do cálculo $2^{-\Delta \Lambda C T}$ e os RNU-43 e RNU-48 foram utilizados como controles endógenos. Testes estatísticos foram aplicados para estudar as variáveis envolvidas e curvas de Kaplan-Meyer foram usadas para avaliar a sobrevida livre de recidiva (SLR) e sobrevida câncer-específica (SCE). Resultados: Dos 14 miRNA estudados a maioria apresentou subexpressão nos dois grupos de tumor analisados, com exceção do miR-10a para o grupo pTa de baixo grau e do miR-100, 21 e 205 para os tumores pT2/pT3 de alto grau, onde demonstraram-se superexpressos. Essas diferenças de expressão de miRNA entre os dois grupos foram estatisticamente. Quando estudamos a relação entre expressão de miRNA e a evolução dos pacientes através de curvas de sobrevida, observamos que maiores níveis de expressão do miR-21 relacionou-se com menor SLR para tumores pTa. Ainda, maiores concentrações de miR-10a e miR-145 se associaram com menor SLR e maiores níveis de miR-10a com menor SCE para tumores pT2-3. Conclusões: Demonstramos um predomínio de subexpressão de miRNA em 
carcinomas de bexiga. Os miR-100, miR-10a, miR-21 e miR-205 demonstraram diferenças no perfil de expressão para grau e estadiamento dentro dos dois grupos de tumor, sendo capazes de diferenciá-los. Maiores níveis de miR-21 se relacionaram com menor SLR para tumores pTa de baixo grau, enquanto maiores concentrações de miR-10a estiveram associadas com menor SLR e SCE para tumores pT2/pT3 de alto grau.

Descritores: Neoplasias da bexiga urinária, micro RNAs, Diagnóstico, Prognóstico 


\section{SUMMARY}

Dip Júnior NG. Analysis of micro RNA expression in bladder urothelial carcinoma [thesis]. Sao Paulo: University of Sao Paulo Medical School; 2012.

Introduction: Bladder cancer $(\mathrm{BC})$ is the second most common malignancy of the urinary tract, with 386,000 cases estimated and 150,000 deaths in 2011. Urothelial carcinomas (UC) represent $95 \%$ of BC cases, and knowledge of the molecular pathways associated with $\mathrm{BC}$ carcinogenesis is crucial to identify new diagnostic and prognostic biomarkers, and development of new target molecular therapies. MicroRNAs (miRNAs) are short non-coding RNA molecules that play important roles in the regulation of gene expression by acting directly on mRNAs, leading to either mRNA degradation or inhibition of translation, involved in many physiological and pathological processes, including cancer. Objectives: To characterize miRNAs expression profiles in UC, associating with classic prognostic factors: grade and stage. Moreover, correlate miRNA expression with tumor recurrence and survival. Material and Methods: Fourteen miRNAs (miR-100, miR-10a, miR-21, miR-205, miR-let7c, miR-125b, miR-143, miR-145, miR-221, miR-223, miR-15a, miR-16-1, miR199a e miR-452) were isolated from surgical specimens from 60 patients classified in two groups: 30 patients with low-grade non-invasive pTa UC that underwent TURB, 30 with high-grade invasive pT2/pT3 UC underwent radical cystectomy. The control group consists in five normal bladder tissue taken from patients that underwent retropubic prostatectomy to treat benign prostatic hyperplasia (BPH). miRNA processing involved three phases: (1) miRNA extraction by specific kits, (2) cDNA generation (3) miRNA amplification through qRT-PCR. Expression profiles were obtained by relative quantification determined by $2^{-\Delta \Delta c t}$ method. Endogenous control were RNU-43 and RNU-48. Statistic tests were used to study the prognostic variables and Kaplan-Meyer curves were constructed to analyze disease-free (DFS) and disease-specific (DSS) survivals. Results: All miRNAs were underexpressed in both groups, except miR-10a in pTa and miR-100, 21 and 205 in pT2/pT3 tumors, that where over-expressed. miR-100, miR-21, miR-10a and miR-205 differentialy expressed in both groups and this differences were statistically significant. The Kaplan-Meyer survival curves showed that higher levels of miR-21 were related to shorter DFS for pTa group. Also, higher levels of miR-10a and miR-145 were associated with shorter DFS and higher levels of miR-10a were also related to shorter DSS in pT2/pT3 group. Conclusions: The majority of miRNA were shown to be underexpressed in bladder UC. miR-100, miR-10a, miR-21 and miR-205 were differentially expressed considering tumor grade and stage. The miRNA profile was able to distinguish pTa low grade and pT2-3 high grade tumors. Higher levels of miR21 were related to shorter DFS in $\mathrm{pTa}$, while higher levels of miR-10a were associated with shorter DFS and DSS in pT2-3, high grade UC.

Descriptors: Bladder neoplasms, micro RNAs, Diagnosis, Prognosis 
1. INTRODUÇÃO 


\subsection{Considerações Gerais}

O câncer de bexiga $(\mathrm{CaB})$ é o segundo tumor maligno urológico em incidência e uma das neoplasias mais estudadas atualmente, com história e biologia ainda não bem definidas. O seu desenvolvimento está relacionado à exposições ambientais que através de mecanismos genéticos e epigenéticos alteram a maquinaria celular propiciando a instalação do processo carcinogênico. No mundo, ele é responsável por aproximadamente 386.000 novos casos e 150.000 óbitos por ano (Jemal et al., 2011), sendo considerado uma patologia de grande impacto sócioeconômico com custos extremamente elevados para os sistemas de saúde (Botteman et al., 2003).

Parâmetros clínicos e patológicos convencionais são empregados para graduação e estadiamento dessa neoplasia e são as únicas ferramentas atualmente utilizadas para predizer os desfechos da doença. Contudo, a habilidade de previsão desses parâmetros é limitada e faltam dados que permitam uma análise prospectiva dos riscos de progressão e comportamento do $\mathrm{CaB}$.

O conceito de que o $\mathrm{CaB}$ é uma doença de várias fases é suportado por uma série de evidências científicas e uma gama de alterações são necessárias para que o tumor se apresente clinicamente. Dessa forma, ele tem sido utilizado como uma das mais importantes fontes de informação sobre eventos mutacionais que engatilham as vias carcinogênicas e o desenvolvimento de tumores sólidos humanos (Knowles, 2008; McConkey et al., 2010).

Apesar das vias genético-moleculares estarem relativamente bem demonstradas e alguns marcadores tumorais estabelecidos, existem muitas questões a serem respondidas em relação ao comportamento biológico da doença sendo necessários novos métodos que prevejam o comportamento do $\mathrm{CaB}$ de forma mais específica. 


\subsection{Epidemiologia do Câncer de Bexiga}

O câncer é um dos maiores problemas de saúde pública em muitas partes do mundo. Segundo o National Cancer Institute, atualmente uma em cada quatro mortes nos Estados Unidos (EUA) deve-se a ele, sendo a segunda causa geral de morte, representando $23,2 \%$ do total de mortes nesse país.

O CaB coloca-se neste painel de importância como o segundo tumor mais comum do trato gênito-urinário (Enokida e Nakagawa, 2008), assumindo o 70 lugar entre os tumores e a 9a causa de óbito. No Brasil, em 2009, foram registrados 3002 óbitos (2090 homens e 912 mulheres) e a projeção para 2012 é de 8900 novos casos (www.inca.gov.br). Do nascimento até a morte, a chance de um homem desenvolver $\mathrm{CaB}$ é de 3,8\% e a mulher 1,2\%, incluindo o tipo invasivo e o carcinoma in situ (Cis).

É um tumor raro antes dos 40 anos, com aumento significativo após a sétima década de vida (Jemal et al., 2011). Apesar de o tumor ser mais frequente no homem, existem evidências que demonstram que na mulher ele tem um comportamento mais agressivo (Mungan et al., 2000). A maior incidência desses tumores em homens não é completamente explicada por diferenças no hábito de fumar e ocupacionais, os dois principais fatores de risco para a doença. Quando se leva em consideração a incidência e mortalidade em mulheres, parece que as multíparas têm risco menor que as nulíparas, provavelmente devido às alterações hormonais relacionadas à gestação, e este risco pode ser cada vez menor quanto maior a paridade (Cantor et al., 1992).

Variações biológicas também podem modificar a expressão e ação de genes relacionados às diversas fases da carcinogênese, tais como a conversão de prócarcinógenos em carcinógenos, a detoxificação carcinogênica e o reparo do DNA.

Oitenta e seis por cento dos CaB são diagnosticados na forma localizada, 8\% com extensão locorregional e $4 \%$ já como doença metastática. A sobrevida em cinco anos vem aumentando, sendo de $74 \%$ em 1975-1977, 78\% em 1984-1986 e 82\% em 
1999-2005, com redução de mortalidade média de 5\% entre 1990 e 2006 (Jemal et al., 2011). A melhoria desses índices tem relação direta com a precocidade do diagnóstico e a maior disponibilidade e eficácia do tratamento.

Existe um impacto importante na sobrevida quando se leva em consideração os diferentes estágios tumorais. Nos EUA, a sobrevida em seis anos é de $94 \%$ para Cis, $74 \%$ para os tumores pTa e pT1, 36\% para a doença locorregional e apenas $6 \%$ para o CaB disseminado (Jemal et al., 2011).

\subsubsection{Fatores de risco ambientais}

O fator de risco mais bem estabelecido para o CaB é o consumo do tabaco na forma de cigarros, embora esta associação não seja tão forte quanto a observada entre o tabagismo e o desenvolvimento de neoplasias malignas respiratórias. Apesar disso, o fumo aumenta o risco de tumores em duas a quatro vezes, e o aumento da intensidade e/ou duração do consumo está diretamente relacionado a um incremento do mesmo, com período médio de latência de 20 a 30 anos, de modo que 30 a 50\% dos CaB são causados pelo uso do cigarro (Kirkali et al., 2005). Enzimas metabólicas, vitaminas e outros agentes podem modificar a suscetibilidade induzida pelo tabagismo, e o risco retorna aos níveis basais apenas após 20 a 30 anos o indivíduo ter deixado de fumar.

A ocupação é o segundo fator de risco mais importante para a doença. Foi estimado que a exposição ocupacional pode ser responsável por até $20 \%$ de todos os cânceres vesicais. Exposição à $\beta$-naftilamina, 4-aminobifenil (ABP) e benzidina, principalmente entre os trabalhadores de indústrias de tinta e de borracha, mostram relação direta com o desenvolvimento da doença. Contudo, existem muitos outros fortes candidatos a carcinógenos como a ortotoluidina, que é usada na fabricação de tintas, borracha, produtos farmacêuticos e pesticidas (Markowitz e Levin, 2004). De fato, muitas ocupações têm sido relacionadas ao aumento do risco para o desenvolvimento do $\mathrm{CaB}$, principalmente a exposição às aminas aromáticas 
(arilaminas) e também ao alumínio, ferro, carvão e diesel (Theriault et al., 1984; Boffetta e Silverman, 2001; Gaertner e Theriault, 2002).

A infecção urinária crônica está associada ao desenvolvimento de $\mathrm{CaB}$, principalmente o carcinoma de células escamosas. Esse tipo de tumor pode ocorrer em pacientes vítimas de trauma raquimedular e pacientes sondados por longo tempo, onde infeç̧ões de repetição são comuns. O processo inflamatório crônico pode gerar nitritos e nitrosaminas, que levam a um aumento da proliferação celular, propiciando erros genéticos. 


\subsection{Manejo do Câncer de Bexiga}

Muitas características do $\mathrm{CaB}$ foram estudadas na tentativa de predizer o comportamento do tumor. $O$ estadiamento e a graduação tumoral são fundamentais para decisão terapêutica, e o entendimento da epidemiologia e estratégias de rastreamento podem ser úteis na prevenção e deteç̧ão precoce da doença.

Embora o arsenal diagnóstico e terapêutico seja bastante amplo e todo esforço voltado às tentativas de melhoria de sobrevida, o CUB ainda cursa com respostas insatisfatórias aos tratamentos, progressão da doença e índices elevados de mortalidade. Isso decorre da rápida progressão e diagnóstico tardio, imprevisibilidade de comportamento das lesões e da falta de métodos que permitam prevê-lo. Dessa forma, existe a necessidade urgente de outras ferramentas que nos permitam classificar e prever com mais segurança o padrão evolutivo do CUB, especialmente técnicas de biologia molecular através de marcadores tumorais confiáveis e específicos.

\subsubsection{Tipos histológicos}

O tipo histológico mais frequente é o carcinoma urotelial de bexiga (CUB), que ocorre em 80 a 90\% dos casos e pode se apresentar de modo bastante variado, desde uma pequena lesão intravesical, bem diferenciada, não invasiva até a doença avançada que invade a parede vesical e os órgãos adjacentes, sendo os principais fatores prognósticos o grau e o estádio tumoral (McConkey et al., 2010).

Outros tipos de tumor de origem epitelial são menos comuns e incluem o carcinoma de células escamosas, relacionado à infecções urinárias crônicas e infestação por Schistosoma hematobium e o adenocarcinoma, que pode ser derivado do úraco ou primário da bexiga (Heney, 1992). Tumores mesenquimais e linforreticulares também acometem a bexiga, mas são raros. 


\subsubsection{Estadiamento e graduação tumoral}

\subsubsection{Estadiamento TNM}

O estádio patológico está entre os mais importantes fatores prognósticos no CUB e é crítico para a tomada de condutas e acompanhamento do paciente. $\mathrm{O}$ sistema mais comumente utilizado é o que avalia extensão tumoral (T), o comprometimento de linfonodos $(\mathrm{N})$ e a presença de metástases (M), atualizado periodicamente pela Junta Americana Contra o Câncer (AJCC)(Tabela 1).

De modo simplificado, o estadiamento discrimina dois tipos principais de tumores com implicações importantes na decisão terapêutica. O CUB denominado erroneamente como "superficial" pode ser classificado como não invasivo (pTa) ou invasivo na lâmina própria (pT1), e o CUB invasivo é aquele que acomete pelo menos a camada muscular própria ou músculo detrusor, sendo estadiado pT2. O comprometimento da gordura perivesical o classifica como pT3 e a invasão de órgãos adjacentes e parede pélvica como pT4. Entre 70 a $80 \%$ dos tumores vesicais são pTa ou pT1 e têm como característica altas taxas de recorrência (50 a 70\%) sendo que apenas 10 a 15\% progridem para maior grau ou estádio. Aqueles que já se apresentam como invasivos ao diagnóstico, que correspondem a 10 a $20 \%$ dos casos, tendem a progredir rapidamente e têm prognóstico desfavorável (Borden et al., 2005).

Apesar dessa distinção entre os tipos tumorais, existe ainda grande dificuldade em diferenciar de maneira absoluta quais os tumores que progredirão e/ou recorrerão após o tratamento inicial, pois tumores de morfologia similar podem comportar-se de maneira diferente. Este fato é relevante no momento em que as modalidades terapêuticas, tanto curativas quanto paliativas, apresentam graus expressivos de morbidade. 
Tabela 1 - Classificação TNM/AJCC 2010

\section{Tumor Primário (T)}

Tx

TO

$\mathrm{Ta}$

Tis

T1

T2

T3

T4

\section{Linfonodos (N)}

Tumor primário não pode ser avaliado

Sem evidência de tumor primário

Tumor papilífero não invasivo

Carcinoma in situ (Cis)

Invade a lâmina própria

Invade a muscular própria superficialmente Invade a muscular própria profundamente Invade a gordura perivesical microscopicamente Invade a gordura perivesical macroscopicamente Invade o estroma próstatico, útero ou vagina Invade a parede pélvica ou abdominal

\section{Nx}

NO

N1

N2

N3
Linfonodos não podem ser avaliados

Sem evidência de metástase linfonodal

Único linfonodo positivo em região de drenagem primária

Múltiplos linfonodos em regiões de drenagem primária

Cadeia ilíaca comum positiva

\section{Metástases à distância (M)}

\begin{tabular}{ll}
\hline Mx & Metástases não podem ser avaliadas \\
M0 & Sem evidência de metástase à distância \\
M1 & Presença de metástases à distância \\
\hline
\end{tabular}




\subsubsection{Graduação histológica}

O grau histológico é ao lado do estádio, o mais importante fator de risco para progressão de lesões neoplásicas no CUB. O sistema adotado atualmente é aquele publicado pela OMS/ISUP.

- Lesões planas

- Lesões planas com atipias

- Carcinoma in situ (Cis)

- Lesões papilíferas

- Papiloma

- Neoplasia urotelial com baixo potencial de malignidade (NUBPM)

- Carcinoma papilífero de baixo grau

- Carcinoma papilífero de alto grau

$\mathrm{Na}$ tentativa de simplificar a linguagem e o entendimento entre patologistas, urologistas e oncologistas, o sistema OMS/ISUP passou a denominar os carcinomas papilíferos uroteliais em apenas duas categorias: baixo e alto grau. Carcinoma urotelial papilífero de baixo grau possui uma aparência geral com mínimas variações na arquitetura e/ou características citológicas, que são facilmente reconhecidas. Os tumores de alto grau são caracterizados por uma aparência desorganizada a partir de importantes anormalidades arquiteturais e citológicas. Vários estudos validaram a aplicabilidade desse sistema de graduação. Desai et al. (2000) estudando 120 pacientes com tumores pTa e pT1 pelo sistema de classificação OMS/ISUP e suas relações com padrões imuno-histoquímicos observaram o que segue na Tabela 2. Embora papilomas não cursem com recorrência ou progressão e NUBPM apenas com recorrência, lesões de baixo e alto grau mostraram progressão e, em alguns casos, resultaram em óbito. 
Tabela 2 - Prognóstico das neoplasias uroteliais segundo Desai et al., 2000

\begin{tabular}{lcccc}
\hline & Papiloma & NUBPM & Baixo grau & Alto grau \\
\hline Recorrência & 0 & $33,3 \%$ & $64,1 \%$ & $56,4 \%$ \\
Progressão & 0 & 0 & $10,5 \%$ & $27,1 \%$ \\
Invasão da lâmina própria & 0 & 0 & $2,6 \%$ & $8,3 \%$ \\
Invasão do detrusor & 0 & 0 & $5,3 \%$ & $6,3 \%$ \\
Metástases & 0 & 0 & $10,6 \%$ & $25 \%$ \\
\hline
\end{tabular}

\subsubsection{Métodos diagnósticos}

Várias ferramentas têm auxiliado na prevenção e diagnóstico do CUB, porém elas ainda são um tanto quanto inespecíficas quando alguns aspectos são considerados.

O rastreamento tem por objetivo melhorar a sobrevida através da deteç̧ão precoce do tumor. Métodos computacionais sugerem que ele pode ser vantajoso e reduzir a mortalidade em indivíduos de alto risco. Contudo, seu papel ainda não está totalmente estabelecido (Kirkali et al., 2005).

O sintoma mais comum é a hematúria indolor, que ocorre em aproximadamente $85 \%$ dos pacientes (Kirkali et al., 2005). A vasta maioria dos pacientes é diagnosticada através desse sinal típico de suspeição, associado à citologia urinária e cistoscopia, métodos que tornam o custo de seguimento da doença extremamente elevado (Babjuk et al., 2009).

Tomografia Computadorizada (TC) e Ressonância Nuclear Magnética (RNM) representam os principais métodos de imagem para estadiamento da doença. Contudo, apesar de métodos de alta tecnologia, eles não são capazes de diferenciar lesões entre pT1 e pT3 porque não podem identificar a extensão microscópica do CUB (Paik et al., 2000). Assim, os maiores problemas com esses métodos são os erros de super e subestadiamento (Tritschler et al., 2011). Para melhorar essa 
acurácia, técnicas interessantes como tomografia com emissão de pósitrons (PETCT) e RNM com nanopartículas de ferro têm sido recentemente introduzidas (Eisner e Feldman, 2009; Belakhlef et al., 2012).

A ressecção transuretral (RTU) do tumor vesical propicia informações diagnósticas e benefícios terapêuticos. Os principais objetivos da RTU são remover todo tecido tumoral se tecnicamente factível, e obter material de boa qualidade que permita adequada análise histopatológica (Babjuk et al., 2009; Miyamoto e Epstein, 2010).

Marcadores moleculares oferecem o potencial de caracterizar neoplasias uroteliais individualmente e de forma mais completa em relação à avaliação histológica apenas. Eles podem ser empregados na avaliação da recorrência tumoral, estadiamento molecular, detecção de doença avançada, identificação de alvos terapêuticos, previsão de resposta aos tratamentos e, principalmente, na detecção precoce da doença mesmo antes de seu aparecimento (Proctor et al., 2010). O crescente avanço da biologia molecular dos tumores uroteliais de bexiga tem auxiliado pesquisadores a traçarem uma relação direta entre os achados genético-moleculares e os resultados clínicos.

\subsubsection{Tratamento}

O tratamento do $\mathrm{CaB}$ depende de sua forma de apresentação principalmente do tipo histológico, do estádio e do grau (Miyamoto e Epstein, 2010).

Neoplasias não músculo-invasivas ( $\mathrm{pTa}$ e pT1) recorrem com freqüência e progridem para doença músculo-invasiva em um número limitado de casos, sendo geralmente submetidas a tratamento mais conservador. A RTU é sempre a primeira forma de tratamento para essas neoplasias seguida de terapia intravesical imuno ou quimioterápica. O tratamento de eleição do CUB não invasivo é a imunoterapia baseada no bacilo de Calmette-Guérin (BCG), que ainda não possui um protocolo 
padrão de utilização, no que diz respeito ao tempo e freqüência de aplicações (Babjuk et al., 2009). Estudos de meta-análise confirmam o benefício do BCG após a RTU, em relação à RTU apenas ou associada com QT na prevenção de recidiva e progressão de tumores não invasivos. A terapia de manutenção é sempre indicada nos tumores de alto risco. O esquema ideal ainda não está definido, porém um dos esquemas empíricos mais utilizados é o do Southwest Oncology Group (SWOG). A cistectomia radical é recomendada em pacientes nos quais houve falha do BCG. $O$ atraso no tratamento cirúrgico radical pode levar ao comprometimento da sobrevida câncer-específica (Fritsche et al., 2010).

Em tumores músculo-invasivos, a cistectomia é a melhor forma de controle da doença propiciando as maiores taxas de sobrevida (Herr et al., 2004), e deve ser realizada precocemente, devido a alta velocidade de progressão desses tumores. Gore et al. (2009) demonstraram que quanto mais precoce sua realização, maior é a sobrevida câncer-específica e menor a mortalidade e que, quando existe um atraso maior que três meses no tratamento cirúrgico radical estes parâmetros se invertem. O protocolo do National Comprehensive Cancer Network (NCCN) e muitos outros protocolos definem como padrão-ouro de terapia para o CaB músculo-invasivo a cistectomia radical associada à linfadenectomia pélvica, enquanto tratamentos alternativos ficam reservados aos casos onde existem comorbidade graves (Montie et al., 2009; Gore et al., 2009). Por fim, protocolos de preservação vesical podem ser aplicados a pacientes selecionados. Esses protocolos ainda não estão definidos e várias formas de tratamento são aplicadas e/ou combinadas entre si, e englobam RTU radical, QT intravesical, radioterapia, braquiterapia intravesical, cistectomia parcial, entre outros. 


\subsection{Biologia Molecular do Câncer de Bexiga}

Um grande número de eventos genéticos está envolvido na etiologia, progressão e resposta ao tratamento do CUB (Garcia del Muro et al., 2004). A elucidação de vias moleculares envolvidas no processo carcinogênico da doença é essencial para o entendimento de sua etiopatogenia e comportamento.

\subsubsection{Alterações genéticas do CUB não invasivo}

As vias carcinogênicas das quais derivam os tumores papilíferos de baixo grau não invasivos e os carcinomas de alto grau, invasivos são específicas e mutuamente exclusivas e estão ilustradas na Figura 1 (van Rhijn et al., 2004; Bakkar et al., 2003; Pandith et al., 2010). A maioria das neoplasias malignas vesicais é não músculo-invasiva na apresentação inicial e sua principal rota carcinogênica é via mutação do gene que codifica o receptor do fator de crescimento fibroblástico tipo 3 (FGFR3). Porém, menos comumente mutações do gene RAS também têm sido descritas.

O gene FGFR3, localizado na região cromossômica 4p16.3 (Thompson et al., 1991) tem 18 éxons e pertence à família dos receptores de fator de crescimento do tipo tirosina quinase, envolvidos em funções relacionadas à embriogênese e manutenção da homeostase tecidual (Pandith et al., 2010). Esses receptores regulam vários processos biológicos, incluindo proliferação, diferenciação e migração celular, além da apoptose (Ornitz et al., 1996). Possuem uma estrutura comum, que compreende um domínio extracelular, um domínio transmembrana hidrofóbico e um domínio intracelular tirosina quinase. A ligação do FGF ao seu receptor FGFR3 leva ao estímulo dos segundos mensageiros através do domínio intracelular. Essa via de ativação pode produzir tumores bem diferenciados e de baixo grau. Mutações ou outras alterações que levam à superatividade de FGFR3 alteram a proliferação celular, mas têm pouco efeito na diferenciação e apoptose, 
propiciando uma vantagem para o crescimento das células cancerosas, mantendo, porém, sua estabilidade genômica.

Dois mecanismos são capazes de levar à atividade anormal de FGFR3, isto é, a translocação $t(4 ; 14)$ que resulta em superexpressão da proteína, e a mutação puntiforme que resulta em ativação anômala do receptor sem a necessidade do ligante. A primeira evidência de que FGFR3 poderia ser um oncogene foi observada no mieloma múltiplo, uma neoplasia plasmocítica, onde a expressão alterada do gene foi observada em 10 a $25 \%$ dos pacientes. Mutações de FGFR3 no CUB foram relatadas pela primeira vez por Cappellen et al. (1999), que as identificaram em 35\% desses tumores. As mutações nos códons 248, 249 e 375 compreendem mais de 95\% de todas as mutações de FGFR3, sendo o códon 249 responsável por aproximadamente $70 \%$ delas.

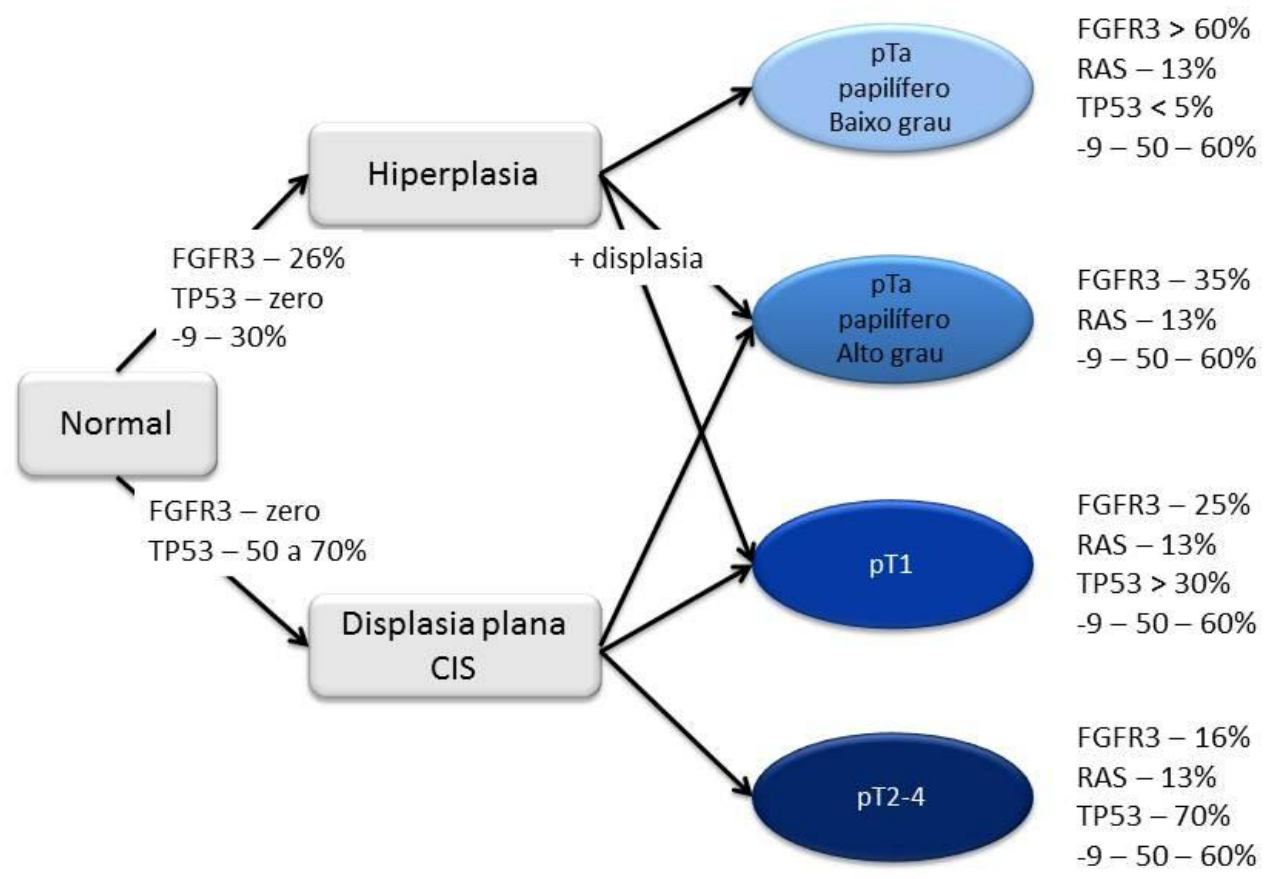

Figura 1 - Vias de carcinogênese do carcinoma urotelial de bexiga 
As mutações mais freqüentes de FGFR3 podem ser provocadas pelo fumo ou exposição ambiental a carcinógenos que criam um resíduo extracelular de cisteína e ativam o domínio tirosina quinase, cursando com diminuição da especificidade pelo ligante e conseqüente dimerização e autofosforilação do domínio intracelular. van Rhijn et al. (2001) relataram uma associação entre a mutação de FGFR3 e a presença de carcinomas uroteliais de baixo grau ou papilomas em mais de $70 \%$ dos casos de tumores pTa. Nos tumores músculo-invasivos essas mutações podem estar presentes, mas em taxas bastante reduzidas (até 15\% dos casos). Apesar desses dados de literatura apontarem o FGFR3 mutado como marcador molecular do pTa, eles são controversos na previsão do risco de recorrência e progressão da doença (Pandith et al., 2010).

Em 2007, Tomlinson et al. desenharam um estudo para investigar a mutação no gene FGFR3 e sua associação com a superexpressão de seu produto protéico, correlacionando-os com o estádio e grau tumoral, e $85 \%$ dos tumores que apresentaram mutação, também possuíam superexpressão protéica de FGFR3. Parece possível que a mutação em FGFR3 seja um evento precoce no desenvolvimento desse tipo de tumor e, na maioria dos casos, pode proteger da progressão para doença músculo-invasiva.

Mutações no oncogene RAS também têm sido relacionadas a tumores não invasivos. Em 1982, Der et al. descobriram que o gene HRAS, um dos primeiros oncogenes humanos descritos, também estava associado ao CUB sendo identificado na linhagem celular T24. Existem três genes da família RAS, o H-RAS, o K-RAS e o NRAS que têm um envolvimento direto no desenvolvimento de $30 \%$ dos cânceres humanos (van der Weyden e Adams, 2007). RAS atua regulando e controlando diversas funções celulares como a proliferação, diferenciação, motilidade e apoptose, em resposta a sinais extracelulares. No CUB parece agir através da ativação da via MAPK (proteína quinase mitogênica ativada) ou das vias AKT/STAT (Jebar et al., 2005). Mo et al. (2007) estudaram H-RAS e o comportamento dos tumores vesicais não invasivos e demonstraram uma relação entre o oncogene e o 
grau e a agressividade tumoral. Os autores concluíram que a superativação de $\mathrm{H}$ RAS por mutação puntiforme e superexpressão, é necessária e suficiente para induzir tumores vesicais não invasivos e que a inibição dessa atividade poderia ser uma alternativa terapêutica. Finalmente, Przybojewska et al. (2000) mostraram que H-RAS encontra-se ativo em $84 \%$ dos espécimes de CUB não invasivos. Mutações no gene N-RAS se mostraram semelhantes às do H-RAS, sugerindo uma relação entre eles na neoplasia vesical, enquanto que alterações no K-RAS parece ser um evento raro.

Interessante é que mutações do gene RAS e FGFR3 parecem não ocorrer concomitantemente sendo, portanto, eventos mutuamente exclusivos indicando equivalência biológica desses dois tipos de mutação (Jebar et al., 2005).

Uma vez que a ativação do FGFR3 através da mutação é o evento-chave para o desenvolvimento de tumores pTa de baixo grau, especula-se seu papel como o primeiro marcador molecular de doença não agressiva (Rieger-Christ et al., 2003). Ainda, FGFR3 pode ser alvo de drogas e o bloqueio do receptor com anticorpos é de grande interesse, sendo considerado como potencial alvo terapêutico no CUB. Martinez-Torrecuadrada et al. (2005) conduziram um estudo para investigar o efeito do anticorpo Fv de cadeia simples humano (scFv) como inibidor específico da função de FGFR3. Os autores relatam que foram capazes de bloquear a proliferação celular na linhagem tumoral de AcB RT112, que expressa altos níveis de FGFR3.

\subsubsection{Alterações genéticas do CUB invasivo}

A maioria dos eventos genéticos conhecidos no CUB é descrita em tumores invasivos e muitos deles, como a mutação do gene p53, retinoblastoma (RB1) e PTEN, estão associados a mau prognóstico. Carcinomas uroteliais invasivos de bexiga são neoplasias mais agressivas e de alta instabilidade genética (Knowles, 2008). 
O produto do gene p53 é uma proteína supressora tumoral que responde a diversos sinais de estresse celular regulando a transcrição de uma série de genes que induzem à parada do ciclo celular, apoptose, senescência, reparo do DNA e alterações no metabolismo da célula. São descritas mutações somáticas de p53 em mais da metade das neoplasias humanas e mutações germinativas envolvidas com síndromes hereditárias que promovem o desenvolvimento de uma série de tumores. Ao contrário de FGFR3, a perda de função do gene p53 leva a uma instabilidade genômica importante na geração de tumores de alto grau e estádio (Hainaut e Hollstein, 2000). Esrig et al., (1994) e Sarkis et al. (1994) foram os primeiros a demonstrar que alterações de p53 são importantes marcadores de recorrência e mortalidade no CUB. O gene p21, também conhecido como CDKN1A, codifica um inibidor de ciclinas CDK2 e CDK4, funcionando como um regulador do ciclo celular. A expressão desse gene é controlada pela proteína p53, exercendo um efeito negativo na fase $\mathrm{G} 1$ do ciclo celular, frente a uma variedade de estresses. As anormalidades conjuntas de p21 e p53 prevêem mau prognóstico e menor sobrevida livre de doença.

A suscetibilidade do gene RB1, um protótipo de gene supressor tumoral, tem sido associada com desenvolvimento e/ou progressão do CUB. Essa fosfoproteína é um regulador negativo do ciclo celular, estabiliza a heterocromatina, mantendo a sua estrutura. Mutações desse gene estão marcadamente associadas ao desenvolvimento do retinoblastoma infantil, sarcoma osteogênico e câncer de bexiga (www.ncbi.nlm.nih.gov/gene). A inativação de RB1 está vinculada ao CUB, mais especificamente à doença invasiva com pior comportamento, especulando-se sua possível utilização como marcador prognóstico. Avaliando o papel do RB1 no tumor de bexiga, Gallucci et al., em 2005, observaram que sua deleção heterozigótica esteve associada com estágios avançados da doença (pT3-pT4). Os autores finalizaram com o achado de que $86 \%$ dos tumores apresentaram deleção heterozigótica e 11\% homozigótica do gene RB1, e esse comportamento se associou a graus mais altos, estádios avançados e sobrevida reduzida. Cordon-Cardo et al. (1992) avaliaram 48 tumores provenientes de cistectomia radical e mostraram que, 
dos 38 pacientes que apresentavam doença músculo-invasiva, 34\% tinham alteração na expressão de RB1, sendo essa mutação praticamente ausente nos tumores não invasivos. Chegaram à conclusão que tumores que apresentam tais mutações têm comportamento mais agressivo e menor sobrevida.

Uma vez que mais da metade dos tumores invasivos têm deficiências nas vias p53 e/ou RB1, restaurar as funções dessas vias poderia retomar os processos fisiológicos celulares, promover a apoptose, prevenir a progressão e controlar o crescimento tumoral (Wu, 2009). Várias pequenas moléculas recentemente descobertas com habilidade de ligação no gene p53 mutante ou na proteína truncada são capazes de restaurar suas funções. Dois protótipos são o CP-31398 e o PRIMA-1, capazes de reativar a função do p53 e induzir a apoptose maciça.

O gene homólogo da fosfatase e tensina (PTEN) está situado no braço longo do cromossomo 10 (10q23) e também funciona como um tradicional supressor tumoral, com papéis no controle da proliferação, migração e invasão celulares através da via PI3K/AKT/mTOR (Wu, 2009; McConckey et al., 2010). Apesar de ter influência no desenvolvimento de tumores vesicais não invasivos, PTEN está muito mais associado com as vias promotoras e de progressão do CUB invasivo. Embora existam evidências que sugiram seu papel na iniciação e progressão neoplásica, parece que PTEN não é capaz de promovê-las sozinho (Tsuruta et al., 2006). Dados recentes mostram que quando a perda de função de PTEN encontra-se associada com mutações em p53, o tumor invasivo se instala e progride mais rapidamente, com pior prognóstico e menor sobrevida (Puzio-Kuter et al., 2009).

Associações de alterações genéticas dentro da via carcinogênica do CUB invasivo parecem ser o principal evento que leva à iniciação e progressão desses tumores uroteliais (Figura 1). 


\subsubsection{Epigenética do CUB}

Alterações genéticas apenas não são capazes de explicar a diversidade molecular do câncer, e outros mecanismos também podem afetar a expressão dos genes e as vias de sinalização. Alterações epigenéticas como a hipermetilação do DNA e desacetilação de histonas, que ocorrem sem modificar a estrutura do DNA, parecem contribuir para a transformação maligna e progressão do CUB (Dalmay, 2008; Enokida e Nakagawa, 2008) e podem ser promovidas por exposição a estímulos externos, incluindo o tabagismo, dieta e agentes carcinogênicos.

Uma variedade de genes importantes em diversos processos celulares podem apresentar hipermetilação do DNA em taxas que oscilam entre 1\% e 98\% (Kim et al., 2005; Friedrich et al., 2005; Marsit et al., 2007; Yates et al., 2007; Ellinger et al., 2008; Lodygin et al., 2008). Além disso, algumas dessas alterações epigenéticas podem ser reguladas por micro RNA. Hipermetilação pode ser detectada no urotélio normal e no Cis de pacientes portadores de tumores invasivos, indicando que essas aberrações epigenéticas já estão presentes em estágios precoces da doença (Brait et al., 2008). Considerando o modelo atual de carcinogênese vesical, sugere-se que a hipermetilação de genes é mais típica de tumores invasivos e tem sido relacionada com pior prognóstico e menor sobrevida, de forma que tais alterações foram sugeridas como biomarcadores para CUB. Brait et al. (2008), usando um grupo de sete genes, demonstraram que a metilação de suas áreas promotoras permite estratificar doença invasiva e não invasiva. Por fim, Yates et al. (2007) relataram que hipermetilação da área promotora de E-caderina esteve associada à progressão da doença e morte por câncer.

Outro mecanismo epigenético é a repressão da transcrição através da interação de micro RNA (miRNA) em seqüências específicas do RNA mensageiro (RNAm), que será discutido a seguir. 


\subsubsection{Micro RNA}

Após a sua descoberta há quase 20 anos (Lee et al., 1993), os miRNA têm sido reconhecidos como moléculas que atuam especificamente no controle póstranscricional da maioria do genoma de eucariotos. Eles são uma família de pequenos RNA que variam de 19 a 25 nucleotídeos expressos em uma ampla variedade de organismos, englobando plantas, vermes e mamíferos incluindo o homem (Pillai et al., 2005). Muitos miRNA são altamente conservados entre as espécies e a maquinaria de seu processamento pode ser encontrada em arqui e eubactérias, comprovando sua característica ancestral. Atualmente existem mais de 1400 miRNA, relacionados com a regulação de mais de $30 \%$ dos genes humanos (www.mirnabodymap.org; Lewis et al., 2005) envolvidos em múltiplos processos de desenvolvimento e diferenciação celular, apoptose, homeostase e vias metabólicas (Ambros, 2003; Bartel, 2004; Blenkiron e Miska, 2007).

\subsubsection{Biogênese de miRNA}

Após sua transcrição pela RNA polimerase II, o precursor primário do miRNA, denominado pri-miRNA, é submetido à ação do complexo microprocessador nuclear Drosha e então convertido em pré-miRNA, uma molécula de fita dupla de aproximadamente 60-70 nucleotídeos (Han et al., 2004; Lee et al., 2004; Gregory et al., 2004; Kim, 2005). O pré-miRNA é exportado do núcleo para o citoplasma pela Exportina-5, proteína especializada no transporte nucleocitoplasmático de macromoléculas, incluindo os ácidos ribonucleicos (Yi et al., 2003). Uma vez no citoplasma, o pré-miRNA é clivado pela enzima Dicer, transformando-se em um miRNA de tamanho pequeno (19 a 25 nucleotídeos) de fita dupla, conhecido como miRNA duplex. Este, por sua vez, sofre novamente a ação da Dicer, que cliva a dupla fita e produz o miRNA maduro de fita única, que então é incorporado a um complexo efetor denominado RISC (complexo silenciador induzido por RNA)(Lee et al., 2003; Carmell e Hannon, 2004; Bartel, 2004). O RISC guia o miRNA maduro até seu RNAm alvo, onde ocorrerá uma interação de complementariedade de bases 
perfeita ou incompleta, que levará à clivagem do RNAm ou à inibição da tradução de proteínas, respectivamente (Meister et al., 2004; Pillai, 2005). A Figura 2 resume todos esses processos descritos.

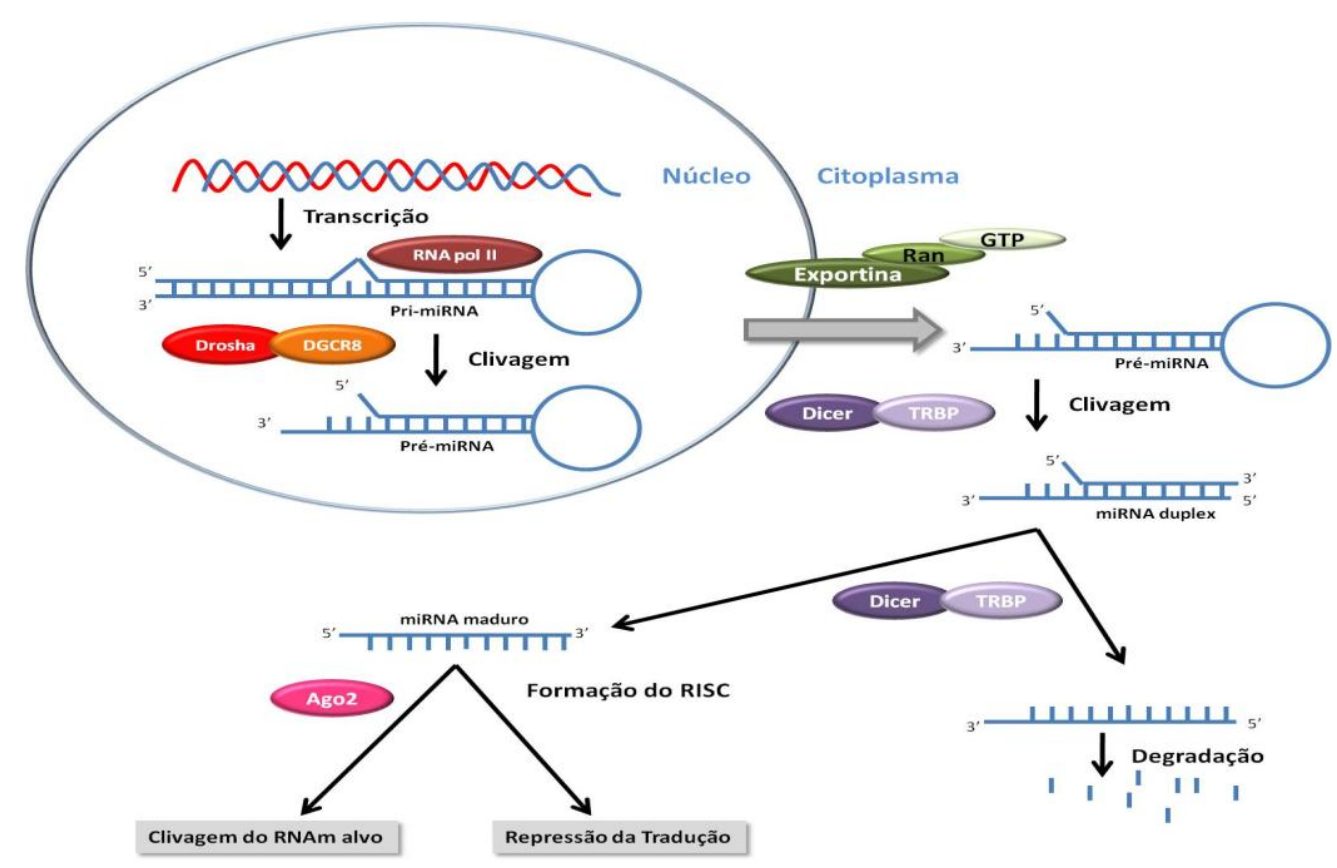

Figura 2 - Esquema demonstrando a biogênese de miRNA

\subsubsection{Funções de micro RNA}

Embora a grande maioria dos estudos tenha se voltado ao papel dos miRNA no desenvolvimento e progressão de doenças, diagnóstico, prognóstico e estratégias terapêuticas, eles são fundamentais nos fenômenos de embriogênese, desenvolvimento e diferenciação celular, proliferação e metabolismo (Dalmay, 2008).

Dentro da pesquisa oncológica, os miRNA têm se apresentado como supressores de tumor ou oncogênicos, demonstrando alterações que podem caracterizar diferentes tipos de câncer (Calin e Croce, 2006; Blenkiron e Miska, 2007). Embora existam estudos explorando perfis de expressão de miRNA no CUB, 
os dados ainda são escassos e o campo de exploração bastante vasto (Gottardo et al., 2007; Gregory et al., 2008; Neely et al., 2008; Ichimi et al., 2009; Veerla et al., 2009). 
2. OBJETIVOS 
Os objetivos deste estudo são:

\subsection{Primário}

- Caracterizar um perfil de expressão de micro RNA no carcinoma urotelial de bexiga

\subsection{Secundários}

- Comparar o padrão de expressão dos miRNA entre o carcinoma urotelial de alto grau invasivo e o carcinoma urotelial de baixo grau não invasivo

- Relacionar o perfil de expressão dos miRNA com recidiva e progressão da neoplasia em pacientes tratados por CUB 
3. MÉTODOS 


\subsection{Pacientes}

Foi estudado o perfil de expressão de 14 miRNA de 60 pacientes divididos em dois grupos: 30 pacientes com CUB de baixo não músculo-invasivo ( $\mathrm{pTa}$ ) submetidos à ressecção transuretral e 30 pacientes com CUB de alto grau invasivo na muscular própria ou tecido adiposo perivesical (pT2-3) submetidos à cistectomia radical. O grupo controle é constituído por cinco pacientes sem anormalidades vesicais que sofreram tratamento cirúrgico aberto para o tratamento de HPB. Os pacientes e os controles foram tratados entre janeiro de 2008 e dezembro de 2009, no Hospital das Clínicas da Faculdade de Medicina da Universidade de São Paulo (HCFMUSP) e no Instituto do Câncer do Estado de São Paulo (ICESP) pela equipe do Prof. Dr. Miguel Srougi. A tabela 3 mostra as características demográficas dos dois grupos de pacientes e do grupo controle.

Tabela 3 - Características demográficas dos grupos estudados

\begin{tabular}{|c|c|c|c|c|c|c|c|c|c|}
\hline & \multicolumn{3}{|c|}{$\begin{array}{c}\text { CUB de baixo grau não } \\
\text { invasivo } \\
\text { pTa }(n=30)\end{array}$} & \multicolumn{3}{|c|}{$\begin{array}{c}\text { CUB de alto grau invasivo } \\
\text { pT2-3 }(n=30)\end{array}$} & \multicolumn{3}{|c|}{$\begin{array}{l}\text { Controles } \\
(n=5)\end{array}$} \\
\hline & \multirow[t]{2}{*}{$\begin{array}{l}\text { Sexo } \\
(\%)\end{array}$} & \multicolumn{2}{|c|}{$\begin{array}{l}\text { Idade } \\
\text { (anos) }\end{array}$} & \multirow[t]{2}{*}{$\begin{array}{l}\text { Sexo } \\
(\%)\end{array}$} & \multicolumn{2}{|c|}{$\begin{array}{l}\text { Idade } \\
\text { (anos) }\end{array}$} & \multirow[t]{2}{*}{$\begin{array}{c}\text { Sexo } \\
(\%)\end{array}$} & \multicolumn{2}{|c|}{$\begin{array}{l}\text { Idade } \\
\text { (anos) }\end{array}$} \\
\hline & & Média & $\begin{array}{l}\text { Mediana } \\
\text { (mín-máx) }\end{array}$ & & Média & $\begin{array}{l}\text { Mediana } \\
\text { (mín-máx) }\end{array}$ & & Média & $\begin{array}{l}\text { Mediana } \\
\text { (mín-máx) }\end{array}$ \\
\hline Masculino & 86,7 & 68,2 & $\begin{array}{c}67,5 \\
(47-82)\end{array}$ & 53,3 & 64,4 & $\begin{array}{c}66 \\
(41-79)\end{array}$ & 100 & 66 & $\begin{array}{c}66 \\
(61-71)\end{array}$ \\
\hline Feminino & 13,3 & 61,8 & $\begin{array}{c}61 \\
(57-68)\end{array}$ & 46,7 & 65 & $\begin{array}{c}67,5 \\
(46-81)\end{array}$ & 0 & - & - \\
\hline
\end{tabular}

Os pacientes foram informados sobre os objetivos deste estudo e assinaram o termo de consentimento informado (Anexo B). O tempo médio de acompanhamento foi de 17,7 meses, com mediana de 16 meses, variando de 3 a 46 meses. Para os tumores pTa, o seguimento se deu através de cistoscopia e citologia urinária trimestrais nos primeiros 24 meses, seguidos dos mesmos exames semestrais do terceiro ao quinto ano do diagnóstico. Para tumores invasivos pT2-3 
o acompanhamento se fez por TC abdominal e de tórax trimestral nos primeiros dois anos, semestral do terceiro ao quinto ano e anual a partir do quinto ano de pós-operatório. Reinterveções terapêuticas foram feitas conforme a necessidade de cada caso. Este estudo foi aprovado pelo Comitê de Ética desta instituição sob número 0176/10 (Anexo A).

\subsection{Exame macro e microscópico}

Os espécimes cirúrgicos foram examinados a fresco pelo patologista e o pesquisador executante deste trabalho, imediatamente após sua ressecção, sendo seccionado fragmento de $1 \mathrm{~cm}^{2}$, armazenado imediatamente em criotubo Eppendorf de 1,5 $\mathrm{ml}$ com $1 \mathrm{ml}$ de RNA holder (fixador de RNA) e mantidos em freezer $-80{ }^{\circ} \mathrm{C}$ no Laboratório de Investigação Médica Urológica (LIM-55) da Faculdade de Medicina da Universidade de São Paulo (FMUSP).

Após a secção do fragmento para extração de miRNA, os espécimes cirúrgicos foram fixados em formalina $10 \%$ por um período de até 24 horas. Todas as peças provenientes de RTU ou cistectomia radical foram submetidas a estudo histológico para análise dos fatores prognósticos clássicos. As peças foram habitualmente processadas e incluídas em parafina, seccionadas em cortes de 4 a 6 $\mu \mathrm{m}$, coradas por hematoxilina-eosina e analisadas em microscópio óptico pelo mesmo patologista, garantindo a presença da neoplasia em pelo menos $75 \%$ da amostra. Foram avaliados os seguintes parâmetros prognósticos:

a. Graduação histológica segundo a classificação adotada pela OMS/ISUP 2004.

b. Estadiamento patológico TNM segundo a AJCC 2010. 


\subsection{Processamento do RNA}

\subsubsection{Isolamento do miRNA}

Os miRNA foram isolados com o kit mirVana ${ }^{\circledR}$ (Ambion) de acordo com as recomendações do fabricante (Anexo C). Este kit permite o isolamento de todos os tipos de RNA. Os espécimes congelados a $-80{ }^{\circ} \mathrm{C}$ foram macerados e colocados em tubo de microcentrífuga de $1,5 \mathrm{ml}$ estéril. Ao tubo foram então adicionados $500 \mu \mathrm{l}$ do tampão de lise e $50 \mu \mathrm{l}$ do aditivo de homogeneizar e a solução deixada 10 minutos no gelo. Logo após, foram adicionados $500 \mu$ lde ácido fenol-clorofórmio e as amostras foram vortexadas e centrifugadas na velocidade máxima de 10.000 rpm por 5 minutos em temperatura ambiente. A fase aquosa foi removida para um novo tubo e foi adicionado um terço do volume de etanol $100 \%$ e então, a solução transferida para um filtro e centrifugada a $10.000 \mathrm{rpm}$ por 15 segundos. O filtro que contém o RNA total foi armazenado. No filtrado onde continha o miRNA, foram adicionados dois terços de etanol $100 \%$. A solução foi transferida para uma nova coluna e centrifugada a $10.000 \mathrm{rpm}$ por 15 segundos. Em seguida, foi feita uma lavagem com $700 \mu \mathrm{l}$ de wash solution $1 / 3$, e as amostras centrifugadas por 15 segundos a $10.000 \mathrm{rpm}$, seguidas por mais duas lavagens com $500 \mu \mathrm{l}$ de wash solution 2/3, centrifugadas nos intervalos por 15 segundos a $10.000 \mathrm{rpm}$. Neste momento, foram adicionados $100 \mu \mathrm{l}$ de água livre de RNAse a $95{ }^{\circ} \mathrm{C}$ no filtro e as amostras novamente centrifugadas a $10.000 \mathrm{~g}$ por 15 segundos. O filtrado contendo o miRNA foi então armazenado em freezer $-80^{\circ} \mathrm{C}$ até ser utilizado. A concentração e pureza foram estimadas em espectrofotômetro Nanodrop ${ }^{\circledR}$ (ND-1000, Wilmington, EUA) $(260 / 280 \mathrm{nM})$.

\subsubsection{Síntese do CDNA}

O miRNA foi diluído em água livre de nucleases e utilizado $3 \mu$ deste, onde foram adicionados 0,15 $\mu \mathrm{l}$ do mix de dNTPs (100 mM total), 0,19 $\mu \mathrm{l}$ de inibidor de RNAse $(20 \mathrm{U} / \mu \mathrm{l}), 1,5 \mu \mathrm{l}$ do tampão da enzima (RT Buffer 10X), 0,5 $\mu \mathrm{l}$ da enzima 
Multiscribe ${ }^{\mathrm{TM}} R T$ enzyme (50 U/ $\left.\mu \mathrm{l}\right), 3,66 \mu \mathrm{l}$ de água livre de nucleases e $1 \mu \mathrm{l}$ de primers específicos para cada miRNA, totalizando $10 \mu \mathrm{l}$. As misturas foram submetidas a $16{ }^{\circ} \mathrm{C}$ por 30 minutos, $42{ }^{\circ} \mathrm{C}$ por 30 minutos e $85{ }^{\circ} \mathrm{C}$ por 5 minutos para síntese da fita de cDNA em aparelho Termociclador Veriti ${ }^{\circledR}$ (Applied Biosystems, California, USA).

Abaixo segue o modelo esquemático de síntese do DNA complementar dos miRNA.

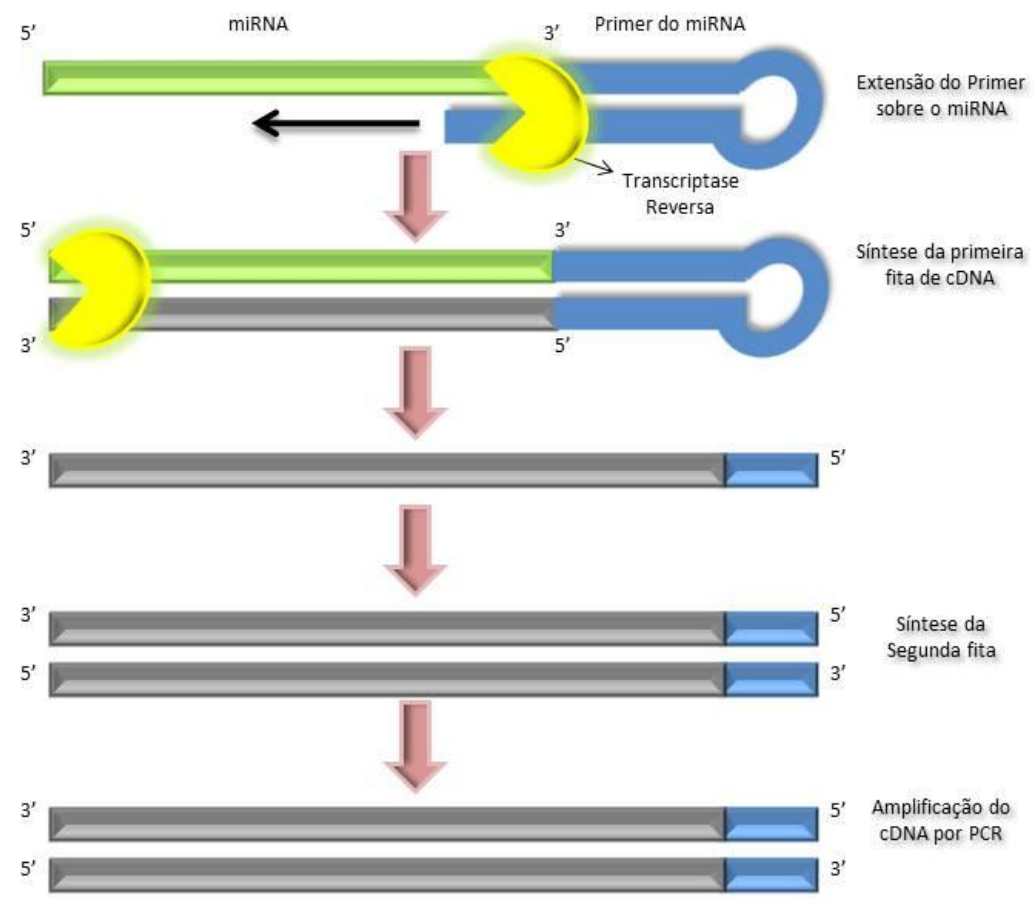

Figura 3 - Síntese do DNA complementar

\subsubsection{Amplificação do miRNA}

Os primers utilizados para amplificação dos miRNA foram adquiridos da Applied Biosystems, California, USA, que desenha primers com as características necessárias para os experimentos de PCR em Tempo Real (RT-PCR) no termociclador $A B I 7500$ Fast. 
Para quantificação das amostras foi utilizado o reagente TaqMan ${ }^{\circledR}$ (Applied Biosystems, California, USA). Este protocolo utiliza dois iniciadores não fluorescentes e uma sonda com dupla marcação que se anela à região localizada entre os iniciadores. Esta marcação dupla é formada por um fluoróforo que emite luz quando excitado e um quencher que absorve a luz emitida pelo fluoróforo. Durante os ciclos da PCR, a sonda é quebrada pela Taq polimerase na etapa de extensão do iniciador anelado. Esta quebra da sonda elimina a absorção pelo quencher da fluorescência emitida que pode ser então medida através de uma câmera situada na parte superior do equipamento. A quantificação da emissão absorvida pela câmera após quebra da sonda permite então a detecção do produto de RT-PCR (Figura 4). Brevemente, a reação foi preparada adicionando-se $5 \mu$ do MasterMix, 3,5 $\mu \mathrm{l}$ de água livre de nucleases, $1 \mu \mathrm{l}$ do cDNA e 0,5 $\mu \mathrm{l}$ do primer específico para cada miRNa estudado em placas para PCR. Logo após, as reações foram inseridas no equipamento de qRT-PCR e processadas pelo aparelho durante 2 minutos a $50{ }^{\circ} \mathrm{C}$, 10 minutos a $95{ }^{\circ} \mathrm{C}$ e 40 ciclos termais de 15 segundos a $95{ }^{\circ} \mathrm{C}$ seguidos de 1 minuto a $60{ }^{\circ} \mathrm{C}$. Os valores de expressão de cada amostra para cada miRNA estão expostos nos anexos D e E.

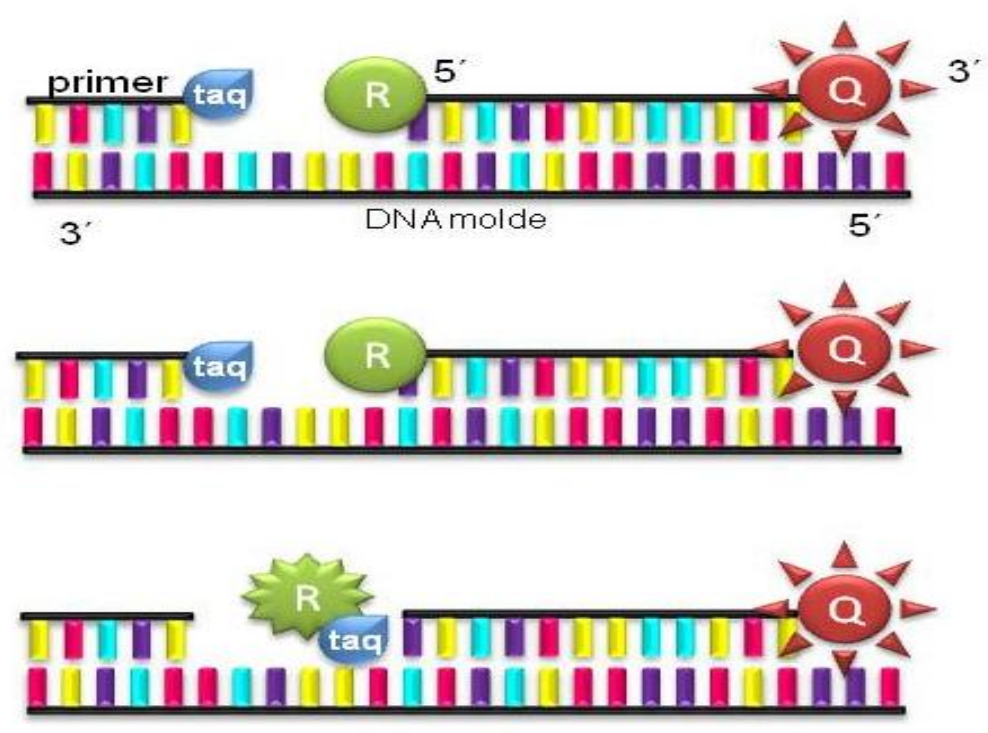

Figura 4 - Amplificação do miRNA pelo método TaqMan ${ }^{\circledR}$ 


\subsection{Análise dos resultados}

Os 14 miRNA avaliados neste estudo, suas características e seus possíveis genes-alvos estão demonstrados nas Tabelas 4 e 5. Com exceção do miR-100, escolha dos miRNA para esse estudo foi baseada em dados da literatura que demonstraram papéis fundamentais e/ou promissores desses miRNA nas vias carcinogênicas de tumores uroteliais. O miR-100 especificamente foi selecionado para análise porque, além de fazer parte de todas as linhas de pesquisa do nosso laboratório, existem dados escassos sobre sua a ação, tanto na via tumorigênica da neoplasia não invasiva quanto na invasiva. Os níveis de expressão dos miRNA foram obtidos pela quantificação relativa dos níveis de expressão determinados pelo método $2^{-\Delta \Lambda C T}$, para o qual $\Delta \Delta C T=\mathrm{dCT}_{1}-\mathrm{dCT}_{2}$, onde $\mathrm{dCT}_{1}=\mathrm{CT}$ do miRNA-alvo, (amostra tumoral) - CT da média do controle endógeno (amostra tumoral), e $\mathrm{dCT}_{2}=$ CT da média dos controles (amostras de tecido vesical normal) - CT da média do controle endógeno (amostra de tecido vesical normal). No gráfico logarítmico, esse método padroniza a expressão do controle normal como uma linha basal (representada pelo número 1) e a expressão relativa de cada miRNA para cada amostra tumoral é demonstrada em vezes o normal para mais nos casos de superexpressão e para menos nos de subexpressão.

Todas as reações foram realizadas em duplicata e os pequenos RNA nucleolares RNU43 e RNU48 (Applied Biosystems, CA, USA) usados como controle endógeno. 
Tabela 4 - Micro RNA analisados e seus possíveis genes-alvo

\begin{tabular}{|c|c|c|}
\hline MicroRNA & Gene-alvo & Referências \\
\hline 100 & $\begin{array}{l}\text { THAP2, SMARCA5, } \\
\text { BAZ2A, FGFR3 }\end{array}$ & $\begin{array}{l}\text { Zhou et al., 2002; Bessière et al., } \\
\text { 2008; Veerla et al., 2009; Catto et } \\
\text { al., } 2009\end{array}$ \\
\hline 10a & FGFR3, HOXA-1 & $\begin{array}{l}\text { Veerla et al., 2009; Garzon et al., } \\
2006\end{array}$ \\
\hline 21 & PTEN, p53 & $\begin{array}{l}\text { Neely et al., 2008; Wu et al., 2009; } \\
\text { Catto et al., 2009; McConkey et al, } \\
2010\end{array}$ \\
\hline 205 & $\begin{array}{l}\text { p53, PTEN, ZEB-1, } \\
\text { ZEB-2 }\end{array}$ & $\begin{array}{l}\text { Gottardo et al., 2007; Gregory et } \\
\text { al., 2008; Neely et al., } 2008\end{array}$ \\
\hline Let-7c & RAS, MYC & $\begin{array}{l}\text { Reinhart et al., 2000; Johnson et } \\
\text { al., } 2005\end{array}$ \\
\hline $125 b$ & $\begin{array}{c}\text { KRT-7, MUC-1, E2F3, } \\
\text { p53 }\end{array}$ & $\begin{array}{l}\text { Ichimi et al., 2009; Le et al., 2009; } \\
\text { Rajabi et al., 2010; Huang et al., } \\
2011\end{array}$ \\
\hline 143 & RAS & Lin et al., 2009 \\
\hline 145 & $\begin{array}{c}\text { KRT-7, FSCN-1, c- } \\
\text { MYC/p53 }\end{array}$ & $\begin{array}{l}\text { Ichimi et al., 2009; Chiyomaru et } \\
\text { al., 2010; Sachdeva et al., } 2009\end{array}$ \\
\hline 221 & p27KIP1, DDIT4 & $\begin{array}{l}\text { Gottardo et al., 2007; Pineau et al., } \\
2010\end{array}$ \\
\hline 223 & MEF2C, STMN-1 & $\begin{array}{l}\text { Gottardo et al., 2007; Wong et al., } \\
2008\end{array}$ \\
\hline $15 a$ & $\mathrm{BCL} 2$ & Calin et al., 2002 \\
\hline $16-1$ & $\mathrm{BCL} 2$ & Calin et al., 2002 \\
\hline 199a & KRT7, mTOR, PODXL & $\begin{array}{l}\text { Ichimi et al., 2009; Fornari et al., } \\
\text { 2010; Cheung et al., } 2011\end{array}$ \\
\hline 452 & Ainda não definido & Veerla et al., 2009 \\
\hline
\end{tabular}


Tabela 5 - Especificações dos micro RNA estudados

\begin{tabular}{|c|c|c|c|}
\hline MicroRNA & $\begin{array}{l}\text { Localização } \\
\text { Cromossômica }\end{array}$ & Sequência & $\begin{array}{c}\text { Número de } \\
\text { Bases }\end{array}$ \\
\hline 100 & $11 q 24.1$ & AACUGUUUGCAGAGGAAACUGA & 22 \\
\hline $10 a$ & $17 q 21.32$ & UACCCUGUAGAUCCGAAUUUGUG & 23 \\
\hline 21 & $17 q 23.1$ & UAGCUUAUCAGACUGAUGUUGA & 22 \\
\hline 205 & $1 q 32.2$ & UCCUUCAUUCCACCGGAGUCUG & 22 \\
\hline Let-7c & $21 q 21.1$ & UGAGGUAGUAGGUUGUAUGGUU & 22 \\
\hline $125 b$ & $11 q 24.1$ & UCCCUGAGACCCUAACUUGUGA & 22 \\
\hline 143 & $5 q 32$ & UGAGAUGAAGCACUGUAGCUC & 22 \\
\hline 145 & $5 q 32$ & GUCCAGUUUUCCCAGGAAUCCCU & 23 \\
\hline 221 & Xp11.3 & AGCUACAUUGUCUGCUGGGUUUC & 23 \\
\hline 223 & $\mathrm{Xq12}$ & UGUCAGUUUGUCAAAUACCCCA & 22 \\
\hline $15 a$ & $13 q 14.2$ & UAGCAGCACAUAAUGGUUUGUG & 22 \\
\hline $16-1$ & $13 q 14.2$ & UAGCAGCACGUAAAUAUUGGCG & 22 \\
\hline 199a & 19p13.2 & CCCAGUGUUCAGACUACCUGUUC & 23 \\
\hline 452 & Xq28 & AACCCGUAGAUCCGAACUUGUG & 22 \\
\hline
\end{tabular}


A figura 5 demonstra de modo esquemático a metodologia aplicada e desenvolvida neste estudo.
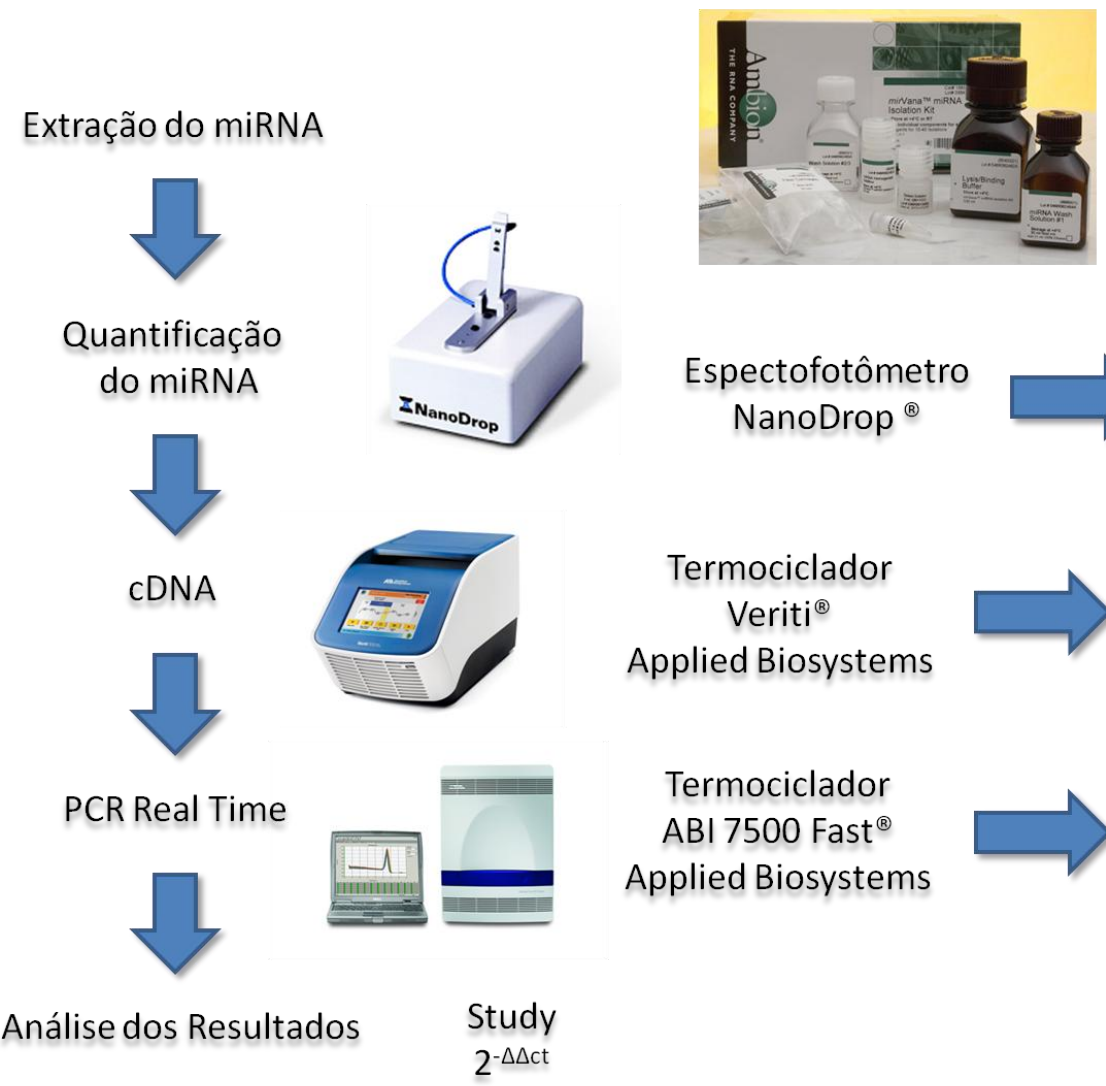

Kit mirVana ${ }^{\circledR}$

Ambion

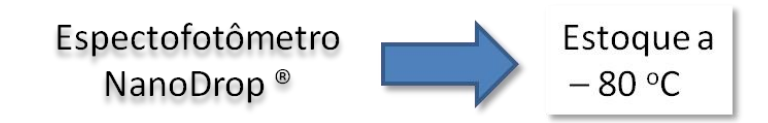
Termociclador Veriti $^{\circledR}$

Applied Biosystems

$16^{\circ} \mathrm{C} \rightarrow 30 \mathrm{~min}$ $42^{\circ} \mathrm{C} \rightarrow 30 \mathrm{~min}$. $85^{\circ} \mathrm{C} \rightarrow 5 \mathrm{~min}$.

Termociclador ABI 7500 Fast $^{\circledR}$ Applied Biosystems

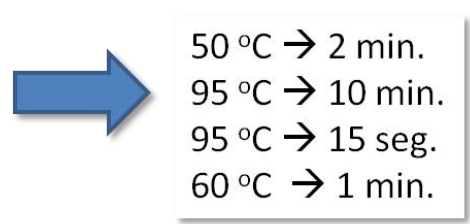
Análise dos Resultados Study
$2^{-\Delta \Delta c}$

Figura 5 - Esquema metodológico do estudo

\subsection{Análise estatística}

Os métodos estatísticos foram empregados para comparar o perfil de expressão dos miRNA entre os dois grupos de tumores e os fatores prognósticos. Para grupos homogêneos, utilizamos o Teste T para comparar dois grupos e ANOVA para três ou mais grupos. Para aqueles não homogêneos, usamos o Teste de MannWhitney para comparar dois grupos e o Teste de Kruskal-Wallis para três ou mais grupos. O Teste do Qui-quadrado foi empregado para comparar grupos em escala nominal. Os dados foram transformados em gráficos logarítmicos para análise e a expressão de cada amostra para um determinado miRNA é relativa ao controle e expressa em vezes. Os resultados foram alcançados utilizando-se o programa de 
análise estatística SPSS 19.0 para Windows e estão apresentados como médias geométricas com intervalo de confiança de $95 \%$.

Foram também construídas curvas de Kaplan-Meyer para estudo de sobrevida livre de recidiva (SLR) e sobrevida câncer-específica (SCE), com o intuito de relacionar os perfis dos miRNA com o comportamento do CUB. 
4. RESULTADOS 


\subsection{Padrão de expressão geral em carcinoma urotelial de bexiga}

Os resultados da expressão dos 14 miRNA nos CUB de baixo grau, não invasivos e nos CUB de alto grau, invasivos estão expostos na Tabela 5 e Figuras 6 e 7. A maior parte dos miRNA encontrou-se subexpressa nos tumores analisados, exceto o miR-100, 21 e 205 em tumores pT2-3 e miR-10a em tumores pTa, que estão superexpressos.

\subsection{Perfil de expressão dos miRnA nos carcinomas de baixo grau, pTa e} carcinomas de alto grau, pT2-3

Os miRNA 100, 10a, 21 e 205 mostraram diferenças de expressão comparando os dois grupos de tumores (Figuras 6 e 7 e Tabela 6).

Todos os tumores pTa de baixo grau apresentaram subexpressão de miR100 , enquanto que nos tumores pT2-3 de alto grau houve superexpressão em $57,7 \%$. A média de expressão de miR-100 em tumores de baixo grau pTa foi de apenas 0,04 versus 24,39 nos carcinomas de alto grau pT2-3 ( $<<0,001)$.

O miR-10a mostrou um perfil inverso de expressão em relação ao miR-100, isto é, esteve superexpresso em $73,3 \%$ dos tumores de baixo grau, pTa e subexpresso em 93,3\% naqueles de alto grau, pT2-3, com médias de expressão de 46,38 e 0,23 , respectivamente $(p<0,001)$.

Os miRNA 21 e 205 também se mostraram significativamente superexpressos nos tumores de alto grau, pT2-3. A média de expressão de miR-21 foi de 1,08 e 18,17 nos tumores de baixo grau, pTa e de alto grau, pT2-3 respectivamente $(p=0,02)$. As médias de miR-205 nos mesmos grupos foram de 0,07 e $6,91(p<0,001)$. 
Tabela 6 - Níveis de expressão dos 14 miRNA conforme grau e estádio

\begin{tabular}{|c|c|c|c|c|c|c|}
\hline \multirow[b]{2}{*}{ miRNA } & \multicolumn{3}{|c|}{$\begin{array}{l}\text { Grau Histológico } \\
\text { Média } \\
\text { Mediana (mín-máx) }\end{array}$} & \multicolumn{3}{|c|}{$\begin{array}{c}\text { Estadiamento Patológico } \\
\text { Média } \\
\text { Mediana (mín-máx) }\end{array}$} \\
\hline & Baixo $(n=30)$ & Alto $(n=30)$ & $\mathbf{p}$ & pTa $(n=30)$ & $\begin{array}{c}\text { pT2/T3 } \\
(n=30)\end{array}$ & $\mathbf{p}$ \\
\hline 100 & $\begin{array}{c}0,04 \\
0,0008 \\
\left(8,94^{-13}-0,44\right)\end{array}$ & $\begin{array}{c}24,39 \\
1,77 \\
(0,02-526,6)\end{array}$ & $<0,001$ & $\begin{array}{c}0,04 \\
0,0008 \\
\left(8,94^{-13}-0,44\right)\end{array}$ & $\begin{array}{c}24,39 \\
1,77 \\
(0,02-526,6)\end{array}$ & $<0,001$ \\
\hline $10 a$ & $\begin{array}{c}46,38 \\
4,88 \\
(0,004-761,2)\end{array}$ & $\begin{array}{c}0,23 \\
0,06 \\
(0,001-1,75)\end{array}$ & $<0,001$ & $\begin{array}{c}46,38 \\
4,88 \\
(0,004-761,2)\end{array}$ & $\begin{array}{c}0,23 \\
0,06 \\
(0,001-1,75)\end{array}$ & $<0,001$ \\
\hline 21 & $\begin{array}{c}1,08 \\
0,4 \\
(0,002-11,14)\end{array}$ & $\begin{array}{c}18,17 \\
0,65 \\
(0,03-407,99)\end{array}$ & 0,02 & $\begin{array}{c}1,08 \\
0,4 \\
(0,002-11,14)\end{array}$ & $\begin{array}{c}18,17 \\
0,65 \\
(0,03-407,99)\end{array}$ & 0,03 \\
\hline 205 & $\begin{array}{c}0,07 \\
0,04 \\
(0,002-0,35)\end{array}$ & $\begin{array}{c}6,91 \\
0,65 \\
(0,009-97,84)\end{array}$ & $<0,001$ & $\begin{array}{c}0,07 \\
0,04 \\
(0,002-0,35)\end{array}$ & $\begin{array}{c}6,91 \\
0,65 \\
(0,009-97,84)\end{array}$ & $<0,001$ \\
\hline Let7c & $\begin{array}{c}1,03 \\
0,02 \\
\left(6,3^{-5}-13,14\right)\end{array}$ & $\begin{array}{c}0,29 \\
0,1 \\
(0,0003-1,41)\end{array}$ & 0,16 & $\begin{array}{c}1,03 \\
0,02 \\
\left(6,3^{-5}-13,14\right)\end{array}$ & $\begin{array}{c}0,29 \\
0,1 \\
(0,0003-1,41)\end{array}$ & 0,31 \\
\hline $125 b$ & $\begin{array}{c}0,15 \\
0,08 \\
\left(9,4^{-5}-0,76\right)\end{array}$ & $\begin{array}{c}0,26 \\
0,06 \\
(0,0001-2,02)\end{array}$ & 0,92 & $\begin{array}{c}0,15 \\
0,08 \\
\left(9,4^{-5}-0,76\right)\end{array}$ & $\begin{array}{c}0,26 \\
0,06 \\
(0,0001-2,02)\end{array}$ & 0,99 \\
\hline 143 & $\begin{array}{c}0,18 \\
0,009 \\
\left(7,4^{-5}-4,13\right)\end{array}$ & $\begin{array}{c}0,18 \\
0,005 \\
\left(1,7^{-6}-3,85\right)\end{array}$ & 0,99 & $\begin{array}{c}0,18 \\
0,009 \\
\left(7,4^{-5}-4,13\right)\end{array}$ & $\begin{array}{c}0,18 \\
0,005 \\
\left(1,7^{-6}-3,85\right)\end{array}$ & 0,76 \\
\hline 145 & $\begin{array}{c}1,61 \\
0,2 \\
(0,002-24,06)\end{array}$ & $\begin{array}{c}0,66 \\
0,13 \\
\left(4,4^{-5}-10,25\right)\end{array}$ & 0,27 & $\begin{array}{c}1,61 \\
0,2 \\
(0,002-24,06)\end{array}$ & $\begin{array}{c}0,66 \\
0,13 \\
\left(4,4^{-5}-10,25\right)\end{array}$ & 0,48 \\
\hline 221 & $\begin{array}{c}1,22 \\
0,3 \\
(0,003-17,64)\end{array}$ & $\begin{array}{c}0,48 \\
0,34 \\
(0,06-1,92)\end{array}$ & 0,89 & $\begin{array}{c}1,22 \\
0,3 \\
(0,003-17,64)\end{array}$ & $\begin{array}{c}0,48 \\
0,34 \\
(0,06-1,92)\end{array}$ & 0,98 \\
\hline 223 & $\begin{array}{c}0,49 \\
0,1 \\
(0,002-9,49)\end{array}$ & $\begin{array}{c}1,007 \\
0,29 \\
(0,009-6,2)\end{array}$ & 0,21 & $\begin{array}{c}0,49 \\
0,1 \\
(0,002-9,49)\end{array}$ & $\begin{array}{c}1,007 \\
0,29 \\
(0,009-6,2)\end{array}$ & 0,41 \\
\hline $15 a$ & $\begin{array}{c}2,76 \\
1,04 \\
(0,1-15,3)\end{array}$ & $\begin{array}{c}13,53 \\
0,69 \\
(0,02-331,1)\end{array}$ & 0,78 & $\begin{array}{c}2,76 \\
1,04 \\
(0,1-15,3)\end{array}$ & $\begin{array}{c}13,53 \\
0,69 \\
(0,02-331,1)\end{array}$ & 0,93 \\
\hline $16-1$ & $\begin{array}{c}1,47 \\
0,57 \\
\left(2,6^{-5}-12,3\right)\end{array}$ & $\begin{array}{c}0,76 \\
0,54 \\
(0,001-3,3)\end{array}$ & 0,81 & $\begin{array}{c}1,47 \\
0,57 \\
\left(2,6^{-5}-12,3\right)\end{array}$ & $\begin{array}{c}0,76 \\
0,54 \\
(0,001-3,3)\end{array}$ & 0,95 \\
\hline $199 a$ & $\begin{array}{c}0,36 \\
0,13 \\
(0,0008-2,7)\end{array}$ & $\begin{array}{c}0,69 \\
0,19 \\
(0,002-6,78)\end{array}$ & 0,25 & $\begin{array}{c}0,36 \\
0,13 \\
(0,0008-2,7)\end{array}$ & $\begin{array}{c}0,69 \\
0,19 \\
(0,002-6,78)\end{array}$ & 0,52 \\
\hline 452 & $\begin{array}{c}1,42 \\
0,03 \\
(0,0001-39,87)\end{array}$ & $\begin{array}{c}0,24 \\
0,03 \\
(0,001-3,69)\end{array}$ & 0,39 & $\begin{array}{c}1,42 \\
0,03 \\
(0,0001-39,87)\end{array}$ & $\begin{array}{c}0,24 \\
0,03 \\
(0,001-3,69)\end{array}$ & 0,68 \\
\hline
\end{tabular}




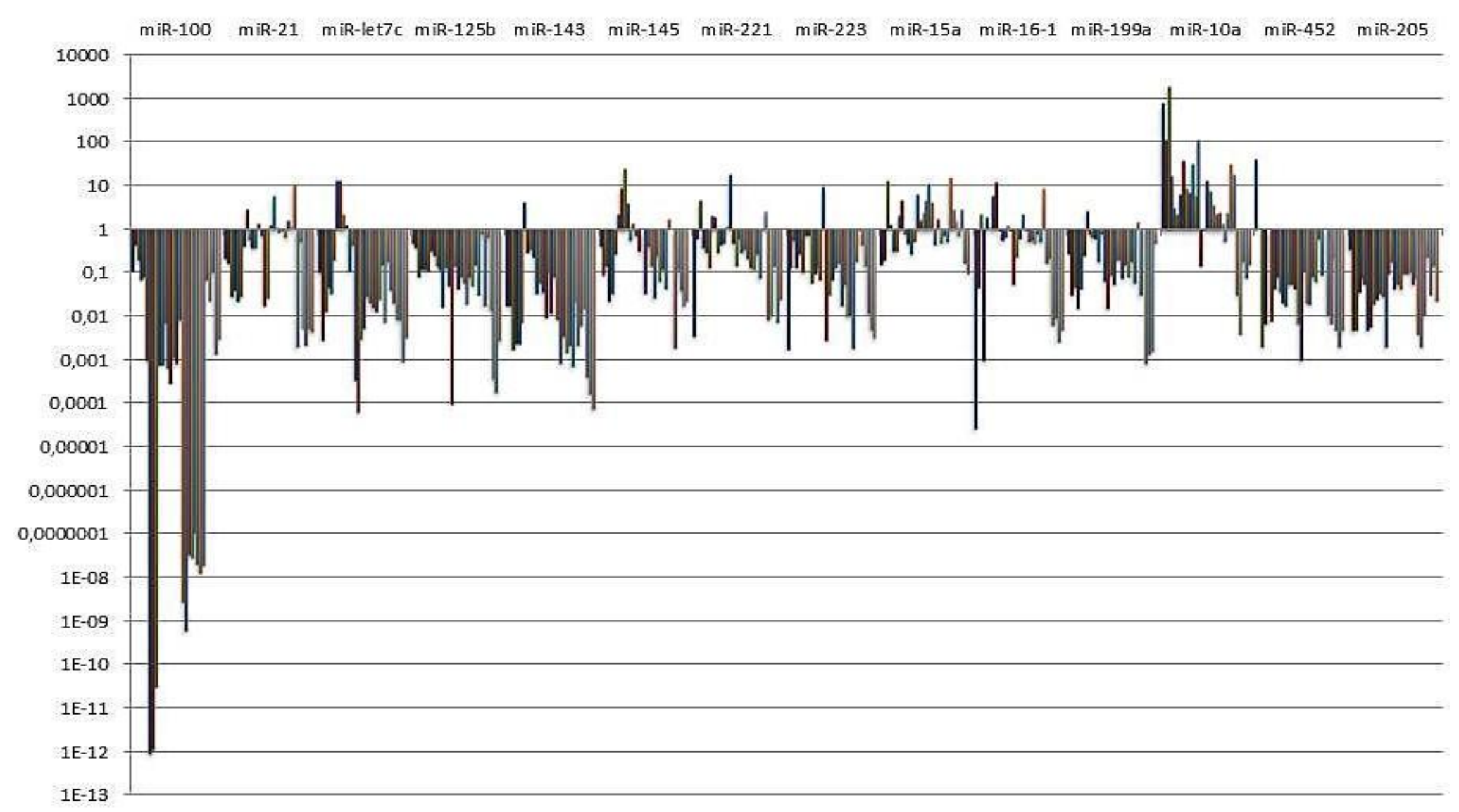

Figura 6 - Perfil de expressão dos 14 miRNA nos tumores de baixo grau pTa 


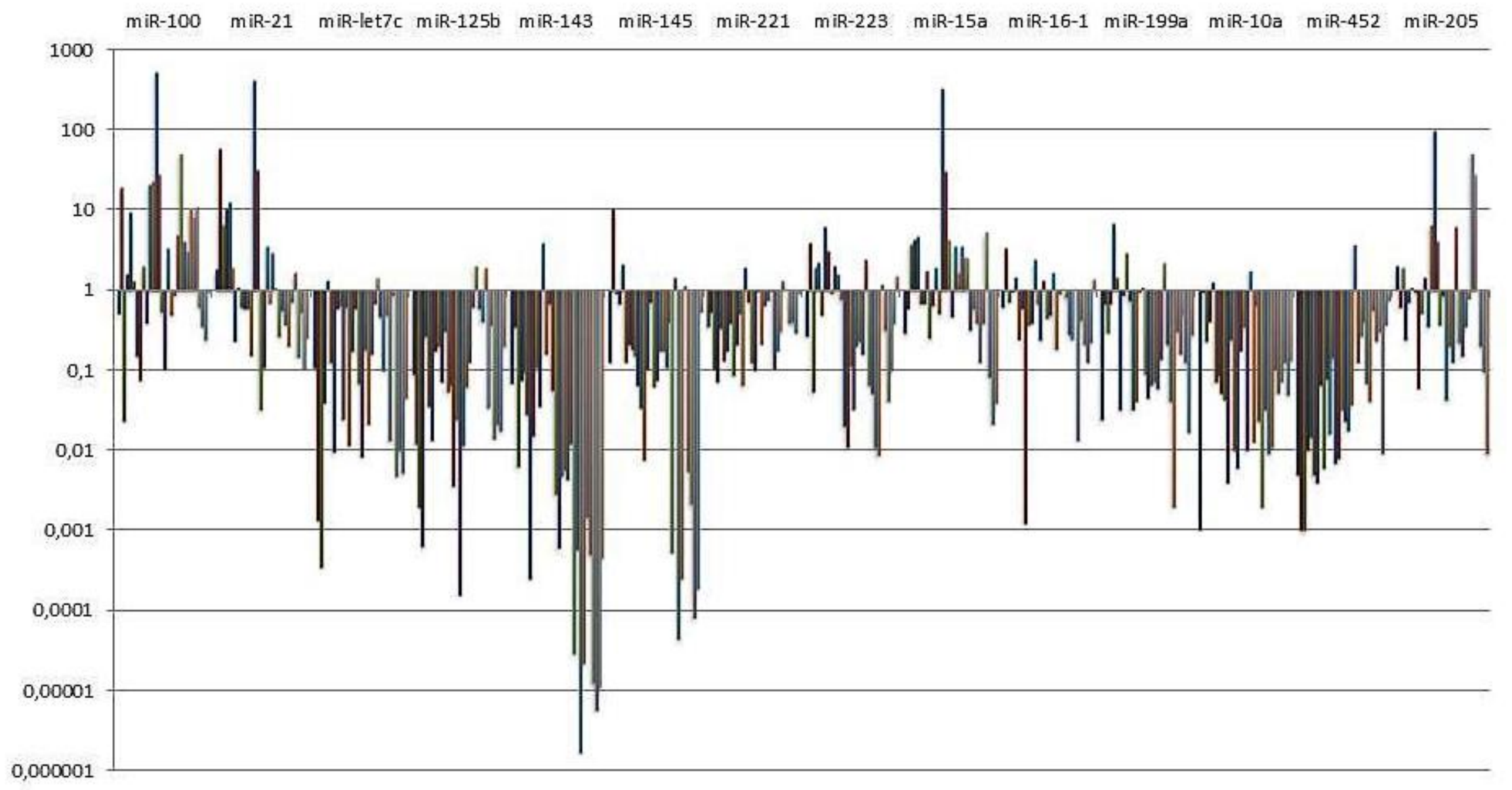

Figura 7 - Perfil de expressão dos 14 miRNA nos tumores de alto grau pT2-3 


\subsection{Perfil de expressão de miRNA, recidiva e sobrevida câncer-específica}

As análises de sobrevida livre de recidiva e sobrevida câncer específica foram realizadas dentro do tempo médio de seguimento de 17,7 meses. 0 menor e 0 maior tempo de acompanhamento foram três e 46 meses, respectivamente, e correspondem a pacientes do grupo pT2-3.

Apenas o miR-21 associou-se significativamente com sobrevida livre de recidiva em tumores pTa de baixo grau. Pacientes que apresentaram níveis de expressão do miRNA menores ou iguais a 1,08 sobreviveram livre da doença por um tempo médio de 24,6 meses. Em contrapartida, aqueles que tiveram expressão acima de 1,08 ficaram livres de doença por apenas 16,3 meses, demonstrando que a maior expressão de miR-21 relacionou-se a maiores taxas de recidiva $(p=0,02)$ (Figura 8).

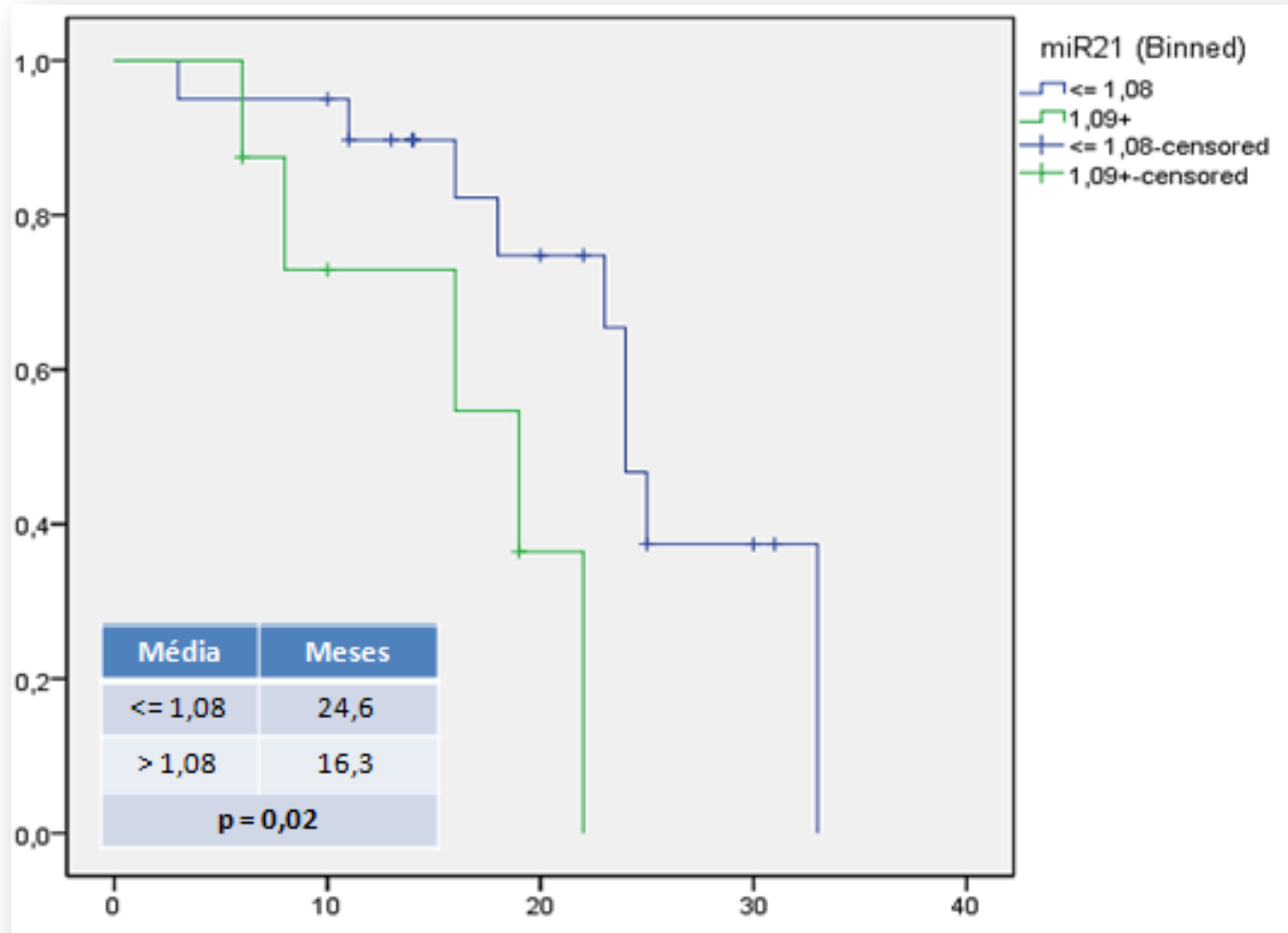

Figura 8 - Curva de Kaplan-Meyer demonstrando a diferença de SLR de tumores pTa de baixo grau em relação à expressão de miR-21 
O miR-10a associou-se tanto com sobrevida livre de recidiva quanto com sobrevida câncer-específica em tumores invasivos de alto grau. Pacientes com níveis de expressão maiores que 0,23 demonstraram menor SLR e SCE, com tempo médio de 13 e 15,3 meses, respectivamente. Por outro lado, perfis de expressão menores ou iguais a 0,23 relacionaram-se com melhores SLR e SCE, com sobrevidas médias respectivas de 26,1 e 27,3 meses. Esses padrões de comportamento propiciaram diferenças estatísticas para SLR $(p=0,007)$ e SCE $(p=0,04)$ em relação ao miR-10a (Figura 9).
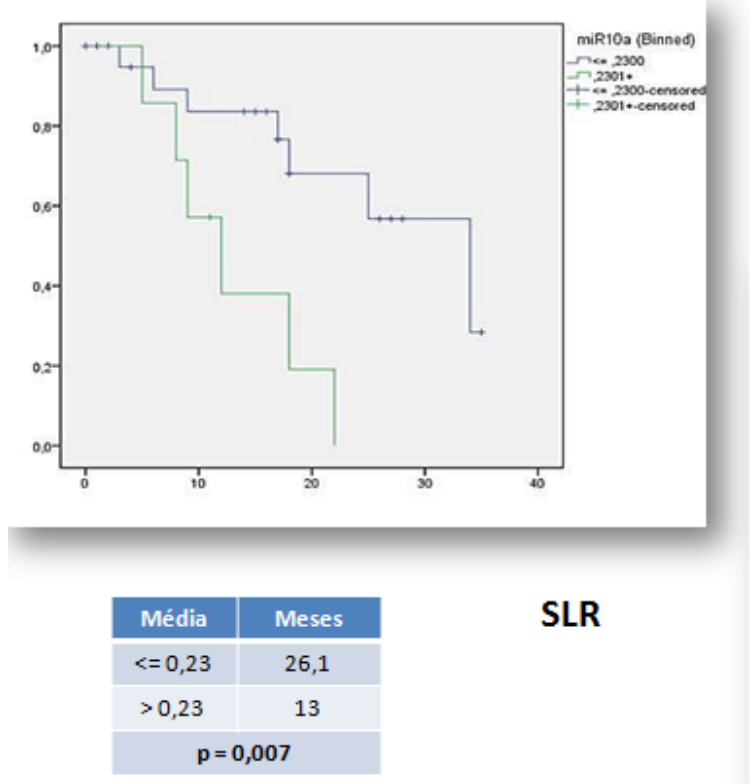

\begin{tabular}{|c|c|}
\hline Média & Meses \\
\hline$<=0,23$ & 27,3 \\
\hline$>0,23$ & 15,3 \\
\hline \multicolumn{2}{|c|}{$p=0,04$} \\
\hline
\end{tabular}

SCE

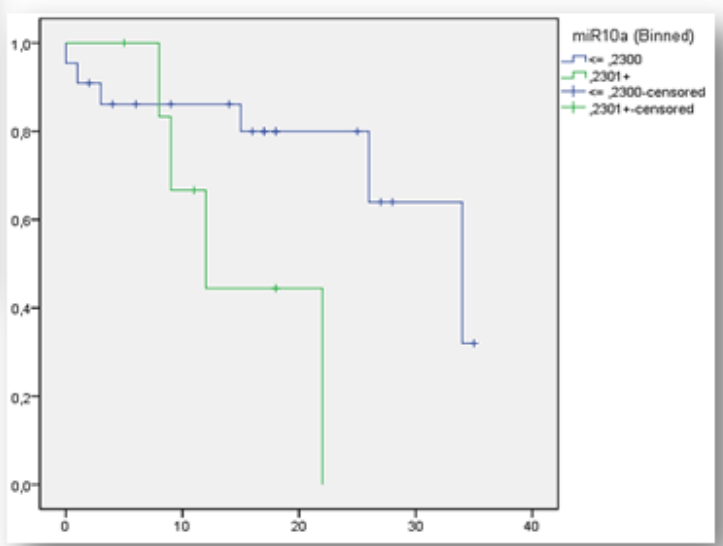

Figura 9 - Curva de Kaplan-Meyer demonstrando as diferenças de SLR e SCE para o miR-10a em tumores de alto grau pT2-3

Considerando o miR-145, níveis acima de 0,66 se correlacionaram com menor sobrevida livre de recidiva para tumores pT2-3 (média de 15,6 meses), enquanto que expressões menores ou iguais a 0,66 se associaram com um tempo médio de sobrevida de 25,2 meses ( $p=0,03$ ) (Figura 10). 


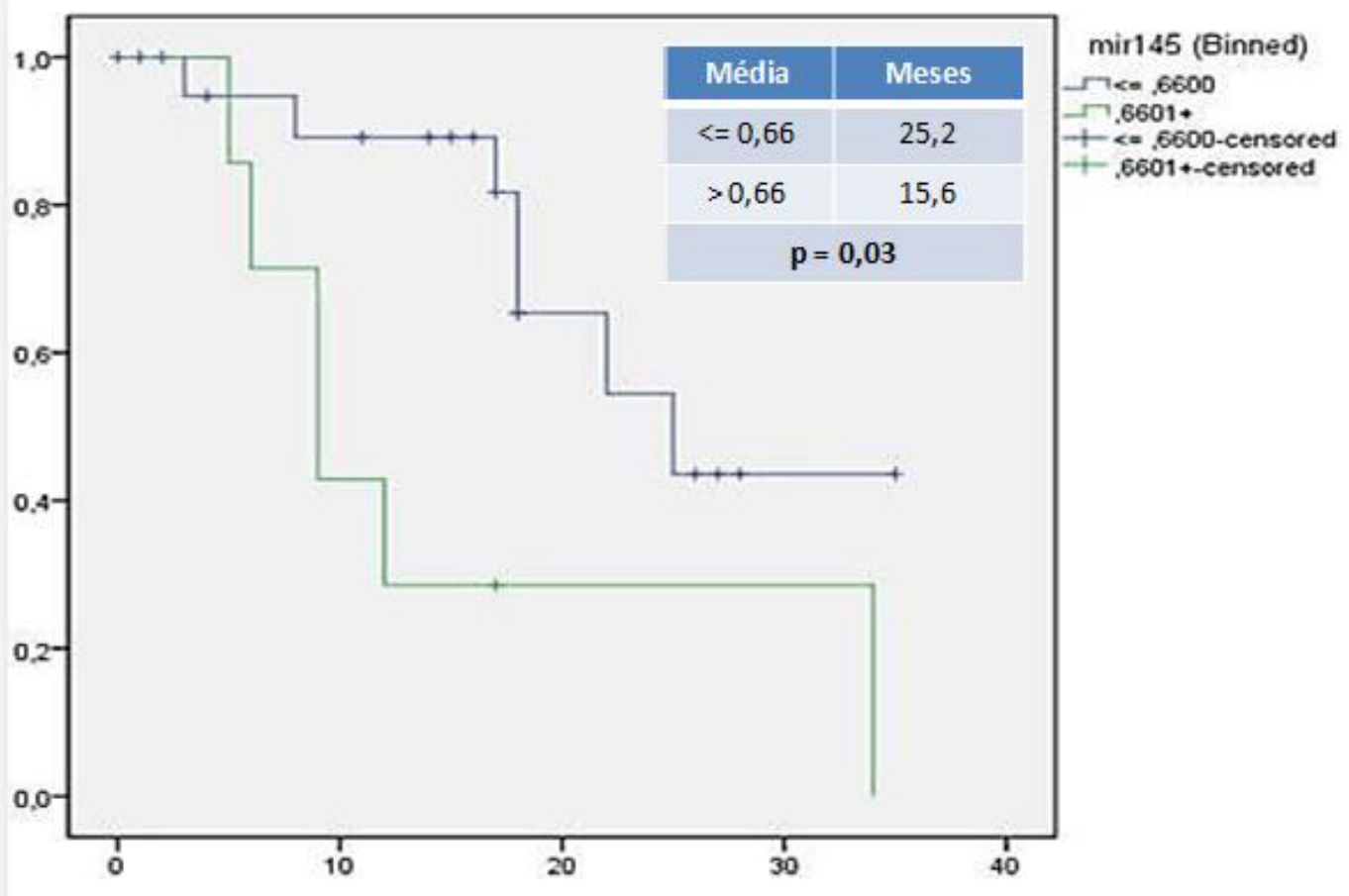

Figura 10 - Curva de Kaplan-Meyer demonstrando as diferenças de SLR em tumores de alto grau pT2-3 em relação à expressão do miR-145 
5. DISCUSSÃO 
Atualmente já estão identificados mais de 1400 miRNA que, regulando aproximadamente um terço dos genes humanos (Lewis et al., 2005), parecem ter papel fundamental nos processos fisiológicos e patológicos de órgãos e tecidos (Bartel e Chen, 2004).

Os achados aqui encontrados estão em concordância com a literatura. Com exceção do miR-10a para pTa de baixo grau e do miR-100, 21 e 205 nos tumores de alto grau pT2-3, que se mostraram superexpressos em mais da metade dos casos, todos os demais apresentaram subexpressão em ambos os grupos tumorais. Este fato é relevante e demonstra que miRNA humanos atuam principalmente como supressores de tumor (Gottardo et al., 2007; Neely et al., 2008; Leite et al., 2009; Ichimi et al., 2009; Veerla et al., 2009; Catto et al., 2009; Sachdeva et al., 2009; Chiyomaru et al., 2010; Dip et al., 2011).

O nosso principal objetivo foi o de identificar assinaturas de expressão de miRNA que possam corroborar a caracterização dos dois grupos específicos de carcinoma urotelial, tanto do ponto de vista molecular, quanto de comportamento. Quando consideramos dois grupos de tumor definidos por grau e estádio distintos, identificamos diferenças de expressão em apenas quatro miRNA (miR-100, miR-10a, miR-21 e miR-205) dos 14 estudados. Esses perfis parecem definir cada grupo tumoral e podem separá-los de modo bastante específico.

O miR-100 apresentou-se subexpresso em todos os carcinomas de baixo grau, pTa. Esse mesmo padrão de expressão tem sido observado no carcinoma de ovário e carcinoma escamoso da cavidade oral (Nagaraja et al., 2010; Henson et al., 2009). No carcinoma urotelial, miR-100 pode ter como seu alvo principal o gene FGFR3, cuja mutação e aumento de atividade está relacionada a essa neoplasia. Em condições fisiológicas, miR-100 exerce regulação negativa sobre FGFR3 diminuindo assim seus níveis de expressão de modo pós-transcricional. Os nossos dados demonstram que pode existir uma via alternativa de carcinogênese dos carcinomas uroteliais de baixo grau que não a mutação ativadora de FGFR3. A subexpressão de miR-100 que encontramos em 100\% dos tumores poderia ser responsável por uma 
superexpressão de FGFR3 e desenvolvimento do carcinoma de baixo grau. Catto et al. (2009) encontraram uma relação inversamente proporcional entre miR-100 e FGFR3, onde a subexpressão do miRNA levou ao aumento de atividade gênica antes da ocorrência de mutação, sugerindo que a concentração aumentada de FGFR3 facilitaria o evento mutacional através do aumento do turnover celular ou da seleção natural de células mutantes. Talvez a perda de expressão de miR-100 seja o primeiro evento desencadeador da doença e poderia ocorrer muito antes de seu aparecimento clínico. A importância deste fato é que essa característica molecular poderia ser utilizada para o diagnóstico precoce em indivíduos expostos a agentes de risco e também prever o comportamento da doença, permitindo um tratamento conservador de preservação vesical devido às raras chances de progressão e de excelente sobrevida. Podemos sugerir que miR-100 possa ser utilizado na prática clínica como um possível marcador diagnóstico e prognóstico do CUB pTa de baixo grau.

Por outro lado, a maior parte dos tumores invasivos esteve associada à superexpressão de miR-100 (56,7\%). Especula-se que ele aja como controlador negativo do gene THAP-2, envolvido diretamente no controle da proliferação celular através da modulação de proteínas que controlam o ciclo celular como pRB e E2F (Bessière et al., 2008). A perda de função dos genes RB1, p53 e PTEN, está envolvida na rota carcinogênica de tumores invasivos, promovendo a instabilidade genômica facilitando a sua progressão (Figura 1). A superexpressão de miR-100 em pT2-3 poderia promover o silenciamento de THAP-2 e, consequentemente, de RB1. Os genes BAZ2A e SMARCA5 também são alvos do miR-100 e estão associados com a repressão de transcrição do DNA e instabilidade cromossômica (Zhou et al., 2002; Bozhenok et al., 2002). Contudo, esses genes ainda não foram estudados em CUB e necessitam de melhores investigações que comprovem seus papéis na carcinogênese vesical.

Para o miR-10a, encontramos uma superexpressão em 73,3\% dos tumores pTa contra apenas $6,7 \%$ dos tumores pT2-3. O miR-10a está localizado no 
cromossomo 17q21, dentro do cluster gênico HOXB, entre os genes HOXB-4 e HOXB-5, tendo provável papel regulador na diferenciação celular (Garzon et al., 2006; Huang et al., 2010; Foley et al., 2011). Além do padrão usual de ação sobre a região não traduzida 3' do RNAm, o miR-10a pode se ligar à região 5' do RNAm e aumentar a tradução de proteínas ribossomais, regulando positivamente a tradução protéica global (Orom et al., 2008). Essas interações poderiam exercer um estímulo proliferativo, afetando a habilidade de diferenciação e promovendo a transformação celular, característica de neoplasias de um modo geral.

Nosso resultado é consistente com aquele publicado por Veerla et al. (2009). Naquele estudo os autores mostram uma expressão de miR-10a 2,47 vezes maior em tumores não invasivos pTa em relação aos tumores invasivos, pT1 e pT2-3. Mesmo sem estabelecer uma relação mecanística entre o miR-10a e o gene FGFR3, os autores especulam uma associação entre eles, que poderia ser fundamental à carcinogênese de CUB, pTa.

Embora alguns estudos atuais demonstrem um papel oncogênico da família miR-10 em outras neoplasias humanas, o miR-10a pode possuir uma função bastante ampla, dependendo do tipo de tumor e suas características genéticomoleculares. Por exemplo, Ma et al. (2007) e Weiss et al. (2009) observaram em câncer de mama e pâncreas um papel oncogênico do miR-10, estando sua superexpressão diretamente associada à maior agressividade tumoral, desenvolvimento de metástases e pior prognóstico. Já Agirre et al. (2008) evidenciaram uma relação entre a subexpressão desse miRNA e o aumento da proliferação celular e progressão da leucemia mielóide crônica.

Ainda que a superexpressão de miR-10a esteja relacionada a tumores de baixo grau, não invasivos, demonstramos que uma expressão menor de miR-10a associou-se com praticamente o dobro de sobrevida livre de recidiva e sobrevida câncer específica. Garzon et al. (2006) descrevem a subexpressão de miR-10a relacionada à superexpressão do gene HOXA-1 e conseqüente diferenciação celular. Assim poderíamos sugerir que quanto maior a subexpressão do miRNA, maiores são 
a expressão de HOXA-1 e a diferenciação da célula neoplásica, propiciando um melhor comportamento do tumor.

O miR-21 apresentou uma acentuada superexpressão em tumores de alto grau invasivos, sendo praticamente 17 vezes maior que nos não invasivos ( $\mathrm{pTa}=$ 1,08 vs pT2/pT3 = 18,17; p =0,02). O mesmo foi descrito por Neely et al. (2008) que demonstraram expressão de miR-21 10 vezes maior em CUB invasivo de alto grau. Evidências atuais determinam o miR-21 como um miRNA verdadeiramente oncogênico, apresentando-se superexpresso na grande maioria dos tumores. Ele é capaz de promover a tumorigênese aumentando a proliferação celular e bloqueando os mecanismos de controle apoptótico. O mesmo foi achado por Si et al. (2006) no câncer de mama.

O miR-21 tem como alvo indireto o gene p53, considerado o mais importante gene envolvido na carcinogênese do CUB invasivo (Esrig et al., 1994). p53 é um gene responsável pelo controle das atividades globais da célula através da inibição do ciclo celular, indução de apoptose e reparo do DNA. Catto et al. (2009) observaram superexpressão do miR-21 associada à inativação do gene p53, relacionando-a com a invasão e progressão tumoral.

PTEN é outro importante gene envolvido nas vias carcinogênicas do CUB e também é alvo de miR-21 (Wu, 2009; McConkey et al., 2010; Meng et al., 2007). PTEN é uma fosfatase lipídica que suprime a via carcinogênica PI3K/AKT e bloqueia o crescimento celular, caracterizando-se como um clássico gene supressor tumoral. Em uma revisão atual dos mecanismos genético-moleculares envolvidos na iniciação e progressão do CUB, McConkey et al. (2010) sugerem que a perda de função de PTEN é muito mais comum em CUB invasivo relacionado à inativação da via PTEN/PI3K/AKT/mTOR caracterizando um fator de pior prognóstico.

Demonstramos ainda que a superexpressão de miR-21 esteve associada à pior sobrevida livre de recidiva nos tumores pTa, e que a SLR é 51\% maior para os casos que cursaram com níveis de expressão menores ou iguais a 1,08 (16,3 versus 
24,6 meses). Esse fato fortalece as características oncogênicas do miR-21 apresentadas nesse estudo.

Todos os demais miRNA se mostraram subexpressos no dois grupos de tumores.

Todos os tumores pTa e 63,3\% dos pT2-3 mostraram subexpressão de miR205. Embora praticamente dois terços dos tumores invasivos de alto grau tenham demonstrado subexpressão do miRNA, a média dos níveis de expressão dos 30 casos tende à superexpressão relativamente considerável $(6,91)$. 0 miR-205 tem sido definido como um supressor de tumor e está envolvido na transição epitéliomesenquimal (EMT), processo pelo qual uma neoplasia maligna tem habilidade de realizar uma etapa fundamental à progressão tumoral, ou seja, a disseminação para outros órgãos. O miR-205, assim como a família miR-200, inibem ZEB-1 e ZEB-2 que fisiologicamente atuam suprimindo E-caderina, uma molécula de adesão responsável por manter o epitélio com suas características fisiológicas habituais (Gregory et al., 2008). A perda de expressão do miR-205 permite a hiperatividade de ZEB-1 e ZEB-2 que, por sua vez, acabam por anulando as funções da E-caderina, consentindo assim a disjunção epitelial facilitadora do processo de metastatização. EMT é crucial para a manutenção e sucesso do processo neoplásico, estando diretamente relacionada com pior comportamento, maior agressividade tumoral e, consequentemente, pior prognóstico e menor sobrevida. O papel do miR-205 é praticamente o mesmo em vários tipos de tumores humanos, que é o de dificultar sua disseminação. Alguns autores já demonstraram sua subexpressão em câncer de pulmão do tipo não pequenas células, câncer de mama e próstata (Lebanony et al., 2009; Wu et al., 2009; Gandellini et al., 2009).

No CUB tem-se mostrado a hipermetilação aberrante de regiões promotoras no cromossomo 1q32.2, localização do gene produtor do miR-205 (Wiklund et al., 2011). Neely et al., em 2008, estabeleceram que a relação miR-21:miR-205 aumenta progressivamente conforme a progressão tumoral. De forma muito interessante, Brabletz e Brabletz (2010) demonstraram que a alça auto-regulável ZEB/miR-200 é 
crucial para definir o estado da célula. Desse modo, quando a alça está em favor de ZEB, o estado progressivo prepondera, ocorrendo disseminação tumoral além das barreiras epiteliais. Por outro lado, quando ela está em favor da família miR-200, o estado proliferativo prevalece, levando ao crecimento do tumor. Segundo os autores, o tecido neoplásico necessita de ambos os estados, isto é, um proliferativo inicial que fará o tumor crescer, e outro progressivo mais tardio, responsável pelo processo de metastatização. Muito interessante é que a subexpressão de miR-200 favoreceria o processo de disseminação mas, após definidos os sítios de metástases, a proliferação deverá novamente ocorrer, sendo, portanto, necessária a reexpressão de miR-200. Esse fato é ilustrado em nossos resultados onde demonstramos que miR-205, um miRNA símile à família miR-200 esteve subexpresso em $100 \%$ dos tumores pTa, condizente com o estado carcinogênico proliferativo inicial. Nos tumores invasivos houve uma re-expressão desse miRNA em um terço dos casos.

Observamos uma perda global de expressão de miR-let7c tanto em tumores pTa $(86,7 \%)$ quanto pT2/pT3 (93,3\%). Esse fato pontua o papel supressor deste miRNA, consolidado em praticamente todas as neoplasias onde foi estudado, e reflete sua ação fundamental na proteção contra eventos malignos. Os oncogenes RAS e c-MYC são alvos de miR-let7c e sua subexpressão está relacionada ao desenvolvimento neoplásico (Reinhart et al., 2000; Johnson et al., 2005). RAS é o segundo oncogene mais importante na tumorigênese de pTa de baixo grau ( $\mathrm{Wu}$, 2005). Mutações puntiformes levam a alterações gênicas que, por sua vez, promovem um estímulo exagerado das vias AKT e STAT, gerando alta taxa de proliferação celular. c-MYC é o protótipo do oncogene, tem como papel a inibição de RB1 (Reinhart et al., 2000) e está associado ao CUB pT2-3. c-MYC é capaz de estimular as ciclinas CDK4, CDK6 e D1, promovendo a fosforilação e inativação de RB1 com conseqüente estímulo mitogênico e proliferativo. Por outro lado, c-MYC pode aumentar a função de p53 via inibição de MDM-2, favorecendo a parada do ciclo celular e apoptose (Knowles, 2008). 
Da mesma forma, miR-125b mostrou-se subexpresso em $100 \%$ dos casos pTa e 93,3\% dos pT2-3. O papel do miR-125b é controverso na literatura. Estudos o definem como um miRNA supressor de tumor e, portanto, subexpresso, enquanto outros o classificam como um miRNA oncogênico (Ichimi et al., 2009; Le et al., 2009; Klussmann et al., 2010; Rajabi et al., 2010; Liang et al., 2010). Estudando tumores ovarianos, Guan et al. (2011) observaram um papel protetor de miR-125b onde encontrou-se subexpresso, e sua reintrodução impediu a formação de tumor em camundongos nude infectados com células neoplásicas de ovário humano. Por outro lado, Shi et al. (2011) demonstraram o papel oncogênico do miR-125b no câncer de próstata, uma vez que tem como alvo genes pró-apoptóticos (p53, Puma e Bak-1).

Concordando com nossos achados, Huang et al. (2011), demonstraram subexpressão de miR-125b em tumores vesicais e em linhagens celulares de CUB. miR-125b seria capaz de suprimir a tumorigênese vesical através do silenciamento do fator de transcrição E2F3, fundamental ao ciclo celular. Os autores encontraram uma relação inversa entre eles, e a transfecção de miR-125b em culturas celulares pôde reverter os efeitos proliferativos através da redução dos níveis de E2F3. Outro alvo do miR-125b é o gene KRT-7, envolvido no processo de replicação do DNA, organização do citoesqueleto e regulação da tradução, apresentando-se como um oncogene superexpresso (Ichimi et al., 2009).

Tumores pTa e pT2-3 apresentaram subexpressão de miR-143 (96,7\% para ambos os grupos) e miR-145 (73,3\% e 86,7\%, respectivamente), sugerindo-se funções supressoras tumorais e controladoras das atividades normais da célula. Esses miRNA situam-se muito próximos no cromossomo $5 q 32$ e compartilham a mesma função supressora de tumor. Existem evidências da ação de miR-143 sobre RAS. Como já discutido, RAS mutado leva ao estímulo das vias MAPK/AKT/STAT, que engatilha o desenvolvimento de pTa de baixo grau (Wu, 2009) podendo também estar envolvido nas vias de tumores de alto grau (McConkey et al., 2010). Lin et al. (2009) demonstraram através do estudo de tecidos neoplásicos e linhagens 
celulares de CUB, que a subexpressão do miR-143 é a regra nessas neoplasias. Em tecidos tumorais, o miR-143 apresentou-se 13,7 vezes menor que no controle normal. Nas linhagens tumorais EJ e T24, o miR-143 não foi identificado e quando transfectados às culturas, inibiu significativamente o crescimento celular.

Em relação ao miR-145, vários estudos têm validado este miRNA como um inibidor do ciclo e crescimento celular e indutor de apoptose, diminuindo a possibilidade de invasão e desenvolvimento de metástases, apresentando-se subexpresso em câncer de cólon, pulmão, mama, próstata, entre outros (Ozen et al., 2008; Izzoti et al., 2009; Sachdeva et al., 2009). Nossos resultados estão condizentes com os achados da literatura, e mostram um comportamento de subexpressão marcante do miRNA nos dois grupos de tumor.

Sachdeva e Mo (2010) mostraram em linhagens de câncer de mama que o gene da mucina 1 (MUC-1) esteve envolvido com iniciação, invasão e disseminação tumoral e o miR-145 é capaz de inibir essas características, controlando o desenvolvimento neoplásico. Outro alvo do miR-145 é o gene c-MYC (Sachdeva et al., 2009), um oncogene envolvido no processo carcinogênico do CUB invasivo (Knowles, 2008). O gene p53 é um indutor de miR-145 e está diretamente relacionado à carcinogênese de CUB invasivo de alto grau. Em 2009, Sachdeva et al. observaram que, em condições fisiológicas, níveis mais elevados de p53 devido ao estresse celular levou a um aumento nas concentrações de miR-145 através do elemento de resposta de p53 (p53RE). O miR-145, por sua vez, bloqueia a atividade de c-MYC (um regulador negativo de p21), e a perda de expressão do miRNA pode promover falência na regulação desse oncogene, diminuir os níveis de p21 e aumentar a proliferação celular. Além disso, a via carcinogênica PI3K/AKT é capaz de estimular a produção de miR-145. A interrupção desses complexos mecanismos mediados pela subexpressão do miR-145, poderia levar, ou pelo menos iniciar, a carcinogênese do CUB (Sachdeva e Mo, 2010). Seguindo a mesma ideia, Spizzo et al. (2010) analisando linhagens celulares de câncer de mama, demonstraram o crucial papel supressor do miR-145, e sua transfecção preveniu crescimento e proliferação 
celulares e induziu a apoptose mediada por p53. p53 também pode desencadear a maquinaria enzimática de miRNA, principalmente a RNAse III Drosha, e assim estimular a produção de vários miRNA, incluindo o miR-145. A perda de função de p53 por mutações geraria uma produção inadequada de miR-145 e sua consequente subexpressão (Suzuki et al., 2009). Chiyomaru et al. (2010) demonstraram em CUB uma associação entre o oncogene FSCN-1 e o silenciamento promovido pelo miR-145 e sugerem que a perda de expressão do miRNA geralmente relacionada com tumores vesicais de todos os estádios, permite a perda de silenciamento de FSCN-1 e maior agressividade e capacidade de invasão tumoral.

Encontramos uma associação entre o miR-145 e sobrevida livre de recidiva para tumores invasivos de alto grau. Pacientes sobreviveram livres de doença por um tempo médio de 15,6 meses quando valores de expressão encontravam-se acima de 0,66 , enquanto que esse tempo foi $61,5 \%$ maior para valores menores ou iguais ao ponto de corte (25,2 meses). Apesar da diferença estatística encontrada ( $p$ $=0,03)$, maiores níveis de expressão estiveram associados com maior recidiva e este fato não é condizente com o racional proposto para o miRNA, um verdadeiro supressor de tumor. Esperávamos que concentrações maiores de miR-145 se correlacionassem com melhor comportamento tumoral e prognóstico, e o que podemos especular aqui é que talvez, frente à grande desorganização da maquinaria celular por conta da perda de função de p53, a célula eleve a produção de miR-145 por outros mecanismos que não o mediado por p53. Esse fato poderia ser encarado como um evento celular reacional na tentativa de manter as condições fisiológicas da célula neoplásica.

Oitenta por cento dos tumores pTa e $90 \%$ dos pT2-3 exibiram subexpressão do miR-221, parecendo existir uma tendência à maior subexpressão conforme aumento do grau e estadiamento tumoral. Enquanto a literatura demonstra um papel oncogênico de miR-221 (Sage et al., 2007; Lu et al., 2010), aqui demonstramos resultados discordantes e supomos que miR-221 tenha uma função supressora de tumor no CUB. Pineau et al. (2010) demonstraram superexpressão de 
miR-221 em hepatocarcinoma (HCC) e sugerem sua ação sobre p27KIP1 (inibidor de ciclinas e supressor do ciclo celular) e DDIT4 (regulador negativo de mTOR).

miR-223 esteve subexpresso em tumores pTa e pT2-3 (96,7\% e 66,7\%, respectivamente). Os níveis de subexpressão foram mais evidentes nos pTa não invasivos, mas não houve diferenças entre os grupos. Esse miRNA está subexpresso em leucemias linfocíticas crônicas (LLC) sendo os níveis de subexpressão maiores quanto maior o volume tumoral, a agressividade da doença e a presença de fatores de pior prognóstico (Stamatopoulos et al., 2009). Wong et al. (2008) mostraram que o miR-223 está subexpresso em HCC e que sua restauração em cultura de células inibem a viabilidade celular, através do silenciamento da oncoproteína Statmina-1 (STMN-1). Em tumores ovarianos, miR-223 se mostra superexpresso em neoplasias recidivantes em relação às primárias (Laios et al., 2008). Chen et al. (2008), analisando miRNA no plasma, verificaram superexpressão de miR-223 em pacientes portadores de câncer de pulmão do tipo não pequenas células.

Diferente dos nossos achados, Gottardo et al. (2007), estudando CUB de diversos graus e estádios, encontraram expressão de miR-223 em média 1,5 vezes maior no tumor em relação ao tecido normal.

Metade dos pacientes com tumores pTa apresentou subexpressão de miR15a, enquanto que a $53,3 \%$ dos pT2-3 o fizeram. A subexpressão do miR-16-1 ocorreu na maior parte dos tumores pTa e pT2-3 (73,3\% para os dois grupos), sem existirem diferenças para ambos os miRNA quando comparamos os dois grupos para grau histológico $(p=0,78$ e $p=0,81)$ e estadiamento $(p=0,93$ e $p=0,95)$. Os miR-15a e 16-1 exibiram os resultados mais heterogêneos entre todos os miRNA estudados. Parece não existir um padrão de comportamento para os mesmos no CUB, fato que poderia sugerir um não envolvimento desses miRNA na carcinogênese vesical. Esses dois miRNA supressores estão relacionados ao desenvolvimento de leucemia linfocítica crônica atuando sobre o oncogene BCL-2 (Calin et al., 2002; Cimmino et al., 2005), que parece não ter papel na carcinogênese vesical. 
miR-199a também se mostrou subexpresso nos dois grupos de tumor $193,3 \%$ para $\mathrm{pTa}$ e $83,3 \%$ para $\mathrm{pT} 2-3$ ), sem diferenças significativas observadas para os fatores prognósticos. O mesmo foi descrito por Ichimi et al. (2008) no CUB. Baixos níveis de miR-199a já foram descritos em tumores de ovário, testículo, HCC e osteossarcoma (Chen et al., 2008; Cheung et al., 2011; Fornari et al., 2010; Duan et al., 2011) e o miRNA parece estar diretamente envolvido na progressão tumoral, estando relacionado a um pior prognóstico dessas neoplasias. Fornari et al. (2010) estudando HCC sugerem mTOR como alvo do miR-199a, demonstrando uma relação inversa entre eles. Assim como para HCC, a via PI3K/AKT/mTOR também está envolvida na carcinogênese de CUB invasivo de alto grau e a subexpressão de miR199a poderia explicar o superestímulo à produção de mTOR e, pelo menos em parte, a instalação e progressão tumoral. Cheung et al. (2011) comprovaram que o gene PODXL, produtor de uma proteína anti-adesiva presente em tumores agressivos, está superexpresso em câncer de testículo e é alvo de miR-199a, que encontra-se subexpresso por hipermetilação de sua região produtora. Tanto Chen quanto Cheung procederam a estudos de transfecção do miR-199a em cultura de células tumorais e observaram inibição do crescimento celular, sugerindo seu uso no tratamento daquelas neoplasias.

A marcante subexpressão do miR-452 nos dois grupos de tumor $(93,3 \%$ no grupo pTa e $96,7 \%$ no $\mathrm{pT} 2-3$ ) nos permite supor que esse miRNA tem um papel supressor de tumor no CUB. Além disso, os níveis crescentes de subexpressão e a maior porcentagem de casos subexpressos conforme evoluem grau histológico e estádio tumoral reforçam esse papel, já que quanto maior a agressividade, menores os níveis de expressão do miR-452. Nossos achados se contrapõem àqueles publicados para CUB. Veerla et al. (2009) estudando 14 pacientes, sendo 50\% deles com linfonodos positivos, demonstraram que a superexpressão de miR-452 relacionou-se com a presença de metástases linfonodais. Por outro lado, Mascaux et al. (2009), avaliando carcinoma escamoso brônquico, pontuaram uma perda de expressão do miR-452 relacionada ao mau comportamento tumoral. O miR-452 humano tem aproximadamente 220 genes-alvo e, dentre eles, dois que estão 
diretamente envolvidos com o crescimento e proliferação celular (E2F3 e MEF2C) e que poderiam deixar de ser inibidos pelo miR-452 no CUB. Essa suposição merece estudos mecanísticos complementares.

Embora alguns fatores como o número pequeno de casos e o tempo de seguimento curto possam ter sido limitantes, nosso estudo foi capaz de demonstrar uma diferença na expressão de quatro miRNA em tumores de baixo grau, pTa e de alto grau, pT2-3 que pode ser incorporada às vias moleculares já descritas. Sugerimos que esse perfil de expressão poderia ser utilizado como indicador prognóstico e auxiliar o urologista e oncologista na escolha da melhor conduta terapêutica.

Essa caracterização pode ser utilizada ainda para o desenvolvimento de drogas alvo como, por exemplo, a instilação de miR-100 em carcinomas pTa de baixo grau recidivantes resistentes ao BCG.

São necessários estudos mais amplos e comprovações experimentais da ação dos diferentes miRNA descritos nesse estudo para melhor compreensão do papel dessas moléculas no carcinoma urotelial de bexiga.

\subsection{Considerações finais}

Este estudo preliminar permitiu uma reflexão sobre as verdadeiras funções dos miRNA aqui estudados, não só pelas suas amplas capacidades de ação como também pelas suas habilidades em definir o destino da célula. Considerando os achados promissores aqui encontrados e frente a um mundo ainda não descoberto sobre essas fantásticas moléculas, pretendemos estudar detalhadamente as vias carcinogênicas envolvidas no CUB, na tentativa de identificar seus eventos-chave, introduzindo os miRNA como seus integrantes fundamentais. Assim poderemos especular seus papéis como potenciais marcadores diagnósticos e prognósticos e desenvolver miRNA-alvos para intervenção terapêutica molecular. Além disso, desejamos dosar miRNA na urina e, se isso for possível, tornaremos suas 
mensurações testes não invasivos e de fácil aquisição do material a ser estudado, independente da necessidade de amostras tumorais.

Através desta nova linha de pesquisa montada pelo nosso laboratório, teremos a oportunidade de desenvolver análises mais completas das vias de tumores invasivos e não invasivos por meio de estudos mecanísticos de transfecção/inibição em cultura de células, análise imuno-histoquímica, método de luciferase, Western Blotting e seqüenciamento do DNA dos genes envolvidos, que permitirão o entendimento mais amplo desses processos e, certamente, melhor manejo dessa doença tão prevalente.

Por fim, provavelmente o futuro da terapia de alvo molecular anti-tumoral se baseará não em um, mas num grupo de miRNA que trabalharão em conjunto nas várias etapas do processo tumoral e serão capazes de identificar a doença, prever seu comportamento e controlá-la ou definitivamente tratá-la de modo eficaz. 
6. CONCLUSÕES 
A maioria dos miRNA se mostrou subexpressa no carcinoma urotelial de bexiga de baixo e alto grau, pTa e pT2-3.

Os níveis de expressão de miR-100, miR-10a, miR-21 e miR-205 foram capazes de diferenciar carcinomas de baixo grau, pTa e carcinomas de alto grau pT2-3

Os carcinomas de baixo grau, pTa apresentaram subexpressão de miR-100, miR-21 e miR-205, enquanto que miR-10a mostrou-se superexpresso. No carcinoma de alto grau, pT2-3 o padrão foi exatamente inverso com superexpressão de miR100, miR-21 e miR-205 e subexpressão de miR-10a. Esses perfis distinguem os dois grupos tumorais e poderiam ser utilizados como biomarcadores diagnósticos e prognósticos.

miR-10a e miR-145 relacionaram-se com sobrevida livre de recidiva em tumores pT2-3 e suas maiores expressões traduziram maiores taxas de recidiva. 0 mesmo é válido para o miR-21 em tumores pTa.

miR-10a associou-se com sobrevida câncer-específica em tumores pT2-3 e maiores níveis do miRNA refletiu maior mortalidade pelo carcinoma urotelial de bexiga. 
7. ANEXOS 


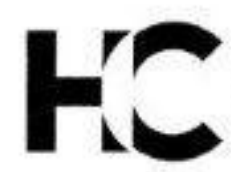

\section{APROVAÇĀO}

A Comissão de Ética para Análise de Projetos de Pesquisa - CAPPesa da Diretoria Clínica do Hospital das Clínicas e da Faculdade de Medicina da Universidade de São Paulo, em sessão de 21/07/2010, APROVOU o Protocolo de Pesquisa $n^{\circ} \mathbf{0 1 7 6} / 10$, intitulado: "ANÁLISE DE EXPRESSĀO DE MICRO RNA EM CARCINOMA UROTELIAL DE BEXIGA" apresentado pelo Departamento de CIRURGIA, inclusive o Termo de Consentimento Livre e Esclarecido.

Cabe ao pesquisador elaborar e apresentar à CAPPesq, os relatórios parciais e final sobre a pesquisa \{Resolução do Conselho Nacional de Saúde $n^{\circ} 196$, de 10/10/1996, inciso IX.2, letra "c").

Pesquisador (a) Responsável: Profa. Dra. Katia Ramos Moreira Leite Pesquisador (a) Executante: Nelson Gaspar Dip Junior; Miguel Srougi; Marcos Francisco Dall'Ogllo; Sabrina Reis; Juliana Sousa Canavez

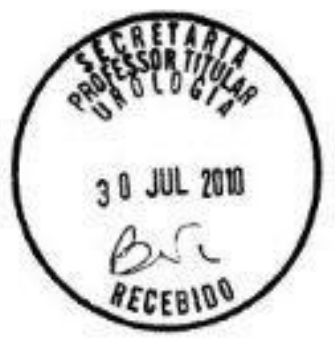

CAPPesq, 21 de Julho de 2010

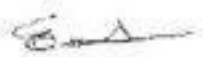

Prof. Dr. Eduardo Massad Presidente da Comissão de Ética para Análise de Projetos de Pesquisa 
Anexo B - Termo de Consentimento Livre e Esclarecido

HOSPITAL DAS CLÍNICAS DA FACULDADE DE MEDICINA DA UNIVERSIDADE DE SÃO PAULO-HCFMUSP

1. DADOS DE IDENTIFICAÇÃO DO SUJEITO DA PESQUISA OU RESPONSÁVEL LEGAL

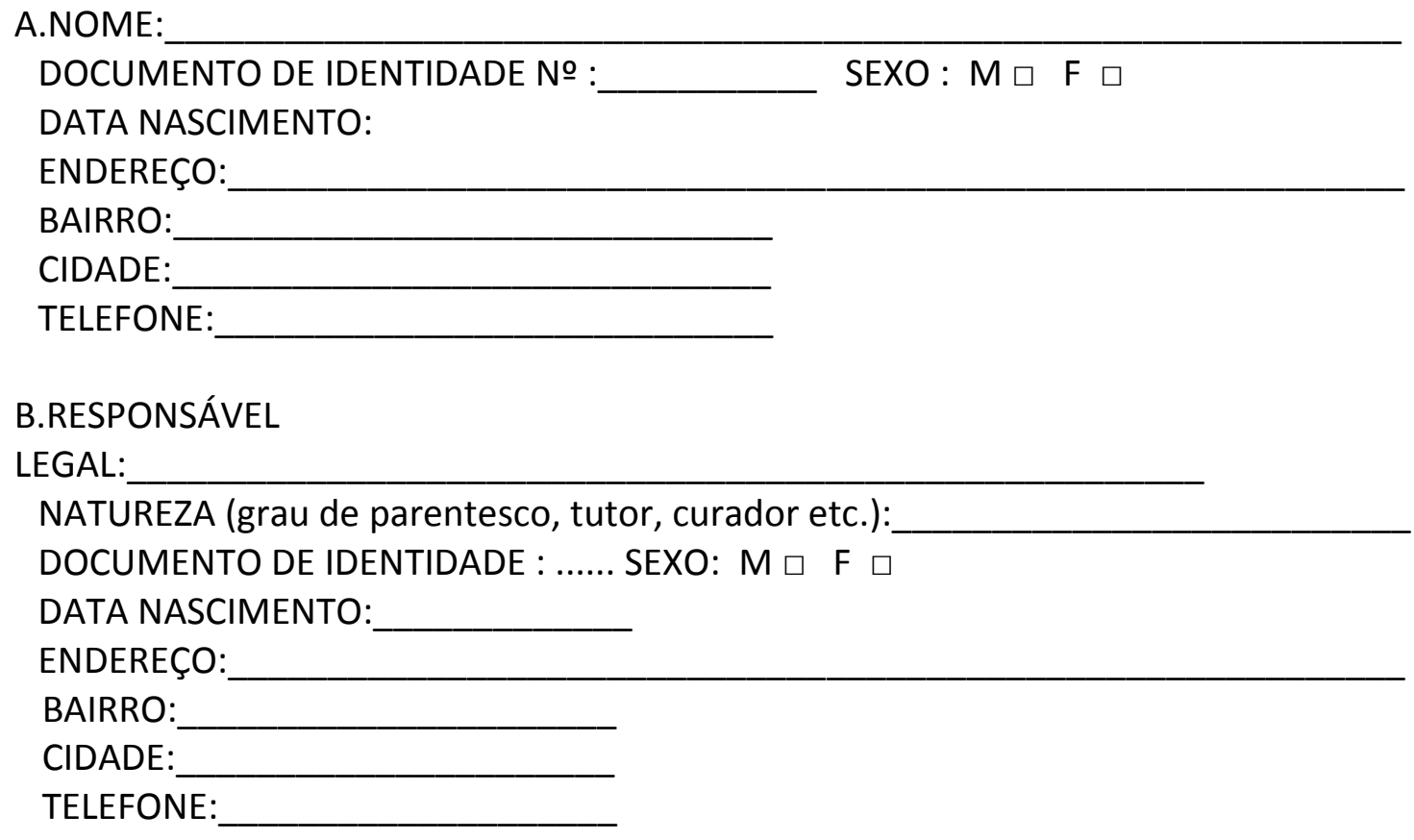

\section{DADOS SOBRE A PESQUISA}

A. TÍTULO DO PROTOCOLO DE PESQUISA: Caracterização da expressão de Micro RNA em Carcinoma Urotelial Invasivo da Bexiga

B. PESQUISADOR : Drạ. Kátia Ramos Moreira Leite

C. CARGO/FUNÇÃO: Médica, chefe do Laboratório de Investigação Médica da Disciplina de Urologia - LIM/55

D. INSCRIÇÃO CONSELHO REGIONAL: № 51442

E. UNIDADE DO HCFMUSP: Departamento de cirurgia, disciplina de urologia

F. AVALIAÇÃO DO RISCO DA PESQUISA:

$\begin{array}{llr}\text { RISCO MÍNIMO } & X & \text { RISCO MÉDIO } \square \\ \text { RISCO BAIXO } \square & & \text { RISCO MAIOR } \square\end{array}$


G. DURAÇÃO DA PESQUISA : 24 meses

\section{ORIENTAÇÕES}

1 - O objetivo desse estudo é avaliar um novo marcador para diagnosticar e/ou definir o prognóstico do câncer de Bexiga.

2 - O trabalho será realizado utilizando parte do tecido que foi retirado durante a sua cirurgia, não acarretará nenhum prejuízo a sua pessoa ou ao próprio material que continuará preservado para seu interesse futuro.

3 - Não será necessário fazer nenhum procedimento adicional.

4-Portanto esta pesquisa não lhe traz nenhum desconforto e nenhum risco. 5 - Não há benefício direto para o senhor, somente no final do estudo poderemos concluir a presença de algum benefício para os pacientes, que poderá ser uma nova ferramenta para a descoberta ou para descartar a hipótese do câncer de Bexiga, ou ainda definir qual o grau de malignidade do seu tumor. 6 - Como não há procedimentos adicionais a serem feitos, não existem procedimentos alternativos.

7 - Garantia de acesso: em qualquer etapa do estudo, você terá acesso aos profissionais responsáveis pela pesquisa para esclarecimento de eventuais dúvidas. O principal investigador é a Dra. Kátia Ramos Moreira Leite, que pode ser encontrado no endereço Av. Dr. Enéas de Carvalho Aguiar $255-7^{\circ}$ andar sala $710-\mathrm{F}$, Telefone (011) 3069 - 8080. Se você tiver alguma consideração ou dúvida sobre a ética da pesquisa, entre em contato com o Comitê de Ética em Pesquisa (CEP) - Rua Ovídio Pires de Campos, 225 - 5o andar - tel: 3069-6442 ramais 16, 17, 18 ou 20, FAX: 3069-6442 ramal 26 - E-mail: cappesq@hcnet.usp.br 8 - É garantida a liberdade da retirada de consentimento a qualquer momento e deixar de participar do estudo, sem qualquer prejuízo à continuidade de seu tratamento na Instituição; 09 - Direito de confidencialidade - As informações obtidas serão analisadas em conjunto com outros pacientes, não sendo divulgado a identificação de nenhum paciente;

10 - Direito de ser mantido atualizado sobre os resultados parciais das pesquisas, quando em estudos abertos, ou de resultados que sejam do conhecimento dos pesquisadores;

11 - Despesas e compensações: não há despesas pessoais para o participante em qualquer fase do estudo, incluindo exames e consultas. Também não há compensação financeira relacionada à sua participação. Se existir qualquer despesa adicional, ela será absorvida pelo orçamento da pesquisa. 12 - Compromisso do pesquisador de utilizar os dados e o material coletado somente para esta pesquisa.

Acredito ter sido suficientemente informado a respeito das informações que li ou que foram lidas para mim, descrevendo o estudo: "Caracterização da expressão de Micro RNA em Carcinoma Urotelial Invasivo da Bexiga". Eu discuti com o Dra Kátia 
Ramos Moreira Leite sobre a minha decisão em participar nesse estudo. Ficaram claros para mim quais são os propósitos do estudo, os procedimentos a serem realizados, seus desconfortos e riscos, as garantias de confidencialidade e de esclarecimentos permanentes. Ficou claro também que minha participação é isenta de despesas e que tenho garantia do acesso a tratamento hospitalar quando necessário. Concordo voluntariamente em participar deste estudo e poderei retirar o meu consentimento a qualquer momento, antes ou durante o mesmo, sem penalidades ou prejuízo ou perda de qualquer benefício que eu possa ter adquirido, ou no meu atendimento neste Serviço.

Assinatura do paciente/representante legal

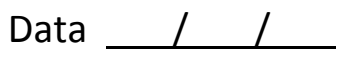

Assinatura da testemunha

Data $1 / 1$

para casos de pacientes menores de 18 anos, analfabetos, semi-analfabetos ou portadores de deficiência auditiva ou visual.

Declaro que obtive de forma apropriada e voluntária o Consentimento Livre e Esclarecido deste paciente ou representante legal para a participação neste estudo.

Dra. Kátia Ramos Moreira Leite (responsável pelo estudo)

Data $1 / 1$ 


\section{Anexo C - Protocolo para Extração de miRNA de Tecido Congelado - mirVana $^{\mathrm{TM}}$ miRNA Isolation Kit (Ambion ${ }^{\circledR}$ )}

1. Medir ou estimar o peso da amostra

2. Macerar o tecido em nitrogênio líquido ou macerador

3. Adicionar 10 volumes da solução de lise (Lysis/Binding Buffer)

4. Adicionar $1 / 10$ do volume do aditivo de homogeneizar (homogenate additive)

5. Deixar a mistura no gelo por 10 minutos

6. Adicionar um volume de ácido fenol-clorofórmio (Acid-phenol:chloroform) igual ao volume da solução de lise

7. Vortex 30-60 segundos

8. Centrifugar 5 minutos em $10.000 \mathrm{rpm}$ em temperatura ambiente

9. Remover cuidadosamente a fase aquosa e transferir para um novo tubo; anotar o volume removido

10. Adicionar $1 / 3$ do volume de etanol $100 \%$

11. Vortex ou inverter o tubo

12. Transferir a amostra para a coluna (volume máximo de $700 \mu \mathrm{L}$ )

13. Centrifugar por 15 segundos a $10.000 \mathrm{rpm}$ temperatura ambiente

14. Coletar o FILTRADO e transferir para um novo tubo; anotar o volume total; o filtro contém RNA e o filtrado os pequenos RNA

15. Adicionar $2 / 3$ do volume de etanol $100 \%$ ao filtrado e misturar

16. Transferir o filtrado para um novo filtro (volume máximo de $700 \mu \mathrm{L}$ )

17. Centrifugar por 15 segundos a $10.000 \mathrm{rpm}$ temperatura ambiente

18. Descartar o filtrado (os miRNAs agora estão no filtro)

19. Adicionar $700 \mu \mathrm{L}$ de wash solution 1 e centrifugar $5-10$ segundos

20. Adicionar $700 \mu \mathrm{L}$ de wash solution $2 / 3$ e centrifugar $5-10$ segundos (1a vez)

21. Adicionar $700 \mu \mathrm{L}$ de wash solution $2 / 3$ e centrifugar $5-10$ segundos ( 2 a vez)

22. Depois de descartar o filtrado, centrifugar por 1 minuto a $10.000 \mathrm{rpm}$ temperatura ambiente, os tubos vazio para secar e remover resíduos

23. Transfira o filtro para um novo tubo e adicionar $100 \mu \mathrm{L}$ de $\mathrm{H} 2 \mathrm{O}$ pré aquecida a 95 C (Elution Solution) e fechar o tubo

24. Centrifugar $10.000 \mathrm{rpm}$ temperatura ambiente por 20-30 segundos

25. Quantificar as amostras e armazenar em freezer $-20^{\circ} \mathrm{C}$ 


\section{Anexo D - Valores de expressão dos 14 miRNA estudados para cada amostra de tumor pTa de baixo grau}

\begin{tabular}{|c|c|c|c|c|c|c|c|c|c|c|c|c|c|c|}
\hline $\begin{array}{c}\text { miRNA } \\
\text { pTa }\end{array}$ & 100 & 21 & Let7c & $125 b$ & 143 & 145 & 221 & 223 & $15 \mathrm{a}$ & $16-1$ & $199 a$ & $10 a$ & 452 & 205 \\
\hline B54 & 0,117 & 0,211 & 0,103 & 0,505 & 0,018 & 0,422 & 0,003 & 0,002 & 0,16 & $2,6^{-5}$ & 0,29 & 761,2 & 39,87 & 0,35 \\
\hline B56 & 0,440 & 0,167 & 0,003 & 0,4 & 0,018 & 0,090 & 0,61 & 0,135 & 0,21 & 0,04 & 0,03 & 113,8 & 0,0001 & 0,005 \\
\hline B61 & 0,198 & 0,029 & 0,013 & 0,085 & 0,002 & 0,144 & 4,61 & 0,554 & 13,57 & 2,33 & 0,05 & 197,4 & 0,002 & 0,005 \\
\hline B74 & 0,072 & 0,040 & 0,05 & 0,128 & 0,002 & 0,023 & 0,392 & 0,132 & 1,32 & 0,001 & 0,01 & 16,11 & 0,007 & 0,036 \\
\hline B75 & 0,083 & 0,022 & 0,034 & 0,123 & 0,002 & 0,033 & 0,307 & 0,285 & 0,32 & 1,89 & 0,04 & 3,194 & 0,0003 & 0,077 \\
\hline B79 & 0,0009 & 0,029 & 0,206 & 0,113 & 0,008 & 0,288 & 0,14 & 0,103 & 0,32 & 1,11 & 0,26 & 2,271 & 0,008 & 0,058 \\
\hline B87 & $8,9^{-13}$ & 0,414 & 13,14 & 0,334 & 4,13 & 2,275 & 2,01 & 0,711 & 2,18 & 6,04 & 2,7 & 6,282 & 0,04 & 0,005 \\
\hline B91 & $1,2^{-12}$ & 2,890 & 12,85 & 0,262 & 0,31 & 9,037 & 1,942 & 0,758 & 4,65 & 12,3 & 0,78 & 37,74 & 0,08 & 0,006 \\
\hline B95 & $3,1^{-11}$ & 0,566 & 2,29 & 0,152 & 0,351 & 24,06 & 0,296 & 0,06 & 0,77 & 0,95 & 0,66 & 9,159 & 0,04 & 0,019 \\
\hline B102 & 0,0007 & 0,373 & 1,234 & 0,12 & 0,228 & 3,947 & 0,452 & 0,098 & 0,48 & 0,56 & 0,63 & 7,156 & 0,02 & 0,025 \\
\hline B107 & 0,0008 & 0,393 & 0,115 & 0,017 & 0,036 & 0,552 & 0,489 & 0,136 & 0,28 & 0,66 & 0,18 & 32,22 & 0,02 & 0,034 \\
\hline B111 & 0,007 & 1,433 & 0,434 & 0,133 & 0,063 & 1,428 & 1,18 & 0,074 & 0,53 & 1,24 & 0,78 & 6,005 & 0,05 & 0,03 \\
\hline B112 & 0,0007 & 0,710 & 0,0003 & 0,053 & 0,036 & 0,711 & 17,64 & 9,494 & 6,58 & 0,95 & 0,06 & 114,3 & 0,06 & 0,002 \\
\hline B118 & 0,0003 & 0,018 & $6,3^{-5}$ & $9,4^{-5}$ & 0,01 & 0,324 & 0,503 & 0,003 & 1,62 & 0,06 & 0,01 & 0,149 & 0,04 & 0,102 \\
\hline B121 & 0,001 & 0,026 & 0,003 & 0,147 & 0,11 & 1,021 & 0,151 & 0,033 & 2,42 & 0,24 & 0,09 & 0,916 & 0,007 & 0,189 \\
\hline B147 & 0,0008 & 1,264 & 0,005 & 0,042 & 0,012 & 0,035 & 0,627 & 0,073 & 4,55 & 0,61 & 0,05 & 12,92 & 0,001 & 0,043 \\
\hline B161 & 0,008 & 5,849 & 0,029 & 0,086 & 0,082 & 0,407 & 0,301 & 0,139 & 11,09 & 2,21 & 0,19 & 7,745 & 0,12 & 0,058 \\
\hline B163 & $2,8^{-9}$ & 1,158 & 0,021 & 0,062 & 0,009 & 0,148 & 0,351 & 0,174 & 4,23 & 0,91 & 0,2 & 3,746 & 0,02 & 0,043 \\
\hline B164 & $6,1^{-10}$ & 0,882 & 0,016 & 0,02 & 0,0008 & 0,026 & 0,212 & 0,018 & 0,46 & 0,52 & 0,08 & 2,302 & 0,02 & 0,101 \\
\hline B169 & $3,4^{-8}$ & 0,926 & 0,013 & 0,081 & 0,003 & 0,248 & 0,133 & 0,054 & 1,73 & 0,58 & 0,16 & 2,447 & 0,08 & 0,099 \\
\hline B170 & $2,8^{-8}$ & 0,655 & 0,025 & 0,051 & 0,001 & 0,065 & 0,12 & 0,01 & 0,5 & 0,5 & 0,09 & 1,406 & 0,06 & 0,105 \\
\hline B193 & $1,2^{-7}$ & 1,666 & 0,162 & 0,154 & 0,002 & 0,126 & 0,278 & 0,011 & 0,74 & 0,8 & 0,19 & 0,543 & 0,6 & 0,055 \\
\hline 4 & $2,1^{-8}$ & 1,144 & 0,008 & 0,032 & 0,0007 & 0,044 & 0,075 & 0,002 & 0,51 & 0,51 & 0,06 & 2,425 & 0,09 & 0,078 \\
\hline 24 & $1,3^{-8}$ & 11,13 & 0,182 & 0,762 & 0,023 & 1,701 & 0,994 & 0,189 & 15,3 & 8,64 & 1,5 & 30,80 & 1,04 & 0,004 \\
\hline 25 & $2^{-8}$ & 0,002 & 0,041 & 0,018 & 0,002 & 1,000 & 2,573 & 0,951 & 2,75 & 0,18 & 0,03 & 18,49 & 0,01 & 0,002 \\
\hline 31 & 0,073 & 0,540 & 0,02 & 0,661 & 0,006 & 0,001 & 0,009 & 0,466 & 1,64 & 0,21 & 1,06 & 0,031 & 0,007 & 0,011 \\
\hline MB2 & 0,023 & 0,005 & 0,009 & 0,014 & 0,016 & 0,120 & 0,01 & 0,146 & 0,7 & 0,006 & 0,0008 & 0,004 & 0,23 & 0,24 \\
\hline MB6 & 0,109 & 0,002 & 0,008 & 0,0004 & 0,0004 & 0,039 & 0,147 & 0,012 & 2,92 & 0,009 & 0,001 & 0,193 & 0,005 & 0,032 \\
\hline MB9 & 0,001 & 0,005 & 0,0009 & 0,0002 & 0,0002 & 0,017 & 0,007 & 0,005 & 0,18 & 0,003 & 0,001 & 0,078 & 0,002 & 0,152 \\
\hline MB12 & 0,003 & 0,004 & 0,003 & 0,003 & $7,4^{-5}$ & 0,023 & 0,025 & 0,003 & 0,1 & 0,005 & 0,5 & 0,157 & 0,005 & 0,024 \\
\hline
\end{tabular}




\section{Anexo E - Valores de expressão dos 14 miRNA estudados para cada amostra de tumor pT2-3 de alto grau}

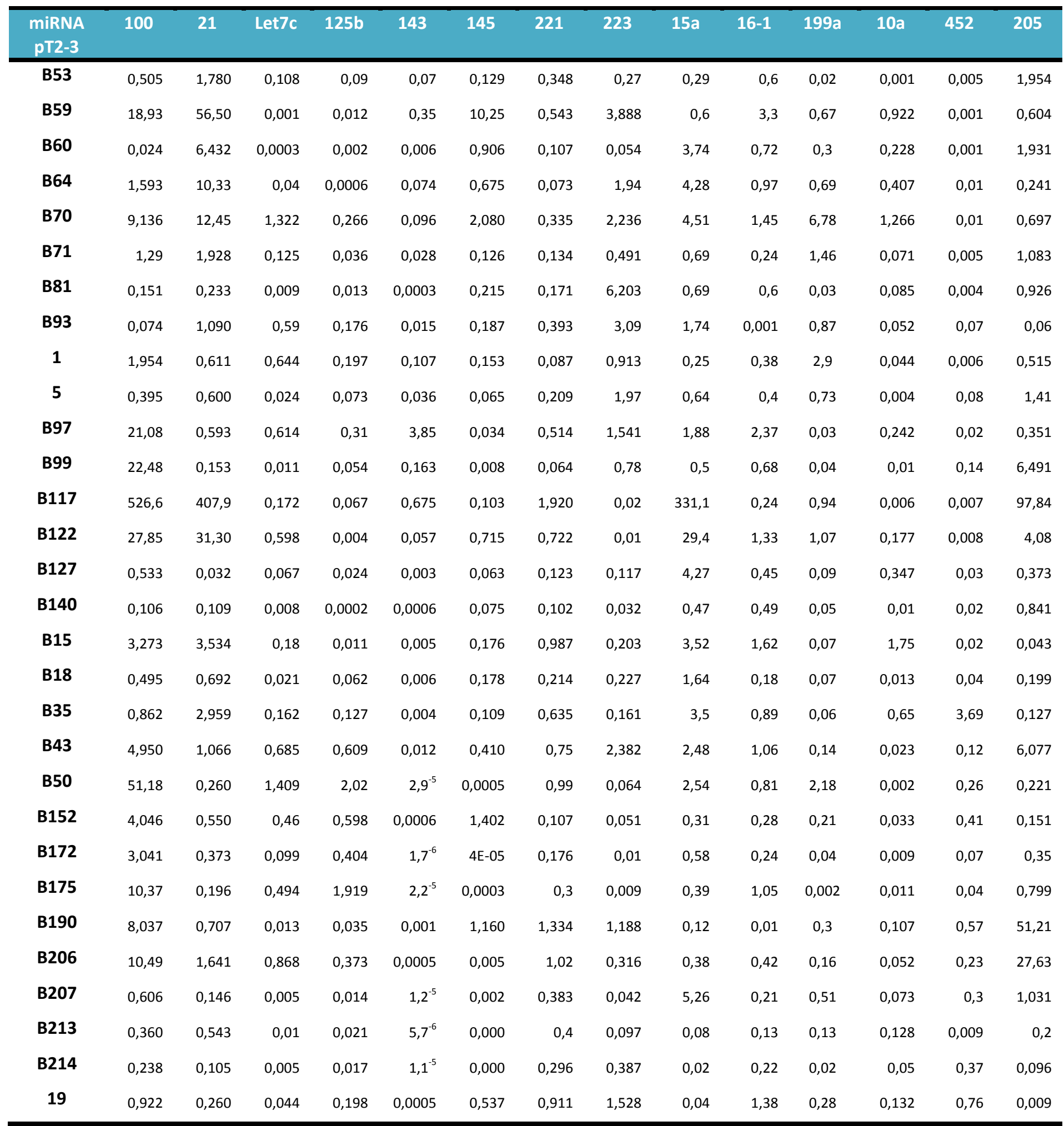


Anexo F - Tempo médio de sobrevida livre de recidiva (SLR) e câncer-específica (SCE) em meses para os 14 miRNA estudados

\begin{tabular}{|c|c|c|c|c|c|c|}
\hline \multirow{2}{*}{ miRNA } & \multicolumn{2}{|c|}{$\begin{array}{l}\text { SLR pTa } \\
(n=30)\end{array}$} & \multicolumn{2}{|c|}{$\begin{array}{c}\text { SLR pT2/pT3 } \\
(n=30)\end{array}$} & \multicolumn{2}{|c|}{$\begin{array}{c}\text { SCE pT2/pT3 } \\
(n=30)\end{array}$} \\
\hline & & p & & p & & p \\
\hline \multirow[t]{2}{*}{100} & $21,79(1)$ & 0,45 & $21,63(1)$ & 0,55 & $22,6(1)$ & 0,57 \\
\hline & $22,37(2)$ & & $21,67(2)$ & & $26,23(2)$ & \\
\hline \multirow[t]{2}{*}{$10 a$} & $22,54(1)$ & 0,83 & 26,13 (1) & 0,007 & $27,34(1)$ & 0,04 \\
\hline & $19,12(2)$ & & $13,05(2)$ & & $15,28(2)$ & \\
\hline \multirow[t]{2}{*}{21} & 24,58 (1) & 0,02 & $22,4(1)$ & 0,85 & $25,04(1)$ & 0,49 \\
\hline & $16,32(2)$ & & $13,5(2)$ & & $13,5(2)$ & \\
\hline \multirow[t]{2}{*}{205} & $23,82(1)$ & 0,24 & $21,92(1)$ & 0,63 & $21,2(1)$ & 0,08 \\
\hline & $19,06(2)$ & & $18(2)$ & & $30,4(2)$ & \\
\hline \multirow[t]{2}{*}{ Let7c } & 21,39 (1) & 0,43 & $21,9(1)$ & 0,96 & 21,39 (1) & 0,12 \\
\hline & $27,33(2)$ & & $23,25(2)$ & & $34(2)$ & \\
\hline \multirow[t]{2}{*}{$125 b$} & $23,78(1)$ & 0,24 & $21,5(1)$ & 0,9 & 21,35 (1) & 0,11 \\
\hline & $17,44(2)$ & & $23,16(2)$ & & $34(2)$ & \\
\hline \multirow[t]{2}{*}{143} & 21,39 (1) & 0,43 & $22,2(1)$ & 0,92 & 24,88 (1) & 0,73 \\
\hline & $27,33(2)$ & & $15(2)$ & & $15(2)$ & \\
\hline \multirow[t]{2}{*}{145} & $22,04(1)$ & 0,95 & $25,19(1)$ & 0,03 & $24,76(1)$ & 0,62 \\
\hline & $23,07(2)$ & & $15,57(2)$ & & $23,13(2)$ & \\
\hline \multirow[t]{2}{*}{221} & 22,86 (1) & 0,7 & $21,79(1)$ & 0,68 & $23,5(1)$ & 0,5 \\
\hline & $21,33(2)$ & & $20,73(2)$ & & $23,85(2)$ & \\
\hline \multirow[t]{2}{*}{223} & 22,86 (1) & 0,7 & 21,47 (1) & 0,61 & $24,5(1)$ & 0,93 \\
\hline & $21,33(2)$ & & $20,61(2)$ & & $22,2(2)$ & \\
\hline \multirow[t]{2}{*}{$15 a$} & 22,98 (1) & 0,66 & 22,4 (1) & 0,85 & $26,57(1)$ & 0,32 \\
\hline & $20,87(2)$ & & $13,5(2)$ & & $18,96(2)$ & \\
\hline \multirow[t]{2}{*}{$16-1$} & 23,55 (1) & 0,19 & $23,95(1)$ & 0,5 & 25,67 (1) & 0,81 \\
\hline & $17,2(2)$ & & $18,3(2)$ & & $21,99(2)$ & \\
\hline \multirow[t]{2}{*}{$199 a$} & 22,19 (1) & 0,97 & $22,78(1)$ & 0,69 & 22,87 (1) & 0,29 \\
\hline & $22,33(2)$ & & $18,86(2)$ & & $24,8(2)$ & \\
\hline \multirow[t]{2}{*}{452} & 23,95 (1) & 0,37 & 19,19 (1) & 0,11 & $23,77(1)$ & 0,72 \\
\hline & $20,92(2)$ & & $30,8(2)$ & & $27(2)$ & \\
\hline
\end{tabular}

1: casos abaixo da média de expressão; 2: casos acima da média de expressão 


\section{REFERÊNCIAS BIBLIOGRÁFICAS}


Agirre $X$, Jiménez-Velasco A, San José-Enériz E, Garate L, Bandrés E, Cordeu L, Aparicio O, Saez B, Navarro G, Vilas-Zornoza A, Pérez-Roger I, García-Foncillas J, Torres A, Heiniger A, Calasanz MJ, Fortes P, Román-Gómez J, Prósper F. Downregulation of hsa-miR-10a in chronic myeloid leukemia CD34+ cells increases USF2mediated cell growth. Mol Cancer Res. 2008;6(12):1830-40.

Ambros V. MicroRNA Pathways in Flies and Worms: growth, death, fat, stress and timing. Cell. 2003;113(6):673-76.

Babjuk M, Oosterlinck W, Sylvester R, Kaasinen E, Böhle A, Palou-Redorta J. EAU Guidelines on Non-Muscle-Carcinoma of the Bladder. Actas Urol Espn. 2009;33(4):361-71.

Bakkar AA, Wallerand H, Radvanyi F, Lahaye JB, Pissard S, Lecerf L, Kouyoumdjian JC, Abbou CC, Pairon JC, Jaurand MC, Thiery JP, Chopin DK, de Medina SGD. FGFR3 and TP53 Gene Mutations Define Two Distinct Pathways in Urothelial Cell Carcinoma of Bladder. Cancer Res. 2003;63(23):8108-12.

Bartel DP, Chen C. Micromanagers of gene expression: the potencially widespread influence of metazoan microRNAs. Nat Rev Genet. 2004;5:396-400.

Bartel DP. MicroRNAs: Genomics, Biogenesis, Mechanism, and Function. Cell. 2004;116(2):281-297.

Belakhlef S, Church C, Jani C, Lakhanpal S. Early Dynamic PET/CT and 18F-FDG Blood Flow Imaging in Bladder Cancer Detection: A Novel Approach. Clin Nucl Med. 2012;37(4):366-8.

Bessière D, Lacroix C, Campagne S, Ecochard V, Guillet V, Mourey L, Lopez F, Czaplicki J, Demange P, Milon A, Girard JP, Gervais V. Structure-function analysis of the THAP zinc finger of THAP1, a large C2CH DNA-binding module linked to Rb/E2F pathways. J Biol Chem. 2008;283(7):4352-63.

Blenkiron C, Miska E. MiRNAs in cancer: approaches, aetiology, diagnostics and therapy. Hum Mol Genet. 2007;16:106-13. 
Boffetta P, Silverman DT. A meta-analysis of bladder cancer and diesel exhaust exposure. Epidemiology. $2001 ; 12(1): 125-30$.

Borden LS, Clark PE, Hall MC. Bladder Cancer. Curr Opin Oncol. 2005;17(3):275-80.

Botteman MF, Pashos CL, Radaelli A, Laskin B, Hauser R. The health economics of bladder cancer: a comprehensive review of the published literature. Pharmacoeconomics. 2003;21:1315-30.

Bozhenok L, Wade PA, Varga-Weisz P. WSTF-ISWI chromatin remodeling complex targets heterochromatic replication foci. EMBO J. 2002;21(9):2231-41.

Brabletz S, Brabletz T. The ZEB/miR-200 feedback loop - a motor of cellular plasticity in development and cancer? EMBO Reports. 2010;11(9):670-77.

Brait M, Begum S, Carvalho AL, Dasgupta S, Vettore AL, Czerniak B, Caballero OL, Westra WH, Sidransky D, Hoque MO. Aberrant promoter methylation of multiple genes during pathogenesis of bladder cancer. Cancer Epidemiol Biomarkers Prev. 2008;17(10):2786-94.

Calin GA, Croce CM. MicroRNA signatures in human cancers. Nat Rev Cancer. 2006;6(11):857-66.

Calin GA, Dumitru CD, Shimizu M, Bichi R, Zupo S, Noch E, Aldler H, Rattan S, Keating M, Rai K, Rassenti L, Kipps T, Negrini M, Bullrich F, Croce CM. Frequent deletions and down-regulation of micro- RNA genes miR15 and miR16 at 13q14 in chronic lymphocytic leukemia. PNAS. 2002;99(24):15524-9.

Cantor KP, Lynch CF, Johnson D. Bladder cancer, parity, and age at first birth. Cancer Causes Control. 1992;3(1):57-62.

Cappellen D, Oliveira C, Ricol D, Medina SGD. Frequent activating mutations of FGFR3 in human bladder and cervix carcinomas. Nat Genet. 1999;23:18-20.

Carmell MA, Hannon GJ. RNase III enzymes and the initiation of gene silencing. Nat Struct Mol Biol. 2004;11(3):214-8. 
Catto JWF, Miah S, Owen HC, Bryant H, Myers K, Dudziec E, Larré S, Milo M, Rehman I, Rosario DJ, Di Martino E, Knowles MA, Meuth M, Harris AL, Hamdy FC. Distinct microRNA alterations characterize high and low grade bladder cancer. Cancer Res. 2009;69(21):8472-81.

Chen R, Alvero AB, Silasi DA, Kelly MG, Fest S, Visintin I, Leiser A, Schwartz PE, Rutherford T, Mor G. Regulation of IKKbeta by miR-199a affects NF-kappaB activity in ovarian cancer cells. Oncogene. 2008;27(34):4712-23.

Chen X, Ba Y, Ma L, Cai X, Yin Y, Wang K, Guo J, Zhang Y, Chen J, Guo X, Li Q, Li X, Wang J, Jiang X, Xiang $Y, X u$ C, Zheng $P$, Li R, Zhang $H$, Shang X, Gong T, Ning G, Wang J, Zen K, Zhang J, Zhang C. characterization of microRNAs in serum: a novel class of biomarkers for diagnosis of cancer and other diseases. Cell Res. 2008;18:997-1006.

Cheung HH, Davis AJ, Lee TL, Pang AL, Nagrani S, Rennert OM, Chan WY. Methylation of an intronic region regulates miR-199a in testicular tumor malignancy. Oncogene. 2011;30(31):3404-15

Chiyomaru T, Enokida H, Tatarano S, Kawahara K, Uchida Y, Nishiyama K, Fujimura L, Kikkawa N, Seki N, Nakagawa M. miR-145 and miR-133a function as tumour suppressors and directly regulate FSCN1 expression in bladder cancer. British J Cancer. 2010;102(5):883-891.

Cimmino A, Calin GA, Fabbri M, lorio MV, Ferracin M, Shimizu M, Wojcik SE, Aqeilan R, Zupo S, Dono M, Rassenti L, Alder H, Volinia S, Liu C, Kipps TJ, Negrini M, Croce CM. miR-15 and miR-16 induce apoptosis by targeting BCL2. PNAS. 2005;102(39):13944-49.

Cordon-Cardo C, Wartinger D, Petrylak D, Dalbagni G, Fair WR, Fuks Z, Reuter VE. Altered expression of the retinoblastoma gene product: prognostic indicator in bladder cancer. J Natl Cancer Inst. 1992;84(16):1251-6.

Dalmay T. MicroRNAs and cancer. J Intern Med. 2008;263(4):366-75. 
Der CJ, Krontiris TG, Cooper GM. Transforming genes of human bladder and lung carcinoma cell lines are homologous to the ras genes of Harvey and Kirsten sarcoma viruses. PNAS. 1982;79(11):3637-40.

Desai S, Lim SD, Jimenez RE, Chun T, Keane TE, McKenney JK, Zavala-Pompa A, Cohen C, Young RH, Amin MB. Relationship of cytokeratin 20 and CD44 protein expression with WHO/ISUP grade in pTa and pT1 papillary urothelial neoplasia. Mod Pathol. 2000;13(12):1315-23.

Dip N, Reis ST, Timoszczuk LS, Abe, DK, Dall'Oglio M, Srougi M, Leite KRM. Underexpression of miR-100 may be a new carcinogenic pathway for low-grade pTa bladder urothelial carcinomas. Mol Biomark Diagn. 2011;2(6):2-6.

Duan Z, Choy E, Harmon D, Liu X, Susa M, Mankin H, Hornicek F. MicroRNA-199a-3p is downregulated in human osteosarcoma and regulates cell proliferation and migration. Mol Cancer Ther. 2011;10(8):1337-45.

Eisner BH, Feldman AS. Nanoparticle imaging for genitourinary cancers. Cancer Biomarkers. 2009;5:75-9.

Ellinger J, El Kassem N, Heukamp LC, Matthews S, Cubukluoz F, Kahl P, Perabo FG, Müller SC, von Ruecker A, Bastian PJ. Hypermethylation of cell-free serum DNA indicates worse outcome in patients with bladder cancer. J Urol. 2008;179(1):34652.

Enokida H, Nakagawa M. Epigenetics in bladder cancer. Int J Clin Oncol. 2008;13(4):298-307.

Esrig D, Elmajian D, Groshen S, Freeman JA, Stein JP, Chen SC, Nichols PW, Skinner DG, Jones PA, Cote RJ. Accumulation of nuclear p53 and tumor progression in bladder cancer. N Engl J Med. 1994;331(19):1259-64. 
Foley NH, Bray I, Watters KM, Das S, Bryan K, Bernas T, Prehn JH, Stallings RL. MicroRNAs $10 \mathrm{a}$ and $10 \mathrm{~b}$ are potent inducers of neuroblastoma cell differentiation through targeting of nuclear receptor corepressor 2. Cell Death Differ. 2011;18(7):1089-98.

Fornari F, Milazzo M, Chieco P, Negrini M, Calin GA, Grazi GL, Pollutri D, Croce CM, Bolondi L, Gramantieri L. MiR-199a-3p regulates mTOR and c-Met to influence the doxorubicin sensitivity of human hepatocarcinoma cells. Cancer Res. 2010;70(12):5184-93.

Friedrich MG, Chandrasoma S, Siegmund KD, Weisenberger DJ, Cheng JC, Toma MI, Huland $H$, Jones PA, Liang $G$. Prognostic relevance of methylation markers in patients with non-muscle invasive bladder carcinoma. Eur $J$ Cancer. 2005;41(17):2769-78.

Fritsche HM, Burger M, Svatek RS, Jeldres C, Karakiewicz PI, Novara G, Skinner E, Denzinger S, Fradet Y, Isbarn H, Bastian PJ, Volkmer BG, Montorsi F, Kassouf W, Tilki D, Otto W, Capitanio U, Izawa JI, Ficarra V, Lerner S, Sagalowsky Al, Schoenberg M, Kamat A, Dinney CP, Lotan Y, Shariat SF. Characteristics and outcomes of patients with clinical T1 grade 3 urothelial carcinoma treated with radical cystectomy: results from an international cohort. Eur Urol. 2010;57(2):300-9.

Gaertner RR, Thériault GP. Risk of bladder cancer in foundry workers: a metaanalysis. Occup Environ Med. 2002;59(10):655-63.

Gallucci M, Guadagni F, Marzano R, Leonardo C, Merola R, Sentinelli S, Ruggeri EM, Cantiani R, Sperduti I, Lopez Fde L, Cianciulli AM. Status of the p53, p16, RB1, and HER-2 genes and chromosomes 3, 7, 9, and 17 in advanced bladder cancer: correlation with adjacent mucosa and pathological parameters. J Clin Pathol. 2005;58(4):367-71. 
Gandellini P, Folini M, Longoni N, Pennati M, Binda M, Colecchia M, Salvioni R, Supino R, Moretti R, Limonta P, Valdagni R, Daidone MG, Zaffaroni N. miR-205 Exerts tumor-suppressive functions in human prostate through down-regulation of protein kinase Cepsilon. Cancer Res. 2009;69(6):2287-95.

Garcia del Muro X, Condom E, Vigués F, Castellsagué X, Figueras A, Muñoz J, Solá J, Soler T, Capellà G, Germà JR. p53 and p21 Expression levels predict organ preservation and survival in invasive bladder carcinoma treated with a combinedmodality approach. Cancer. 2004;100(9):1859-67.

Garzon R, Pichiorri F, Palumbo T, Iuliano R, Cimmino A, Aqeilan R, Volinia S, Bhatt D, Alder H, Marcucci G, Calin GA, Liu C, Bloomfield CD, Andreeff M, Croce CM. MicroRNA fingerprints during human megakaryocytopoiesis. PNAS. 2006;106(13):5078-83.

Gore JL, Lai J, Setodji CM, Litwin MS, Saigal CS; Urologic Diseases in America Project. Mortality increases when radical cystectomy is delayed more than 12 weeks: results from a Surveillance, Epidemiology, and End Results-Medicare analysis. Cancer. 2009;115(5):988-96.

Gottardo F, Liu CG, Ferracin M, Calin GA, Fassan M, Bassi P, Sevignani C, Byrne D, Negrini M, Pagano F, Gomella LG, Croce CM, Baffa R. Micro-RNA profiling in kidney and bladder cancers. Urol Oncol. 2007;25(5):387-92.

Gregory RI, Yan K, Amuthan G, Chendrimada TP, Doratotaj B, Cooch N, Shiekhattar R. The Microprocessor complex mediates the genesis of microRNAs. Nature. 2004;432:235-240.

Gregory PA, Bert AG, Paterson EL, Barry SC, Tsykin A, Farshid G, Vadas MA, KhewGoodall Y, Goodall GJ. The miR-200 family and miR-205 regulate epithelial to mesenchymal transition by targeting ZEB1 and SIP1. Nat Cell Biol. 2008;10(5):593601. 
Guan Y, Yao H, Zheng Z, Qiu G, Sun K. MiR-125b targets BCL3 and suppresses ovarian cancer proliferation. Int J Cancer. 2011;128(10):2274-83.

Hainaut P, Hollstein M. p53 and human cancer: the first ten thousand mutations. Adv Cancer Res. 2000;77:81-137.

Han J, Lee Y, Yeom KH, Kim YK, Jin H, Kim VN. The Drosha-DGCR8 complex in primary microRNA processing. Genes Dev. 2004;18(24):3016-27.

Heney NM. Natural history of superficial bladder cancer. Prognostic features and long-term disease course. Urol Clin North Am. 1992;19(3):429-33.

Henson BJ, Bhattacharjee S, O'Dee DM, Feingold E, Gollin SM. Decreased expression of miR-125b and miR-100 in oral cancer cells contributes to malignancy. Genes Chromosomes Cancer. 2009;48(7):569-82.

Herr H, Lee C, Chang S, Lerner S. Standardization of radical cystectomy and pelvic lymph node dissection for bladder cancer: a collaborative group report. J Urol. 2004;171(5):1823-8.

Huang L, Luo J, Cai Q, Pan Q, Zeng H, Guo Z, Dong W, Huang J, Lin T. MicroRNA-125b suppresses the development of bladder cancer by targeting E2F3. Int J Cancer. 2011;128(8):1758-69.

Huang H, Xie C, Sun X, Ritchie RP, Zhang J, Chen YE. miR-10a contributes to retinoid acid-induced smooth muscle cell differentiation. J Biol Chem. 2010;285(13):9383-9.

Ichimi T, Enokida H, Okuno Y, Kunimoto R, Chiyomaru T, Kawamoto K, Kawahara K, Toki K, Kawakami K, Nishiyama K, Tsujimoto G, Nakagawa M, Seki N. Identification of novel microRNA targets based on microRNA signatures in bladder cancer. Int $J$ Cancer. 2009;125:345-52.

INCA (Instituto Nacional do Câncer) [on-line]. Ministério da Saúde, Brasil; 2011. Disponível em: http://www.inca.gov.br. 
Izzoti A, Calin GA, Arrigo P, Steele VE, Croce CM, De Flora S. Downregulation of microRNA expression in the lungs of rats exposed to cigarette smoke. Faseb J. 2009; 23(3);806-12.

Jebar AH, Hurst CD, Tomlinson DC, Johnston C, Taylor CF, Knowles MA. FGFR3 and Ras gene mutations are mutually exclusive genetic events in urothelial cell carcinoma. Oncogene. 2005;24:5218-25.

Jemal A, Bray F, Center MM, Ferlay Ward E, Forman D. Global Cancer Statistics, 2011. Cancer J Clin. 2011;61(2):69-90.

Johnson SM, Grosshans H, Shingara J, Byrom M, Jarvis R, Cheng A, Labourier E, Reinert KL, Brown D, Slack FJ. RAS is Regulated by the let-7 MicroRNA Family. Cell. 2005;120(5):635-47.

Kim YT, Park SJ, Lee SH, Kang HJ, Hahn S, Kang CH, Sung SW, Kim JH. Prognostic implication of aberrant promoter hypermethylation of CpG islands in adenocarcinoma of the lung. J Thorac Cardiovasc Surg. 2005;130(5):1378.

Kim VN. MicroRNA Biogenesis: Coordinated Cropping and Dicing. Nature. 2005;6:376-385

Kirkali Z, Chan T, Manoharan M, Algaba F, Busch C, Cheng L, Kiemeney L, Kriegmair M, Montironi R, Murphy WM, Sesterhenn IA, Tachibana M, Weider J. Bladder Cancer: Epidemiology, Staging and Grading, and Diagnosis. Urology. 2005;66(6):434.

Klussmann JH, Li Z, Böhmer K, Maroz A, Koch ML, Emmrich S, Godinho FJ, Orkin SH, Reinhardt D. miR-125b-2 is a potential oncomiR on human chromosome 21 in megakaryoblastic leukemia. Gen Dev. 2010;24(5):478-90.

Knowles MA. Molecular pathogenesis of bladder cancer. Int J Clin Oncol. 2008;13(4):287-97. 
Laios A, O'Toole S, Flavin R, Martin C, Kelly L, Ring M, Finn SP, Barrett C, Loda M, Gleeson N, D’Arcy T, McGuinness E, Sheils O, Sheppard B, O'Leary J. Potential role of mir-9 and mir-223 in recurrent ovarian cancer. Mol Cancer. 2008;7:35.

Le MTN, Teh C, Shyh-Chang N, Xie H, Zhou B, Korzh V, Lodish HE, Lim B. MicroRNA$125 \mathrm{~b}$ is a novel negative regulator of p53. Gene Dev. 2009;23:1-15.

Lebanony D, Benjamin H, Gilad S, Ezagouri M, Dov A, Ashkenazi K, Gefen N, Izraeli S, Rechavi G, Pass H, Nonaka D, Li J, Spector Y, Rosenfeld N, Chajut A, Cohen D, Aharonov R, Mansukhani M. Diagnostic assay based on hsa-miR-205 expression distinguishes squamous from nonsquamous non-small-cell lung carcinoma. J Clin Oncol. 2009;27(12):2030-37.

Lee RC, Feinbaum RL, Ambros V. The C. elegans Heterochronic Gene lin-4 Encodes Small RNAs with Antisense Complementarity to lin-14. Cell. 1993;75:843-854.

Lee Y, Ahn C, Han J, Chol H, Kim J, Yim J, Lee J, Provost P, Radmark O, Kim S, Kim VN. The nuclear Rnase III Drosha initiates microRNA processing. Nature. 2003;425:415418.

Lee YS, Nakahara K, Pham JW, Kim K, He Z, Sontheimer EJ, Carthew RW. Disctinct Roles for Drosophila Dicer-1 and Dicer-2 in the siRNA/miRNA Silencing Pathways. Cell. 2004;117:69-81.

Leite KRM, Sousa-Canavez JM, Reis ST, Tomiyama A, Camara-Lopes LH, Sañudo A, Antunes AA, Srougi M. Change in expression of miR-let7c, miR-100, and miR-218 from high grade localized prostate cancer to metastasis. Urol Oncol. 2009;29(3):265269.

Lewis BP, Burge CB, Bartel DP. Conserved Seed Pairing, Often Flanked by Adenosines, Indicates that Thousands of Human Genes are MicroRNA Targets. Cell. 2005;120(1):15-20. 
Liang L, Wong C, Ying Q, Fan DY, Huang S, Ding J, Yao J, Yan M, Li J, Yao M, Ng IO, He X. MicroRNA-125b Suppressed Human Liver Cancer Cell Proliferation and Metastasis by Directly Targeting Oncogene LIN28B. Hepatology. 2010;52(5):1731-40.

Lin T, Dong W, Huang J, Pan Q, Fan X, Zhang C, Huang L. MicroRNA-143 as a Tumor Suppressor for Bladder Cancer. J Urol. 2009;181(3):1372-80.

Lodygin D, Tarasov V, Epanchintsev A, Berking C, Knyazeva T, Körner $H$, Knyazev $P$, Diebold J, Hermeking $\mathrm{H}$. Inactivation of miR-34a by aberrant $\mathrm{CpG}$ methylation in multiple types of cancer. Cell Cycle. 2008;7(16):2591-600.

Lu Q, Lu C, Zhou G, Zhang WZ, Xiao H, Wang X. MicroRNA-221 silencing predisposed human bladder cancer cells to undergo apoptosis induced by TRAIL. Urol Oncol. 2010;28:635-41.

Ma L, Teruya-Feldstein J, Weinberg RA. Tumour invasion and metastasis initiated by microRNA-10b in breast cancer. Nature. 2007;449(7163):682-88.

Markowitz SB, Levin K. Continued Epidemic of Bladder Cancer in Workers Exposed to Ortho-Toluidine in a Chemical Factory. J Occup Environ Med 2004;46(2):154-60.

Marsit CJ, Houseman EA, Schned AR, Karagas MR, Kelsey KT. Promoter hypermethylation is associated with current smoking, age, gender and survival in bladder cancer. Carcinogenesis. 2007;28(8):1745-51.

Martinez-Torrecuadrada J, Cifuentes G, López-Serra P, Saenz P, Martinez A, Casal JI. Targeting the Extracellular Domain of Fibroblast Growth Factor Receptor 3 with Human Single-Chain Fv Antibodies Inhibits Bladder Carcinoma Cell Line Proliferation. Clin Cancer Res. 2005;11(17):6280-90.

Mascaux C, Laes JF, Anthoine G, Haller A, Ninane V, Burny A, Sculier JP. Evolution of microRNA expression during human bronchial squamous carcinogenesis. Eur Respir J. 2009;33(2):352-9. 
McConkey DJ, Lee S, Choi W, Tran M, Majewski T, Lee S, Siefker-Radtke A, Dinney C, Czerniak B. Molecular genetics of bladder cancer: Emerging mechanisms of tumor initiation and progression. Urol Oncol. 2010;28(4):429-40.

Meister G, Landthaler M, Patkaniowska A, Dorsett Y, Tuschl T. Sequence-specific inhibition of microRNA- and siRNA-induced RNA silencing. RNA. 2004;10:544-550.

Meng F, Henson R, Wehbe-Janek H, Ghoshal K, Jacob ST, Patel T. MicroRNA-21 Regulates Expression of the PTEN Tumor Suppressor Gene in Human Hepatocellular Cancer. Gastroenterology. 2007;133:647-58.

Miyamoto H, Epstein JI. Transurethral resection specimens of the bladder: outcome of invasive urothelial cancer involving muscle bundles indeterminate between muscularis mucosae and muscularis propria. Urology. 2010;76(3):600-2.

Mo L, Zheng X, Huang HY, Shapiro E, Lepor H, Cordon-Cardo C, Sun TT, Wu XR. Hyperactivation of Ha-ras oncogene, but not Ink4a/Arf deficiency, triggers bladder tumorigenesis. J Clin Invest. 2007;117(2):314-25.

Montie JE, Clark PE, Eisenberger MA, El-Galley R, Greenberg RE, Herr HW, Hudes GR, Kuban DA, Kuzel TM, Lange PH, Lele SM, Michalski J, Patterson A, Pohar KS, Richie JP, Sexton WJ, Shipley WU, Small EJ, Trump DL, Walther PJ, Wilson TG. Bladder cancer. J Nat/ Compr Canc Netw. 2009;7(1):8-39.

Mungan NA, Aben KK, Schoenberg MP, Visser O, Coebergh JW, Witjes JA, Kiemeney LA. Gender differences in stage-adjusted bladder cancer survival. Urology. 2000;55(6):876-80.

Nagaraja AK, Creighton CJ, Yu Z, Zhu H, Gunaratne PH, Reid JG, Olokpa E, Itamochi H, Ueno NT, Hawkins SM, Anderson ML, Matzuk MM. A link between miR-100 and FRAP1/mTOR in clear cell ovarian cancer. Mol Endocrinol. 2010;24(2):447-63. 
Neely LA, Rieger-Christ KM, Neto BS, Eroshkin A, Garver J, Patel S, Phung NA, McLaughlin S, Libertino JA, Whitney D, Summerhayes IC. A microRNA expression ratio defining the invasive phenotype in bladder tumors. Urol Oncol. 2008;28(1):3948.

Ornitz DM, Xu J, Colvin JS, McEwen DG, MacArthur CA, Coulier F, Gao G, Goldfarb M. Receptor Specificity of the Fibroblast Growth Factor Family. Journal Biol Chem. 1996;271(25):15292-97.

Orom UA, Nielsen FC, Lund AH. microRNA-10a binds the 5'UTR of ribosomal protein mRNA and enhances their translation. Mol Cell. 2008;30(4):460-71.

Ozen $\mathrm{M}$, Creighton $\mathrm{CJ}$, Ozdemir $\mathrm{M}$, Ittmann $\mathrm{M}$. Widespread deregulation of microRNA expression in human prostate cancer. Oncogene. 2008;27(12):1788-93.

Paik ML, Scolieri MJ, Brown SL, Spirnak JP, Resnick MI. Limitations of Computerized Tomography in Staging Invasive Bladder Cancer before Radical Cystectomy. J Urol. 2000;163:1693-96.

Pandith AA, Shah ZA, Siddiqi MA. Oncogenic role of fibroblastic growth factor receptor 3 in tumorigenesis of urinary bladder cancer. Urol Oncol. 2010 (Epub ahead of print).

Pillai RS, Bhattacharyya SN, Artus CG, Zoller T, Cougot N, Basyuk E, Bertrand E, Filipowicz W. Inhibition of translational initiation by Let-7 MicroRNA in human cells. Science. 2005;309(5740):1573-6.

Pillai, RS. MicroRNA function: Multiple mechanisms for a tiny RNA? RNA. 2005;11:1753-1761.

Pineau P, Volinia S, McJunkin K, Marchio A, Battiston C, Terris B, Mazzaferro V, Lowe SW, Croce CM, Dejean A. miR-221 overexpression contributes to liver tumorigenesis. PNAS. 2010;107(1):264-9. 
Proctor I, Stoeber K, Williams GH. Biomarkers in bladder cancer. Histopathology. 2010;57:1-13.

Przybojewska B, Jagiello A, Jalmuzna P. H-RAS, K-RAS, and N-RAS gene activation in human bladder cancers. Cancer Genet Cytogenet. 2000;121(1):73-7.

PubMed - US National Library of Medicine - National Institutes of Health; 2012 Available from: http://www.ncbi.nlm.nih.gov/sites/entrez.

Puzio-Kuter AM, Castillo-Martin M, Kinkade CW, Wang X, Shen TH, Matos T, Shen MM, Cordon-Cardo C, Abate-Shen C. Inactivation of p53 and Pten promotes invasive bladder cancer. Gene Dev. 2009;23:675-80.

Rajabi H, Jin C, Ahmad R, McClary AC, Joshi MD, Kufe D. Mucin I Oncoprotein Expression Is Suppressed by the miR-125b Oncomir. Genes and Cancer. 2010;1(1):62-68.

Reinhart BJ, Slack FJ, Basson M, Pasquinelli AE, Bettinger JC, Rougvle AE, Horvitz HR, Ruvkun G. The 21-nucleotide let-7 RNA regulates developmental timing in Caenorhabditis elegans. Nature. 2000;403:901-906.

Rieger-Christ KM, Mourtzinos A, Lee PJ, Zagha RM, Cain J, Silverman M, Libertino JA, Summerhayes IC. Identification of fibroblast growth factor receptor 3 mutations in urine sediment DNA samples complements cytology in bladder tumor detection. Cancer. 2003;98(4):737-44.

Sachdeva M, Mo Y. MiR-145 Suppresses Cell Invasion and Metastasis by Directly Targeting Mucin 1. Cancer Res. 2010;70(1):378-387.

Sachdeva M, Mo Y. miR-145-mediated suppression of cell growth, invasion and metastasis. Am J Transl Res. 2010;2(2):170-180.

Sachdeva M, Zhu S, Wu F, Wu H, Walia V, Kumar S, Elble R, Watabe K, Mo YY. p53 reppresses c-Myc through induction of the tumor suppressor miR-145. PNAS. 2009;106(9): 3207-12. 
Sage C, Nagel R, Egan DA, Schrier M, Mesman E, Mangiola A, Anile C, Maira G, Mercatelli N, Ciafrè SA, Farace MG, Agami R. Regulation of the p27kip1 tumor suppressor by miR-221 and miR-222 promotes cancer cell proliferation. EMBO J. 2007;26:3699-3708.

Sarkis AS, Dalbagni G, Cordon-Cardo C, Melamed J, Zhang ZF, Sheinfeld J, Fair WR, Herr HW, Reuter VE. Association of P53 nuclear overexpression and tumor progression in carcinoma in situ of the bladder. J Urol. 1994;152(2 Pt 1):388-92.

Shi X, Xue L, Ma A, Tepper CG, Kung HJ, White Wd. miR-12b Promotes Growth of Prostate Cancer Xenograft Tumor through Targeting Pro-Apoptotic Genes. The Prostate. 2011;71:538-49.

Si ML, Zhu S, Wu H, Lu Z, Wu F, Mo YY. miR-21-mediated tumor growth. Oncogene. 2006;1-5.

Spizzo R, Nicoloso MS, Lupini L, Lu Y, Fogarty J, Rossi S, Zagatti B, Fabbri M, Veronese A, Liu X, Davuluri R, Croce CM, Mills G, Negrini M, Calin GA. miR-145 participates with TP53 in death-promoting regulatory loop and targets estrogen receptor- $\alpha$ in human breast cancer cells. Cell Death and Differentiation. 2010; 17(2): 246-54.

Stamatopoulos B, Meuleman N, Haibe-Kains B, Saussoy P, Neste EVD, Michaux L, Heimann P, Martiat P, Bron D, Lagneaux L. microRNA-29c and microRNA-223 downregulation has in vivo significance in chronic lymphocytic leukemia and improves disease risk stratification. Blood. 2009;113(21):5237-45.

Suzuki HI, Yamagata K, Sugimoto K, Iwamoto T, Kato S, Miyazono K. Modulation of microRNA processing by p53. Nature. 2009;460:529-34.

The miRNA body map; 2011. Available from: http://www.mirnabodymap.org/mirna_card.php.

Thériault G, Tremblay C, Cordier S, Gingras S. Bladder cancer in the aluminium industry. Lancet. 1984;1(8383):947-50. 
Thompson LM, Plummer S, Schalling M, Altherr MR, Gusella JF, Housman DE, Wasmuth JJ. A gene encoding a fibroblast growth factor receptor isolated from the Huntington disease gene region of human chromosome 4. Genomics. 1991;11(4):1133-42.

Tomlinson DC, Baldo O, Harnden P, Knowles MA. FGFR3 protein expression and its relationship to mutation status and prognostic variables in bladder cancer. J Pathol. 2007;213(1):91-98.

Tritchler S, Mosler C, Straub J, Buchner A, Karl A, Graser A, Stief C, Tilki D. Staging of muscle-invasive bladder cancer: can computerized tomography help us to decide on local treatment? World J Urol. 2011 (Epub ahead of print).

Tsuruta H, Kishimoto H, Sasaki T, Horie Y, Natsui M, Shibata Y, Hamada K, Yajima N, Kawahara K, Sasaki M, Tsuchiya N, Enomoto K, Mak TW, Nakano T, Habuchi T, Suzuki A. Hyperplasia and carcinomas in Pten-deficient mice and reduced PTEN protein in human bladder cancer patients. Cancer Res. 2006;66(17):8389-96.

van der Weyden L, Adams DJ. The Ras-association domain family (RASSF) members and their role in human tumourigenesis. Biochim Biophys Acta. 2007;1776(1):58

van Rhijn et al., 2001 van Rhijn BW, Lurkin I, Radvanyi F, Kirkels WJ, van der Kwast TH, Zwarthoff EC. The Fibroblast Growth Factor Receptor 3 (FGFR3) Mutation Is a Strong Indicator of Superficial Bladder Cancer with Low Recurrence Rate. Cancer Res. 2001;61:1265-68.

van Rhijn BWG, van der Kwast TH, Vis AN, Kirkels WJ, Boevé ER, Jöbsis AC, Zwarthoff EC. FGFR3 and P53 Characterize Alternative Genetic Pathways in the Pathogenesis of Urothelial Cell Carcinoma. Cancer Res. 2004;64(6):1911-14. 
Veerla S, Lindgren D, Kvist A, Frigyesi A, Staaf J, Persson H, Liedberg F, Chebil G, Gudjonsson S, Borg A, Månsson W, Rovira C, Höglund M. MiRNA expression in urothelial carcinomas: important roles of miR-10a, miR-222, miR-125b, miR-7 and miR-452 for tumor stage and metastasis, and frequent homozygous losses of miR31. Int J Cancer. 2009;124(9):2236-42.

Weiss FU, Marques IJ, Woltering JM, Vlecken DH, Aghdassi A, Partecke LI, Heidecke $C D$, Lerch MM, Bagowski CP. Retinoic acid receptor antagonists inhibit miR-10a expression and block metastatic behavior of pancreatic cancer. Gastroenterology. 2009;137(6):2136-45.e1-7.

Wiklund ED, Bramsen JB, Hulf T, Dyrskjøt L, Ramanathan R, Hansen TB, Villadsen SB, Gao S, Ostenfeld MS, Borre M, Peter ME, Ørntoft TF, Kjems J, Clark SJ. Coordinated epigenetic repression of the miR-200 family and miR-205 in invasive bladder cancer. Int J Cancer. 2011;128(6):1327-34.

Wong QW, Lung RW, Law PT, Lai PB, Chan KY, To KT, Wong N. MicroRNA-223 Is Commonly Repressed in Hepatocellular Carcinoma and Potentiates Expression of Stathmin1. Gastroenterology. 2008;135:257-69.

Wu X. Urothelial Tumorigenesis: A Tale of Divergent Pathways. Nat Rev Cancer 2005;5(9):713-25.

Wu H, Zhu S, Mo Y. Suppression of cell growth and invasion by miR-205 in breast cancer. Cell Res. 2009;19:439-48.

Wu XR. Biology of urothelial tumorigenesis: insights from genetically engineered mice. Cancer Metastasis Rev. 2009;28(3-4):281-90.

Yates DR, Rehman I, Abbod MF, Meuth M, Cross SS, Linkens DA, Hamdy FC, Catto JW. Promoter hypermethylation identifies progression risk in bladder cancer. Clin Cancer Res. 2007;13(7):2046-53.

Yi R, Qin Y, Macara IG, Cullen BR. Exportin-5 mediates the nuclear export of premicroRNAs and short hairpin RNAs. Genes Dev. 2003;17:3011-3016. 
Zhou Y, Santoro R, Grummt I. The chromatin remodeling complex NoRC targets HDAC1 to the ribosomal gene promoter and represses RNA polymerase I transcription. EMBO J. 2002;21(17):4632-40. 
APÊNDICES 


\section{Artigos Científicos Publicados}

1. Journal of Urology; [Ahead of print] November, 2012.

Stage, Grade and Behavior of Bladder Urothelial Carcinomas Defined by Micro RNA Expression Profile

2. Journal of Molecular Biomarkers and Diagnosis 2011;2(6):1-3.

Under-expression of miR-100 may be a new carcinogenic pathway for lowgrade pTa bladder urothelial carcinomas

\section{Artigos Científicos Submetidos}

1. International Brazilian Journal of Urology

Expression Profile of Micro RNA 145 in Urothelial Bladder Cancer

\section{Congressos}

1. XXVIII Congresso Brasileiro de Patologia

Apresentação Oral: Característica de Expressão de Micro RNA 145 no Câncer Urotelial de Bexiga

2. XXXIII Congresso Brasileiro de Urologia

Apresentação Oral: O Papel do Micro RNA 100 no Carcinoma Urotelial de Bexiga de Baixo Grau pTa

3. AUA 2012 Annual Meeting

Micro RNA Profile of Superficial and Invasive Bladder Urothelial Carcinomas Related to Disease-free and Cancer-specific Survival

\section{Prêmio}

1. XXVIII Congresso Brasileiro de Patologia

Apresentação Oral classificada entre as 10 melhores

Ética

1. Aprovação no Comitê de Ética sob número 0176/10 
STAGE, GRADE AND BEHAVIOR OF BLADDER UROTHELIAL CARCINOMAS DEFINED BY THE MICRO RNA EXPRESSION PROFILE

Nelson Dip ${ }^{1}$, Sabrina T. Reis ${ }^{1}$, Luciana S. Timoszczuk ${ }^{1}$, Nayara I. Viana ${ }^{1}$, Camila B. Piantino ${ }^{1}$, Denis R. Morais ${ }^{1}$, Caio M. Moura ${ }^{1}$, Daniel K. Abe ${ }^{1,2}$, Iran A. Silva ${ }^{1}$, Miguel Srougi ${ }^{1}$, Marcos F. Dall'Oglio ${ }^{2}$, Katia R. M. Leite ${ }^{1}$

1. Laboratory of Medical Investigation, Urology Department - LIM55, University of Sao Paulo Medical School, Sao Paulo, Brazil

2. Uro-Oncology Group, Urology Department, Sao Paulo Cancer Institute (ICESP), Sao Paulo, Brazil

Corresponding author:

Nelson Gaspar Dip Júnior

Av. Dr. Arnaldo 455, room 2145

01246-903, Sao Paulo, Brazil

Phone/Fax 5511 3061-7183

nelson.dip@hotmail.com

Funded by FAPESP 10/50824-1

Key words: bladder cancer; urothelial carcinoma; miRNA; biomarkers; diagnosis. 


\section{ABSTRACT}

Purpose: To identify miRNA expression profiles in Urothelial Carcinomas (UC) that are associated with the grade, stage and recurrence-free (DFS) and disease-specific survival (DSS).

Methods: The expression of 14 miRNAs was evaluated by qRT-PCR in surgical specimens from 30 patients with low-grade, non-invasive ( $\mathrm{pTa}$ ) and 30 patients with high-grade invasive (pT2-3) UC. The controls were normal bladder tissue from five patients underwent surgical treatment for BPH. Endogenous controls were RNU-43 and RNU-48. The miRNA profiles were compared, and Kaplan-Meyer curves were contracted to analyze DFS and DSS survivals.

Results: In low-grade pTa, miR-100 was underexpressed in $100 \%$ of the specimens $(p<0.001)$, and miR-10a was overexpressed in 73.3\% ( $p<0.001)$. miR-21 and miR-205 were both overexpressed in high-grade $p T 2-3$ ( $p=0.02$ and $p<0.001$, respectively). The other miRNAs were present at levels similar to those of normal bladder tissue or were underexpressed in both groups of tumors. miR-21 overexpression $(>1.08)$ was related to shorter DFS in patients with low-grade pTa UC, and higher levels of miR-10a (>2.30) were associated with shorter DFS and DSS in patients with highgrade $\mathrm{pT} 2-3 \mathrm{UC}$.

Conclusions: Four miRNA are differentially expressed in both UC groups. miR-100 and miR-10a show under- and overexpression, respectively, in low-grade pTa tumors. miR-21 and miR-205 are overexpressed in pT2-3. In addition, the overexpression of miR-10a and miR-21 are both associated with shorter diseasefree and disease-specific survival. We suggest that miRNAs could be incorporated into UC molecular pathway. These miRNAs could also serve as new diagnostic or prognostic markers and as new target drugs. 


\section{INTRODUCTION}

Bladder cancer $(B C)$ is the second most common malignancy of the urinary tract, with 386,000 cases and 150,000 deaths estimated for $2011^{1}$. Ninety percent of BCs are urothelial carcinomas (UCs), most of which are papillary low-grade, nonmuscle-invasive tumors that recur frequently but rarely progress to muscle invasion 2. However, 10 to $20 \%$ are high-grade, muscle-invasive tumors at diagnosis, and these tumors display aggressive clinical behavior ${ }^{3}$.

There are two different molecular pathways that characterize the two types of tumors, and some authors believe that these profiles should be used to determine the best management course for patients ${ }^{2,4}$.

The most common genetic alteration of low-grade pTa UC is an activating mutation in the fibroblast growth factor receptor 3 (FGFR3) gene ${ }^{5}$, whereas mutations in the $P 53$, retinoblastoma (RB1) and PTEN genes characterize the highgrade $\mathrm{pT} 2-3 \cup \mathrm{C}^{5,6}$.

The FGFR3 gene belongs to a growth factor receptor family related to the tyrosine kinase signaling pathway, which plays an important role in embryogenesis, development, angiogenesis, wound healing, tissue homeostasis, tumorigenesis, the regulation of cellular proliferation, migration and apoptosis ${ }^{5}$. Mutations are the primary phenomenon related to FGFR3 dysfunction, and these mutations often allow FGFR3 to act in a ligand-independent manner ${ }^{5}$. P53, RB1 and PTEN are traditional tumor suppressor genes in which mutations and loss of function are related to the loss of proliferation control, apoptosis and genetic instability, which induce the development of high-grade pT2-3 UC ${ }^{6}$. Epigenetics phenomena such as DNA methylation and histone acetylation can be influenced by metabolic process and carcinogens and have been shown to be related to tumorigenesis by altering the levels of gene expression without changing the DNA.

MicroRNA (miRNA) is a new class of small RNAs that post-transcriptionally control the expression of hundreds of genes, often by promoting the degradation of recently transcribed messenger RNA (mRNA). This process depends on the complementarity between the miRNA and the $3^{\prime}$ untranslated region of the mRNA. miRNAs are involved in many physiological and pathological processes ${ }^{7}$ and have been reported to be differentially expressed in several types of cancers. Currently, there are more than 1,400 known miRNAs in humans ${ }^{8}$, and up to $30 \%$ of genes are thought to be regulated by miRNAs ${ }^{9}$.

Few studies have analyzed miRNAs in bladder urothelial carcinomas ${ }^{10,11,12}$, and our aim was to characterize the miRNA expression profiles in low-grade $\mathrm{pTa}$ 
and high-grade pT2-3 UC. Comparing these profiles will improve the knowledge about the well-known molecular pathway involved in urothelial carcinogenesis.

\section{MATERIAL AND METHODS}

\section{Patients}

Two tumor groups were defined for this study. The first one consists of 30 patients with low-grade, non-invasive pTa urothelial carcinomas who underwent transurethral resection (TUR), and the second group consists of 30 patients with high-grade, invasive pT2-3 urothelial carcinomas that were treated with radical cystectomy, between 2006 and 2009. Seventy-three percent (44/60) of patients were male, and the mean age was 66 years old (range, 41 to 82). There were no differences between groups with respect to the demographic data. The control group consisted of normal bladder tissue from five men with a mean age of 66 years old (range, 61 to 71) who underwent retropubic prostatectomy to treat benign prostatic hyperplasia. All patients provided informed consent, and the study was approved by the Institutional Board of Ethics (\#0176/10). Patients were followed for a mean follow-up period of 16.1 months with cytology and cystoscopy every three months for the first two years and biannually thereafter for an additional five years.

A $1 \mathrm{~cm}^{3}$ portion of each surgical specimen was immediately snap-frozen at $80^{\circ} \mathrm{C}$ for genetic tests, and the remaining tissue fixed in $10 \%$ formalin, routinely processed and stained with hematoxylin and eosin for histological examination. Histological graduation and staging followed the WHO/ISUP 2004 grading and AJCC/TNM 2010 stage, respectively.

\section{miRNA extraction and amplification}

The choice of the miRNAs evaluated in this study was based on their role in the carcinogenesis processes of many different tumors already published in the literature. The miR-100 was specifically selected for analysis because it was already related to UC, having as target FGFR3, an oncogene upregulated in non-invasive, low grade UC.

Before miRNA extraction, part of the frozen tissue was fixed in $10 \%$ formalin, routinely processed and embedded in paraffin, and a slide was stained with hematoxylin and eosin to guarantee the presence of tumor in at least $75 \%$ of the specimen. The mirVana $\mathrm{Kit}^{\circledR}$ (Applied Biosystems, CA, USA) was used for miRNA extraction following the manufacturer's instruction. miRNA CDNA was generated using a Taqman MicroRNA Reverse Transcription Kit ${ }^{\circledR}$ (Applied Biosystems, CA, USA) 
for the following miRNAs: miR-100, miR-10a, miR-21, miR-205, miR-let7c, miR-125b, miR-143, miR-145, miR-221, miR-223, miR-15a, miR-16-1, miR-199a and miR-452; the reverse transcription assays were incubated at $16^{\circ} \mathrm{C}$ for $30 \mathrm{~min}, 42^{\circ} \mathrm{C}$ for $30 \mathrm{~min}$ and $85^{\circ} \mathrm{C}$ for $5 \mathrm{~min}$. The cDNA was stored at $-20^{\circ} \mathrm{C}$ until further use. For miRNA amplification, a Taqman Reagent $\mathrm{Kit}^{\circledR}$ (Applied Biosystems, CA, USA) was used with the 7500 Fast Real-Time PCR System ${ }^{\circledR}$ (Applied Biosystems, CA, USA) using the following reaction conditions: $50^{\circ} \mathrm{C}$ for $2 \mathrm{~min} ; 95^{\circ} \mathrm{C}$ for $10 \mathrm{~min}$; and 40 cycles of $95^{\circ} \mathrm{C}$ for 15 seconds and $60^{\circ} \mathrm{C}$ for $1 \mathrm{~min}$. The expression levels of miRNAs were obtained by relative quantification using the $2^{-\Delta \Delta c t}$ method. The reactions were conducted in duplicate, and RNU-43 and RNU-48 were used as endogenous controls. The formula includes the following mathematical relations: $\triangle \triangle C T=\mathrm{dCT}_{1}-\mathrm{dCT}_{2}$, where $\mathrm{dCT}_{1}=\mathrm{CT}$ of the miRNA-target (tumor sample) - CT of the mean of the endogenous control (tumor sample) and $\mathrm{dCT}_{2}=\mathrm{CT}$ of the mean of the normal controls (normal bladder samples) - CT of the mean of the endogenous control (normal bladder samples). The final result was obtained by applying the $2^{-\Delta \Delta c t}$ method, and findings greater and smaller than 1 are considered to indicate over and underexpression, respectively. All values were standardized relative to the normal control values which are represented as a value of 1 in the figures.

\section{Statistic analysis}

The Mann-Whitney $U$ test, the Kruskal-Wallis test, ANOVA and the $T$ test were used to compare the grade and stage. The distributions of the expression levels of miRNAs were skewed; therefore, the data were log transformed for analyses. The results are presented as geometric means with $95 \%$ confidence intervals $(95 \% \mathrm{Cls})$. Kaplan-Meyer curves were constructed to analyze the diseasefree (DFS) and disease-specific (DSS) survivals.

\section{RESULTS}

The levels of the 14 miRNAs in low-grade pTa and high-grade pT2-3 UC are presented in table 1 and figure 1.

A comparison of miRNAs expression levels in both types of tumor revealed that low-grade pTa UCs were characterized by the significant underexpression of miR-100 (mean 0.04), miR-21 (mean 1.08) and miR-205 (mean 0.07) and the overexpression of miR-10a (mean 46.38). On the other hand, high-grade, invasive pT2-3 UCs exhibited underexpression of miR-10a (mean 0.23) and overexpression of miR-100 (mean 24.39), miR-21 (mean 18.17) and miR-205 (mean 6.91). The behavior profiles for these four miRNAs showed significant differences with respect 
to the grade and stage when we compared the two groups. There were no differences in the expression levels of the other 10 miRNAs studied between the two groups of tumors.

The Kaplan-Meyer curves reveal that the overexpression of miR-21, higher than 1.09, is associated with shorter disease-free survival in patients with low-grade pTa UC. For high-grade pT2-3 tumors, the higher expression of miR-10a was related to shorter recurrence-free and disease-specific survival (Figure 2).

\section{DISCUSSION}

miRNAs have been extensively studied in human tumors, in which these RNAs act as tumor promoters or tumor suppressors. Our results add a possible role for four different miRNAs in bladder urothelial carcinogenesis; these miRNAs could affect the expression of different genes that have already been described as altered in this neoplasia.

Our objective was to identify miRNA expression signatures that could be incorporated to the already well known molecular carcinogenic pathway of UC. Considering the two groups of tumors defined by histological grade and stage, we identified differences in the expression of four miRNAs (miR-100, miR-10a, miR-21 and miR-205).

In the comparison of low-grade pTa and high-grade, muscle-invasive urothelial carcinomas, we found that the underexpression of miR-100, miR-21 and miR-205 and the overexpression of miR-10a are characteristic of the pTa tumor group. It is already known that FGFR3 mutations and, more rarely, RAS mutations are the main events that occur during the development of low-grade pTa UC. Recently, it was suggested by Catto et al. ${ }^{10}$ that FGFR3 is a target for miR-100. They found an inverse association between miR-100 and FGFR3, suggesting that miR-100 underexpression that occurred in all cases could allow enhanced gene activity and higher levels of FGFR3 protein, thus facilitating mutational events before the occurrence of point mutations through higher cell turnover and the selection of mutant cells. The mechanism proposed for the loss of miR-100 function is the DNA methylation promoted by aromatic amines and carcinogens present in tobacco and other chemical compounds. Consequently, miR-100 underexpression could be used as a new biomarker in patients at risk for the development of urothelial tumors, predominantly smokers and workers in the chemical industries. 
The majority $(56.7 \% ; 17 / 30)$ of invasive tumors were associated with miR100 overexpression (mean 24.39). Most likely, in this case, miR-100 acts on another target, THAP-2, a member of the $R B / E 2 F$ family that as an important role in the regulation of proliferation control ${ }^{13}$. The loss of expression of RB1, P53 and PTEN is involved in the carcinogenesis of high-grade, muscle-invasive UC ${ }^{14,15}$. miR-100 overexpression in high-grade pT2-3 could promote THAP-2 silencing and the loss of cell proliferation control.

miR-10a was overexpressed in 73.3\% (22/30) of low-grade pTa UCs and only in $6.7 \%(2 / 30)$ of high-grade pT2-3 UCs. The same result was described by Veerla et al. ${ }^{16}$, who showed that miR-10a expression was 2.47 times higher in pTa tissues than in pT1 and pT2-3 tissues. Even without establishing a mechanistic relationship between miR-10a and the FGFR3 gene, they speculated an association between the two. miR-10a is located in chromosome $17 q 21$ and has been shown to be associated with cell differentiation ${ }^{17,18}$. In addition to the canonical role of this miRNA, it can also bind to the 5' mRNA region, increasing the translation of ribosomal proteins and positively regulating general functions of the cell such as transformation and differentiation ${ }^{19}$.

Interestingly, we found an association between miR-10a overexpression and shorter disease-free and disease-specific survival for patients with high-grade pT2-3 UC. The role of miR-10a in neoplasias is not completely understood. Some studies have shown that miR-10a is oncogenic and overexpressed in breast and pancreatic cancer and that its expression is related to tumor aggressiveness, the development of metastasis and poor prognosis ${ }^{20,21}$. In contrast, Agirre et al. ${ }^{22}$ showed that the underexpression of miR-10a was related to increased cellular proliferation and the progression of chronic myeloid leukemia.

miR-21 was markedly overexpressed in high-grade pT2-3 tumors (18.17 vs 1.08). miR-21 has been constantly described as an oncomiR, being overexpressed in many tumors ${ }^{23}$. Our findings are similar to those of past studies ${ }^{10}$ that showed that miR-21 overexpression is related to P53 inactivation, invasion and tumor progression in bladder cancer. P53 is a target of miR-2 ${ }^{10}$, and the loss of P53 function is the single most important genetic alteration involved in muscle-invasive UC because $P 53$ controls the cell cycle, apoptosis and DNA repair. Furthermore, the $P T E N$ gene is also a target of miR-21, and its loss is involved in UC carcinogenesis via the activation of the PI3K/AKT/mTOR pathway ${ }^{6}$.

Analysis of the follow-up periods of patients with low-grade pTa carcinomas, miR-21 overexpression was found to be correlated with shorter DFS, a result that strengths the hypothesis that this miRNA has an oncogenic role. 
miR-205 was expressed at a higher level in high-grade pT2-3 UC (6.91 vs 0.07). In contrast, past studies have found lower levels of miR-205 in neoplasias, including bladder cancers, and these lower levels were related to the aberrant methylation of the $1 q 32.2$ chromosome, where miR-205 is located ${ }^{28}$. Neely et al. ${ }^{24}$ observed miR-205 underexpression in UC, and interestingly, they have shown that the ratio miR-21:miR-205 increases progressively accordingly tumor progression. miR-205 is also underexpressed in lung, breast and prostate cancers ${ }^{24,25,26}$. The present results are consistent with the rationale proposed only for pTa tumors. miR205 has been defined as a tumor suppressor miRNA involved in the epithelialmesenchymal transition (EMT). This miRNA is part of the miR-200 family, members of which act as inhibitors of ZEB-1 and ZEB-2, which inhibit E-cadherin. E-cadherin is an adhesion molecule that is responsible for the maintenance of physiological cell features ${ }^{11}$. The loss of miR-205 expression allows ZEB-1 and ZEB-2 to be overactive, thus suppressing E-cadherin and facilitating the invasion and dissemination of the neoplasia. Further studies are needed to explain these contradictory results.

We want to propose the incorporation of miRNA expression in the carcinogenic pathway of urothelial carcinomas, as shown in Figure 3. Different expression profiles based on significant numeric values of these four miRNA could be included as a decision tool for medical treatment and follow-up.

Until now, there is no ideal tumor marker for UC and the routine remains the follow up with cytology and cistoscopy. Among the features of an ideal biomarker, its detection in body fluids is critical, and miRNAs are shown to be stable in body fluids as well as in paraffin embedded tissues ${ }^{29}$. Thus, we have initiated a study to identify these four differentially expressed miRNAs in urine of patients being followed by UC. Since we found specific miRNAs related to the two different UC, we could propose their inclusion in the decision making process related to more aggressive treatment if the profile suggest an aggressive tumor or a closer follow up in cases were recurrence is the rule.

\section{CONCLUSIONS}

We have demonstrated that low-grade pTa and high-grade pT2-3 urothelial carcinomas exhibit differences with respect to miRNA expression that could be incorporated into the well-known carcinogenic pathway. The aberrant miRNA levels could be used as new biomarkers to better manage patients with bladder cancer or who are susceptible to the development of the neoplasia. 


\section{REFERENCES}

1. Jemal A, Bray F, Center MM. Global Cancer Statistics 2011. Cancer J Clin 2011;61(2):69-90.

2. Jebar $A H$, Hurst $C D$, Tomlinson DC. FGFR3 and Ras gene mutations are mutually exclusive genetic events in urothelial cell carcinoma. Oncogene 24(33), pp 5218, 2005.

3. Borden LS, Clark PE, Hall MC. Bladder Cancer. Curr Opin Oncol 17(3), pp 275, 2005.

4. van Rhijn BWG, van der Kwast TH, Vis AN. FGFR3 and P53 Characterize Alternative Genetic Pathways in the Pathogenesis of Urothelial Cell Carcinoma. Cancer Res 64(6), pp 1911, 2004.

5. Pandith AA, Shah ZA, Siddiqi MA. Oncogenic role of fibroblastic growth factor receptor 3 in tumorigenesis of urinary bladder cancer. Urol Oncol 2010 (in press).

6. Wu XR. Biology of urothelial tumorigenesis: insights from genetically engineered mice. Cancer Metastasis Rev 28(3-4), pp 281, 2009.

7. Bartel DP. MicroRNAs: Genomics, Biogenesis, Mechanism, and Function. Cell 116(2), pp 281, 2004.

8. The miRNA body map. Available in: http://www.mirnabodymap.org/mirna card.php. Data of 2012.

9. Lewis BP, Burge CB, Bartel DP. Conserved Seed Pairing, Often Flanked by Adenosines, Indicates that Thousands of Human Genes are MicroRNA Targets. Cell 120(1), pp 15, 2005.

10. Catto JWF, Miah S, Owen HC. Distinct microRNA alterations characterize high and low grade bladder cancer. Cancer Res 69(21), pp 8472, 2009.

11. Gregory PA, Bert AG, Paterson BL. The miR-200 family and miR-205 regulate epithelial to mesechymal transition by targeting ZEB1 and SIP1. Nat Cell Biol 10, pp 593, 2008.

12. Chiyomaru T, Enokida H, Tatarano S. miR-145 and mir-133a function as tumour suppressors and directly regulate FSCN1 expression in bladder cancer. Br J Cancer 102(5), pp 883, 2010.

13. Bessière $D$, Lacroix $C$, Campagne $S$. Structure-Function Analysis of the THAP Zinc Finger of THAP1, a Large C2CH DNA-binding Module Linked to Rb/E2F Pathways. J Biol Chem 283(7), pp 4352, 2008.

14. Esrig E, Elmajian D, Groshen S. Accumulation of Nuclear p53 and Tumor Progression in Bladder Cancer. N Engl J Med 331, pp 1259, 1994.

15. Meng F, Henson R, Wehbe-Janek H. MicroRNA-21 Regulates Expression of the PTEN Tumor Suppressor Gene in Human Hepatocellular Cancer. Gastroenterology 133, pp 647, 2007. 
16. Veerla $S$, Lindgren $D$, Kvist A. MiRNA expression in urothelial carcinomas: important roles of miR-10a, miR-222, miR-125b, miR-7 and miR-452 for tumor stage and metastasis, and frequent homozygous losses of miR-31. Int J Cancer 124(9), pp 2236, 2009.

17. Huang $H$, Xie C, Sun X. miR-10a contributes to retinoid acid-induced smooth muscle cell differentiation. J Biol Chem 285(13), pp 9383, 2010.

18. Foley NH, Bray I, Watters KM. microRNAs 10a and $10 \mathrm{~b}$ are potent inducers of neuroblastoma cell differentiation through targeting nuclear receptor corepressor 2. Cell Death Differ 18(7), pp 1089, 2011.

19. Orom UA, Nielsen FC, Lund AH. microRNA-10a binds the 5'UTR of ribosomal protein mRNA and enhances their translation. Mol Cell 30(4), pp 460, 2008.

20. Ma L, Teruya-Feldstein J, Weinberg RA. Tumour invasion and metastasis initiated by microRNA-10b in breast cancer. Nature 449(7163), pp 682, 2007.

21. Weiss FU, Marques IJ, Woltering JM. Retinoic acid receptor antagonists inhibit miR-10a expression and block metastatic behavior of pancreatic cancer. Gastroenterology 137(6), pp 2136, 2009.

22. Agirre $X$, Jiménez-Velasco $A$, San José-Enériz E. Down-regulation of hsa-miR$10 \mathrm{a}$ in chronic myeloid leukemia CD34+ cells increases USF2-mediated cell growth. Mol Cancer Res 6(12), pp 1830, 2008.

23. Si ML, Zhu S, Wu H. miR-21-mediated tumor growth. Oncogene pp 1, 2006.

24. Neely LA, Rieger-Christ KM, Neto BS. A microRNA expression ratio defining the invasive phenotype in bladder tumors. Urol Oncol 28(1), pp 39, 2008.

25. Lebanony D, Benjamin H, Gilad S. Diagnostic assay based on hsa-miR-205 expression distinguishes squamous from nonsquamous non-small-cell lung carcinoma. J Clin Oncol 27(12), pp 2030, 2009.

26. Wu H, Zhu S, Mo YY. Suppression of cell growth and invasion by miR-205 in breast cancer. Cell Res 19(4), pp 439, 2009.

27. Gandellini P, Folini M, Longoni N. miR-205 Exerts tumor-suppressive functions in human prostate through down-regulation of protein kinase Cepsilon. Cancer Res 69(6), pp 2287, 2009.

28. Wiklund ED, Bramsen JB, Hulf T. Coordinated epigenetic repression of the miR200 family and miR-205 in invasive bladder cancer. Int J Cancer 128(6), pp 1327, 2011.

29. Leite KR, Canavez JM, Tomiyama AH. miRNA analysis of prostate cancer by quantitative real time PCR: comparison between formalin-fixed paraffin embedded and fresh-frozen tissue. Urol Oncol 29(5), pp 533, 2011. 

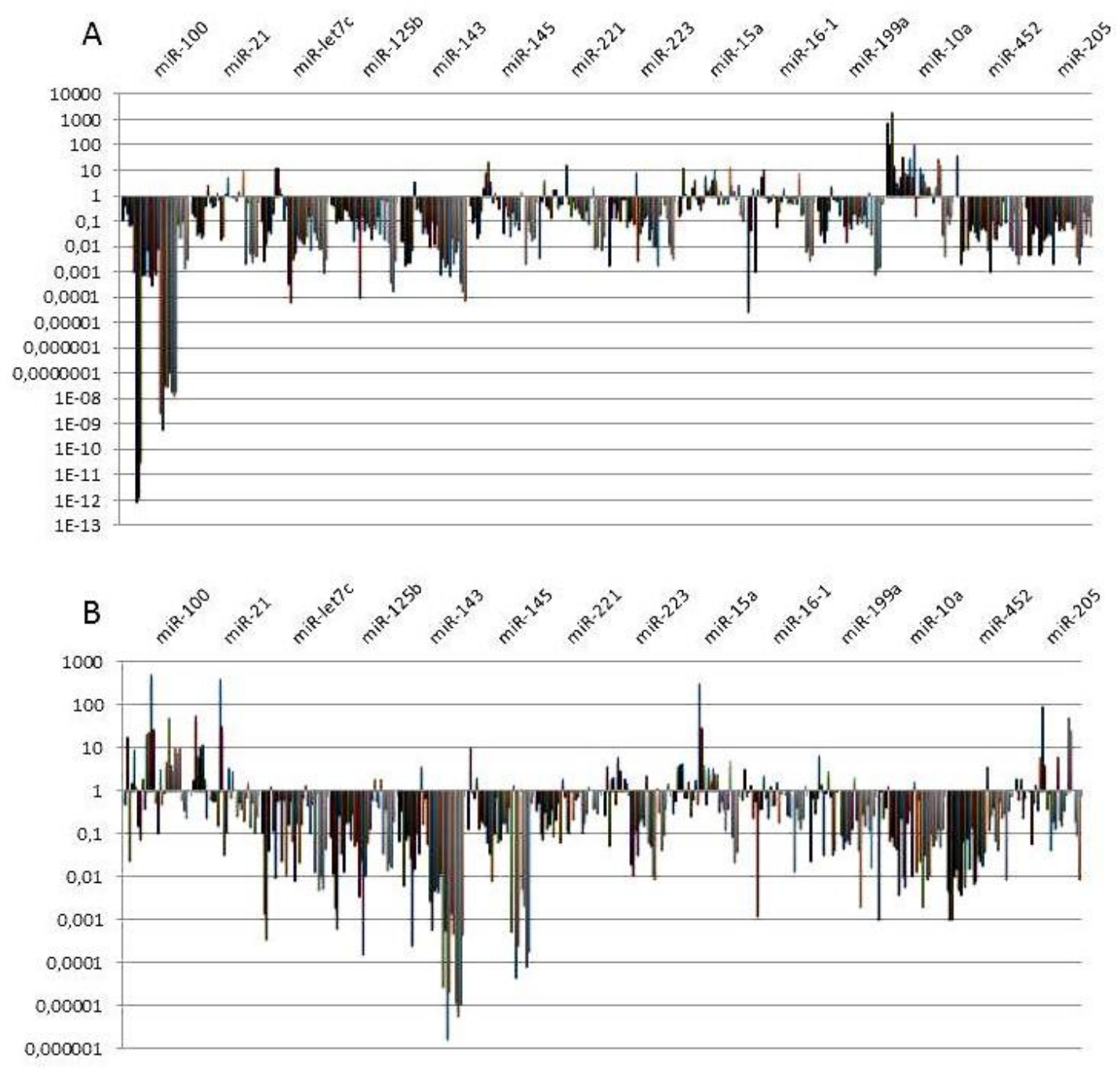

Figure 1. Expression profile of miRNAs in low-grade pTa and high-grade pT2-3 UC. 


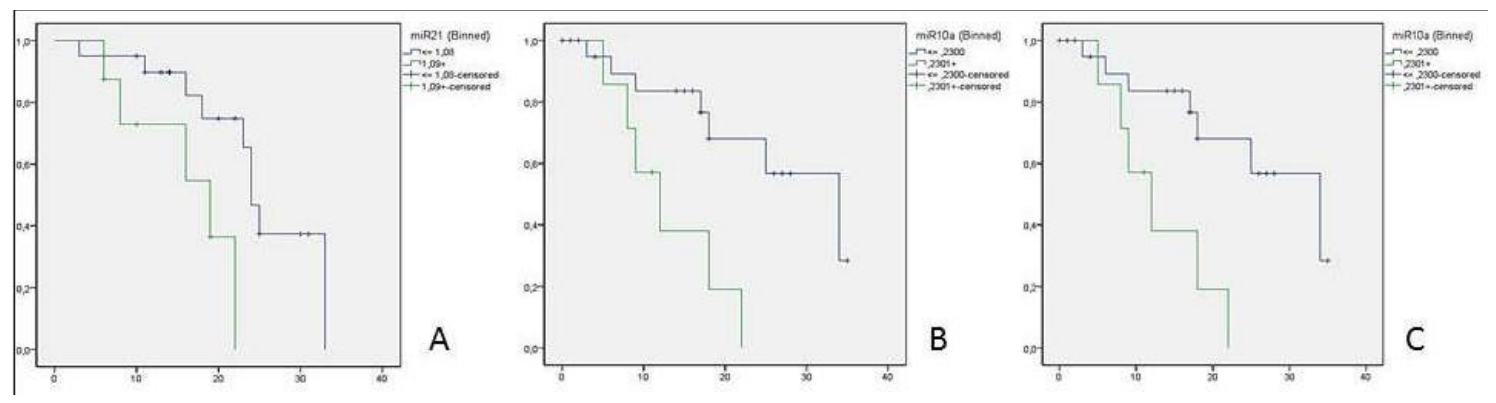

Figure 2. Kaplan-Meyer curves showing shorter DFS in patients with low-grade pTa UC that overexpresses miR-21 (A) and shorter DFS (B) and DSS (C) in patients with high-grade pT2-3 UC that overexpresses miR-10a.

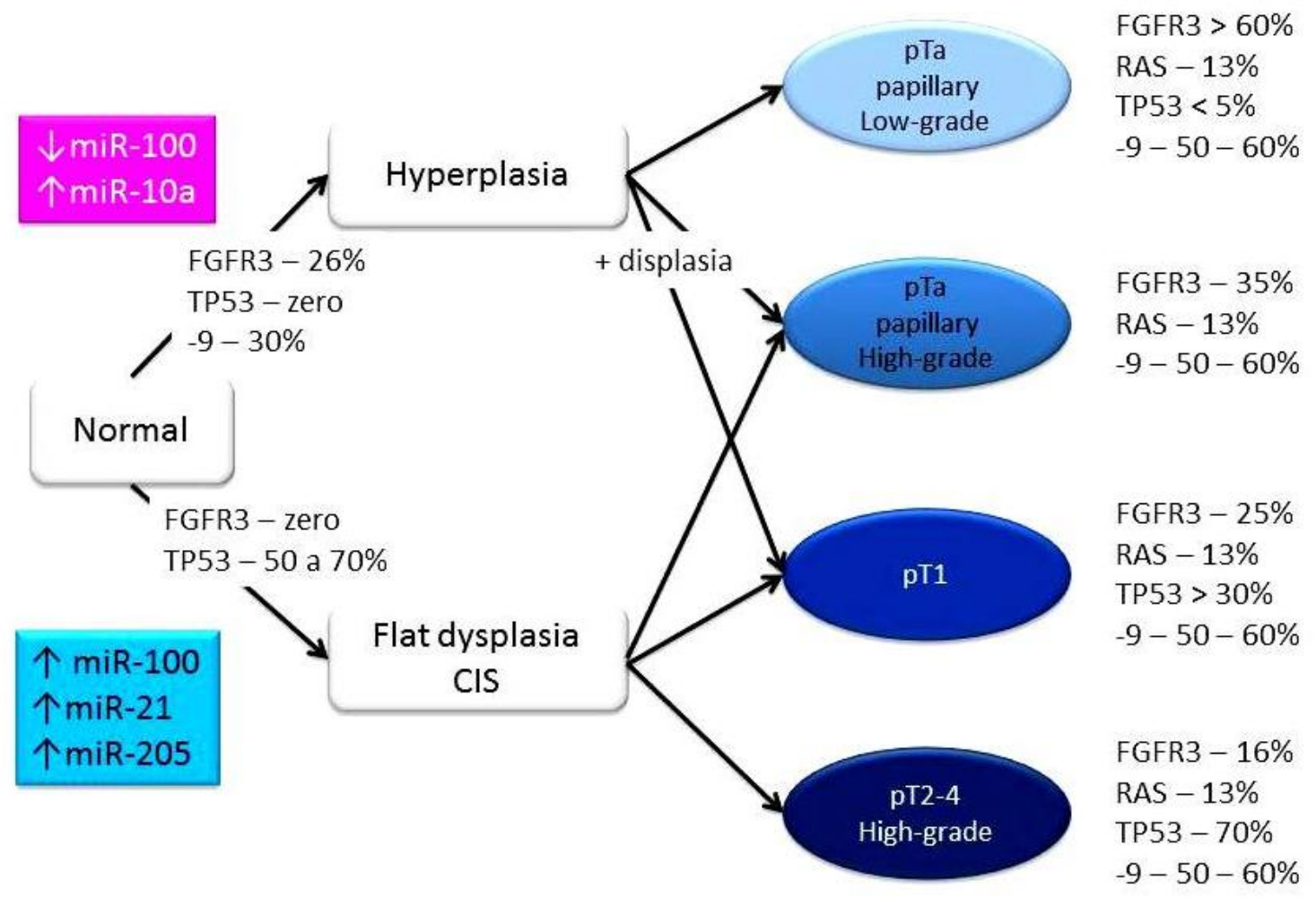

Figure 3. Mechanism of urothelial carcinogenesis incorporating miRNAs. 
Table 1. Levels of miRNA expression in low grade, pTa and in high-grade pT2-3 urothelial carcinomas.

\begin{tabular}{|c|c|c|c|c|}
\hline \multirow[b]{2}{*}{ miRNA } & \multicolumn{2}{|c|}{$\begin{array}{l}\text { Low-grade, pTa } \\
\text { (n= } \mathbf{3 0}) \\
\text { Mean } \\
\text { Median (min-max) }\end{array}$} & \multicolumn{2}{|c|}{$\begin{array}{l}\text { High-grade, pT2/pT3 } \\
\text { (n }=\mathbf{3 0 )} \\
\text { Mean } \\
\text { Median (min-max) }\end{array}$} \\
\hline & & $p$ & & $p$ \\
\hline 100 & $\begin{array}{c}0.04 \\
0.0008 \\
\left(8.94^{-13}-0.44\right)\end{array}$ & $<0.001$ & $\begin{array}{c}24.39 \\
1.77 \\
(0.02-526.6)\end{array}$ & $<0.001$ \\
\hline $10 a$ & $\begin{array}{c}46.38 \\
4.88 \\
(0.004-761.2)\end{array}$ & $<0.001$ & $\begin{array}{c}0.23 \\
0.06 \\
(0.001-1.75)\end{array}$ & $<0.001$ \\
\hline 21 & $\begin{array}{c}1.08 \\
0.4 \\
(0.002-11.14)\end{array}$ & 0.02 & $\begin{array}{c}18.17 \\
0.65 \\
(0.03-407.99)\end{array}$ & 0.03 \\
\hline 205 & $\begin{array}{c}0.07 \\
0.04 \\
(0.002-0.35)\end{array}$ & $<0.001$ & $\begin{array}{c}6.91 \\
0.65 \\
(0.009-97.84)\end{array}$ & $<0.001$ \\
\hline Let7c & $\begin{array}{c}1.03 \\
0.02 \\
\left(6.3^{-5}-13.14\right)\end{array}$ & 0.16 & $\begin{array}{c}0.29 \\
0.1 \\
(0.0003-1.41)\end{array}$ & 0.31 \\
\hline $125 b$ & $\begin{array}{c}0.15 \\
0.08 \\
\left(9.4^{-5}-0.76\right)\end{array}$ & 0.92 & $\begin{array}{c}0.26 \\
0.06 \\
(0.0001-2.02)\end{array}$ & 0.99 \\
\hline 143 & $\begin{array}{c}0.18 \\
0.009 \\
\left(7.4^{-5}-4.13\right)\end{array}$ & 0.99 & $\begin{array}{c}0.18 \\
0.005 \\
\left(1.7^{-6}-3.85\right)\end{array}$ & 0.76 \\
\hline 145 & $\begin{array}{c}1.61 \\
0.2 \\
(0.002-24.06)\end{array}$ & 0.27 & $\begin{array}{c}0.66 \\
0.13 \\
\left(4.4^{-5}-10.25\right)\end{array}$ & 0.48 \\
\hline 221 & $\begin{array}{c}1.22 \\
0.3 \\
(0.003-17.64)\end{array}$ & 0.89 & $\begin{array}{c}0.48 \\
0.34 \\
(0.06-1.92)\end{array}$ & 0.98 \\
\hline 223 & $\begin{array}{c}0.49 \\
0.1 \\
(0.002-9.49)\end{array}$ & 0.21 & $\begin{array}{c}1.007 \\
0.29 \\
(0.009-6.2)\end{array}$ & 0.41 \\
\hline $15 a$ & $\begin{array}{c}2.76 \\
1.04 \\
(0.1-15.3)\end{array}$ & 0.78 & $\begin{array}{c}13.53 \\
0.69 \\
(0.02-331.1)\end{array}$ & 0.93 \\
\hline $16-1$ & $\begin{array}{c}1.47 \\
0.57 \\
\left(2.6^{-5}-12.3\right)\end{array}$ & 0.81 & $\begin{array}{c}0.76 \\
0.54 \\
(0.001-3.3)\end{array}$ & 0.95 \\
\hline $199 a$ & $\begin{array}{c}0.36 \\
0.13 \\
(0.0008-2.7)\end{array}$ & 0.25 & $\begin{array}{c}0.69 \\
0.19 \\
(0.002-6.78)\end{array}$ & 0.52 \\
\hline 452 & $\begin{array}{c}1.42 \\
0.03 \\
(0.0001-39.87)\end{array}$ & 0.39 & $\begin{array}{c}0.24 \\
0.03 \\
(0.001-3.69)\end{array}$ & 0.68 \\
\hline
\end{tabular}


Novo Responder Responder atodos Encaminhar | Excluir Lixo Eletrônico Limpar "Marcar como " Mover para " Categorias,

누분

JU-12-149R1

Voltar para mensagens | \&

$\square$ Journal of Urology Adicionar a contatos

$17 / 04 / 2012$

Para Nelson Gaspar Dip

Responder .

Apr 17, 2012

RE: JU-12-149R1

Dear Dr. Dip:

The subject matter of your revised manuscript on STAGE, GRADE AND BEHAVIOR OF BLADDER UROTHELIAL CARCINOMAS DEFINED BY THE MICRO RNA EXPRESSION PROFILE has been recommended for publication in The Journal of Urology. This paper is tentatively scheduled for publication in the November 2012 issue.

We assume, of course, that you have not submitted for publication elsewhere all or a portion of the material contained in this article. In accordance with the policy of other journals, minor deletions and alterations, consistent with good reporting, will be made in the interests of brevity.

It is the responsibility of all authors funded by the National Institutes of Health or from NIH staff to submit an electronic version of their final peer reviewed manuscripts upon acceptance for publication to the National Institutes of Health's PubMed Central to be made publicly available no later than 12 months after the official date of publication. For detailed information visit http://publicaccess.nih.gov/submit_process_journals.htm.

Sincerely yours,

Karl-Erik Andersson, M.D.

Section Editor

William D. Steers, M.D.

Editor 
UNDER-EXPRESSION OF MIR-100 MAY BE A NEW CARCINOGENIC

PATHWAY FOR LOW-GRADE PTA BLADDER UROTHELIAL CARCINOMAS

Nelson Dip ${ }^{1}$, Sabrina T. Reis ${ }^{1}$, Luciana S. Timoszczuk ${ }^{1}$, Daniel Kanda Abe ${ }^{1,2}$ Marcos

Dall'Oglio $^{2}$, Miguel Srougi ${ }^{1}$, Katia R. M. Leite ${ }^{1}$

1. Laboratory of Medical Investigation, Urology Department - LIM55, University of Sao Paulo Medical School, Sao Paulo, Brazil

2. Uro-Oncology Group, Urology Department, Sao Paulo Cancer Institute (ICESP), Sao Paulo, Brazil

Corresponding author

Nelson Gaspar Dip Júnior

Av. Dr. Arnaldo 455, room 2145

01246-903, Sao Paulo, Brazil

Tel/Fax 551130617183

nelson.dip@hotmail.com

Sponsor by: FAPESP 10/50824-1 


\section{ABSTRACT}

Objetives: The pathways involved in the carcinogenesis of bladder urothelial carcinoma have been well established and are used for the development of new diagnostic and prognostic markers for the disease. The main genetic pathway for the development of low-grade pTa urothelial carcinomas is related to FGFR3 mutation. MicroRNAs have been related to processes involved in carcinogenesis in many organs, and miR-100 was recently shown to target FGFR3 messenger RNA. Our aim was to study the profile of expression of miR-100 and FGFR3 in low-grade, pTa bladder urothelial carcinoma.

Methods and Materials: Using qRT-PCR, we studied the expression of miR-100 and FGFR3 in 30 patients who had undergone transurethral resection of low-grade, pTa bladder urothelial carcinoma.

Results and Conclusion: There was under-expression of miR-100 and overexpression of FGFR3 in $100 \%$ of the specimens. Under-expression of miR-100 might be an alternative pathway for low-grade pTa urothelial bladder carcinogenesis and the identification of this molecular alteration may constitute a new diagnostic and prognostic marker for the disease.

Keywords: Micro RNA; Bladder cancer; Carcinogenesis; Molecular pathway; Prognosis; Diagnosis; FGFR3 


\section{INTRODUCTION}

Bladder cancer $(\mathrm{BC})$ is the second most common malignancy of the urinary tract. Approximately 383,300 new cases are estimated for 2011 [1]. Ninety percent of $\mathrm{BC}$ are urothelial carcinomas (UC), previously named transitional cell carcinomas, and the majority are papillary low-grade, non-muscle invasive that recur in up to $80 \%$ of cases but rarely progress to muscle invasion [2,3]. In contrast, 10 to $20 \%$ of tumors are muscle invasive at diagnosis, and $50 \%$ of patients die from metastatic disease [4].

The molecular pathways underlying the main two distinct types of UC, lowgrade, non-muscle invasive, and high-grade, muscle invasive $[2,5]$ have been investigated to identify new potential markers for diagnosis, disease monitoring, prognosis and development of new targeted therapies $[2,6,7]$. The most common genetic alteration of $\mathrm{BC}$ associated with low-grade and stage neoplasias is an activating mutation of the fibroblast growth factor receptor 3 (FGFR3) gene [8,9], whereas mutations in the p53 and retinoblastoma (RB1) genes have as being identified as characteristic of the carcinogenesis pathway for high grade invasive disease $[5,7,10,11]$.

The FGFR3 gene belongs to the growth factor receptor family related to the tyrosine kinase signaling pathway, which plays an important role in embryogenesis, development, angiogenesis, wound healing, tissue homeostasis and tumorigenesis, regulating cellular proliferation, migration and apoptosis [9]. Mutations are the primary phenomenon related to FGFR3 dysfunction allowing its ligand-independent operation $[9,12]$ and the identification of FGFR3 dysfunction has been purposed as a new tumor marker $[5,10,13]$. Other events that may lead to the over-expression of the FGFR3 including alterations in the epigenetic control including DNA methylation, histone acetylation and abnormalities in the expression of microRNAs can also play crucial roles in the development and progression of $\mathrm{BC}$.

MicroRNAs are members of small single-stranded regulatory RNAs (21-25 nucleotides) that can suppress the translation or promote the degradation of mRNA 
regulating the expression of target genes, including transcription factors, oncogenes and tumor suppressor genes. MicroRNAs have been reported to be differentially expressed in several types of cancers. Currently, there are more than 700 miRNAs described in humans, and up to $30 \%$ of genes are thought to miRNA regulated [14]. MicroRNAs are involved in cell development, differentiation, apoptosis, tissue homeostasis and several metabolic pathways $[15,16,17,18]$, and they have been related to carcinogenesis acting as negative regulators of genes related to cancer as typified by the effect of miR-15a and miR-16-1 on BCL2 mRNA, miR-143 and miRlet7c on RAS mRNA and miR-21 on p53 mRNA $[19,20,21,22]$.

Recently authors have demonstrated that the FGFR3 gene is a target of microRNA 100 (miR-100), and the down-regulation of FGFR3 could be involved in the development of low-grade, non-muscle invasive UC. [22,23]. Our aim was to study the expression of miR-100 and the FGFR3 gene in low-grade, non-invasive UC to validate a new carcinogenesis pathway that may be involved in the development of the disease and that could potentially be used as a new biomarker.

\section{METHODS AND MATERIALS}

\section{Patients}

Thirty low-grade non-invasive pTa urothelial carcinomas obtained from patients who underwent transurethral resection were the subject of the study. Eighty-seven percent (26/30) of patients were male; the mean age was 67.6 years old, ranging from 47 to 82 . As control, we used normal bladder tissue from five patients who had undergone retropubic prostatectomy to treat benign prostatic hyperplasia. All patients provided informed consent and the study design was approved by the Institutional Board of Ethics protocol 10/176.

A subsection of the all the specimens were fixed in $10 \%$ formalin routinely processed and stained with hematoxylin and eosin for histological examination. 
Only urothelial low-grade (2004 WHO/ISUP) pTa (2010 AJCC/TNM) tumors were included in the study.

\section{RNA and miRNA extraction and amplification}

Part of the resected tissue was immediately frozen and stored at $-80^{\circ} \mathrm{C}$. At the time of the RNA and microRNA extraction, a fragment of the frozen tissue was fixed in $10 \%$ formalin, routinely processed and embedded in paraffin and a slide was stained with hematoxylin and eosin to guarantee the presence of tumor in at least $75 \%$ of the specimen.

miR-100 expression was examined in all 30 cases; however, because of the relatively small amount of tissue available, FGFR3 messenger RNA expression was only examined in 15 cases.

Total RNA and miRNA was isolated using a RNAaqueous $\mathrm{Kit}^{\circledR}$ (Applied Biosystems, CA, USA) and a mirVana Kit (Applied Biosystems, CA, USA), respectively, according to the manufacturer's instructions. RNA and miRNA concentration was determined by $260 / 280$ nM absorbance using Nanodrop ND1000 spectrophotometer (Thermo Scientific). cDNA was generated using a High Capacity cDNA Reverse Transcription Kit ${ }^{\oplus}$ (Applied Biosystems, CA, USA) for RNA and a Taqman MicroRNA Reverse Transcription Kit (Applied Biosystems, CA, USA) for miRNA. RNA reactions were incubated at $25{ }^{\circ} \mathrm{C}$ for $10 \mathrm{~min}$, followed by $37{ }^{\circ} \mathrm{C}$ for $120 \mathrm{~min}$ and $85^{\circ} \mathrm{C}$ for $5 \mathrm{~min}$, and the miRNA was incubated at $16{ }^{\circ} \mathrm{C}$ for $30 \mathrm{~min}, 42$ ${ }^{\circ} \mathrm{C}$ for $30 \mathrm{~min}$ and $85^{\circ} \mathrm{C}$ for $5 \mathrm{~min}$. The cDNA was stored at $-20^{\circ} \mathrm{C}$ until further use.

For mRNA and miRNA amplification, a Taqman Reagent Kit (Applied Biosystems, CA, USA) was used in the 7500 Fast Real-Time PCR System (Applied Biosystems, CA, USA).

Expression profiles of miR-100 and mRNA FGFR3 were obtained by relative quantification determined using the $2^{-\Delta \Delta c t}$ method. Reactions were conducted in duplicate using $\beta-2$ microglobulin (B2M) as an endogenous control for mRNA analysis and RNU-43 and RNU-48 as endogenous controls for miRNA analysis. 


\section{Statistic analysis}

The distribution of the expression levels of the miRNAs was skewed; therefore, the data were log transformed for analyses. Results are presented as geometric means with a $95 \%$ confidence interval $(95 \% \mathrm{Cl})$.

\section{RESULTS}

The data for miR-100 and FGFR3 expression are presented in Table 1 and Figure 1. All examined cases displayed under-expression of miR-100 and overexpression of FGFR3. The mean and median expression values for miR-100 and FGFR3 were 0.038 and $0.0008(8.94 \mathrm{E}-13-0.44)$, and 1599.6 and 202.95 (3.26 16002.3), respectively.

\section{DISCUSSION}

Molecular pathways are directly involved in the biological behavior of BC and are able to predict disease evolution prior to its complete presentation. Our study revealed that $100 \%$ of low-grade pTa UC showed under-expression of miR$100(30 / 30)$ and over-expression of FGFR3 (15/15), showing a strict association between two events. We sought to prove that FGFR3 is a target of miR-100, and that FGFR3 over-expression is due to the under-expression of miR-100, which is a different mechanism related to $\mathrm{BC}$ carcinogenesis that could be used in clinical practice. Catto et al. (2009), who studied 22 cases of low-grade pTa UC, found the same result and proved FGFR3 as a target for miR-100 in vitro models.

The FGFR3 mutation in BC was initially described in 1999 by Cappellen et al., who identified mutations in $35 \%$ of the tumors they examined. FGFR3 can be abnormally activated through two mechanisms. The first mechanism is the translocation $\mathrm{t}(4 ; 14)(\mathrm{p} 16.3 ; \mathrm{q} 32)$ that results in an increase in mRNA, as has been described in multiple myeloma [25]. The second mechanism is an anomalous over- 
activation of the receptor by a point mutation [26]. Currently, the FGFR3 point mutation is well established in BC carcinogenesis; it is present in more than $70 \%$ of low-grade non-invasive UC $[5,9,13,22]$, and can be caused by tobacco smoke and contact with aromatic amines $[27,28]$. These mutations activate the tyrosine kinase domain, lowering the specificity for the ligand, promoting dimerization independent of the ligand or inducing autophosphorylation of the intracellular domain.

In contrast, approximately $30 \%$ of low-grade pTa UC do not have the FGFR3 mutation suggesting that other regulatory pathways may be involved in the pathogenesis of the tumor. Few studies have evaluated alternative mechanisms of FGFR3 dysfunction in BC $[13,22]$.

It is important to clarify the mechanisms that may be involved in the dysfunction of miR-100 expression. Blick et al. (2011) recently demonstrated that hypoxia could up-regulate FGFR3 and concomitantly down-regulate miR-100 in an HIF-1a dependent manner in BC. In addition, epigenetic events such as methylation could be involved in the silencing of miR-100 [30].

We hypothesize that mechanisms affecting miR-100 expression could be the first molecular event in low-grade pTa UC development, and there is a need for further studies to confirm the precise role of miR-100 as a controller of FGFR3 in BC. If these events precede FGFR3 mutation, we propose the search for miR-100 underexpression as a new tumor diagnostic and prognostic marker.

\section{CONCLUSIONS}

We have demonstrated a profile of miR-100 and FGFR3 expression in lowgrade pTa UC that could precede or be an alternative pathway for bladder carcinogenesis. Further confirmation of the findings presented in this study would constitute new data for the development of novel diagnostic and prognostic markers for bladder carcinogenesis. 


\section{REFERENCES}

1. Jemal A, Bray F, Center MM, Ferlay Ward E, Forman D. Global Cancer Statistics, 2011. Cancer J Clin 2011;61(2):69-90.

2. Jebar AH, Hurst CD, Tomlinson DC, Johnston C, Taylor CF, Knowles MA. FGFR3 and Ras gene mutations are mutually exclusive genetic events in urothelial cell carcinoma. Oncogene 2005;24:5218-25.

3. McConkey DJ, Lee S, Choi W, et al. Molecular genetics of bladder cancer: Emerging mechanisms of tumor initiation and progression. Urol Oncol 2010;28(4):429-40.

4. Borden LS, Clark PE, Hall MC. Bladder Cancer. Curr Opin Oncol 2005;17(3):275-80.

5. van Rhijn BWG, van der Kwast TH, Vis AN, et al. FGFR3 and P53 Characterize Alternative Genetic Pathways in the Pathogenesis of Urothelial Cell Carcinoma. Cancer Research 2004;64:1911-14.

6. Martinez-Torrecuadrada J, Cifuentes G, López-Serra P, Saenz P, Martinez A, Casal JI. Targeting the Extracellular Domain of Fibroblast Growth Factor Receptor 3 with Human Single-Chain Fv Antibodies Inhibits Bladder Carcinoma Cell Line Proliferation. Clin Cancer Res 2005;11(17):6280-90.

7. Castillo-Martin M, Domingo-Domenech J, Karni-Schmidt O, Matos T, CordonCardo C. Molecular pathways of urothelial development and bladder tumorigenesis. Urol Oncol 2010;28(4):401-8.

8. Knowles MA. Molecular pathogenesis of bladder cancer. Int J Clin Oncol 2008;13:287-97.

9. Pandith AA, Shah ZA, Siddiqi MA. Oncogenic role of fibroblastic growth factor receptor 3 in tumorigenesis of urinary bladder cancer. Urol Oncol 2010 (in press).

10. Bakkar AA, Wallerand H, Radvanyi F, et al. FGFR3 and TP53 Gene Mutations Define Two Distinct Pathways in Urothelial Cell Carcinoma of Bladder. Cancer Res 2003;63:8108-12. 
11. Wu XR. Biology of urothelial tumorigenesis: insights from genetically engineered mice. Cancer Metastasis Rev 2009;28:281-90.

12. Ornitz DM, Xu J, Colvin JS, et al. Receptor Specificity of the Fibroblast Growth Factor Family. J Biol Chem 1996;271(25):15292-97.

13. Tomlinson DC, Baldo O, Harnden P, Knowles MA. FGFR3 protein expression and its relationship to mutation status and prognostic variables in bladder cancer. J Pathol 2007;213(1):91-98.

14. Lewis BP, Burge CB, Bartel DP. Conserved Seed Pairing, Often Flanked by Adenosines, Indicates that Thousands of Human Genes are MicroRNA Targets. Cell 2005;120:15-20.

15. Ambros V. MicroRNA Pathways in Flies and Worms. Cell 2003;113(6):673-76.

16. Bartel DP. MicroRNAs: Genomics, Biogenesis, Mechanism, and Function. Cell 2004;116:281-297.

17. Croce CM, Calin GA. miRNAs, cancer and stem cell division. Cell 2005;122(1):6-7.

18. Blenkiron C, Miska E. MiRNAs in cancer: approaches, aetiology, diagnostics and therapy. Hum Mol Genet 2007;16:106-13.

19. Cimmino A, Calin GA, Fabbri M, et al. miR-15 and miR-16 induce apoptosis by targeting BCL2. PNAS 2005;102(39):13944-49.

20. Lin T, Dong W, Huang J, et al. MicroRNA-143 as a Tumor Suppressor for Bladder Cancer. J Urol 2009;181:1372-80.

21. Johnson SM, Grosshans H, Shingara J, et al. RAS is Regulated by the let-7 MicroRNA Family. Cell 2005;120(5):635-47.

22. Catto JWF, Miah S, Owen HC, et al. Distinct microRNA alterations characterize high and low grade bladder cancer. Cancer Res 2009;69(21):8472-81.

23. Nagaraja AK, Creighton CJ, Yu Z, et al. A link between miR-100 and FRAP1/mTOR in clear cell ovarian cancer. Mol Endocrinol 2010;24(2):447-63.

24. Capellen D, Oliveira C, Ricol D, Medina SGD. Frequent activating mutations of FGFR3 in human bladder and cervix carcinomas. Nat Genet 1999;23:18-20. 
25. Richelda R, Ronchetti D, Baldini L, et al. A Novel Chromossomal Translocation $\mathrm{t}(4 ; 14)(\mathrm{p} 16.3 ; \mathrm{q} 32)$ in Multiple Myeloma Involves the Fibroblast Growth-Factor Receptor 3 Gene. Blood 1997;90(10):4062-70.

26. Chesi M, Nardini E, Brents LA, et al. Frequent translocation $t(4 ; 14)(p 16.3 ; q 32.3)$ in multiple myeloma is associated with increased expression and activating mutations of fibroblastic growth factor receptor 3. Nat Genet 1997:16:260-64.

27. Markowitz SB, Levin K. Continued Epidemic of Bladder Cancer in Workers Exposed to Ortho-Toluidine in a Chemical Factory. J Occup Environ Med 2004;46(2):154-60.

28. Kirkali Z, Chan T, Manoharan M, et al. Bladder Cancer: Epidemiology, Staging and Grading, and Diagnosis. Urology 2005;66(6):4-34.

29. Blick C, McCormick R, Ramachandran A, Buffa F, Catto J, Harris AL. The hypoxic and microRNA 100 regulation of FGFR3 in non-muscle invasive bladder cancer. 2011 (in press).

30. Choudhry H, Catto JWF. Epigenetic Regulation of MicroRNA Expression in Cancer. Methods Mol Biol 2011;676:165-184. 


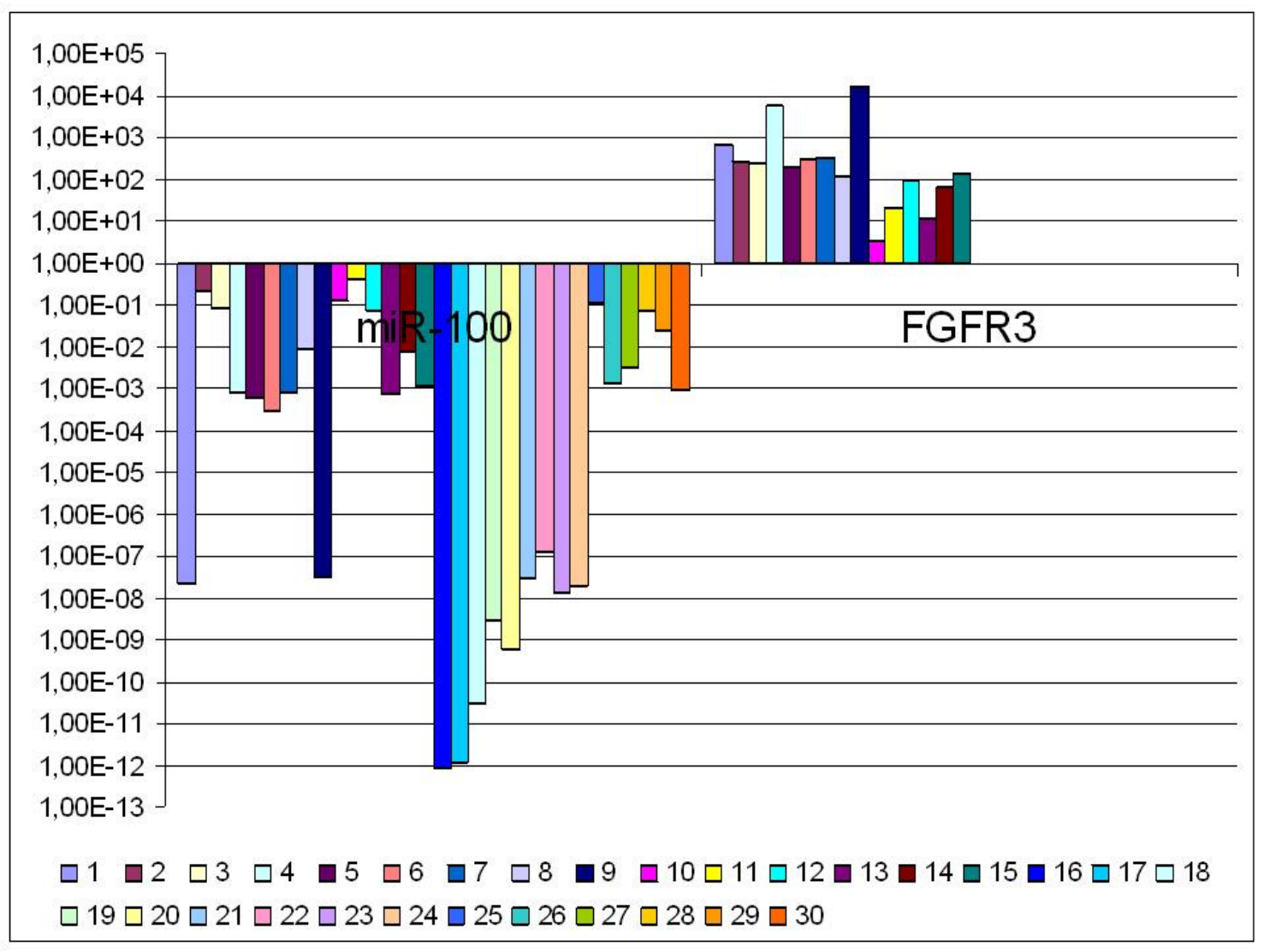

Figure 1. Expression levels of miR-100 and FGFR3. Note under-expression of all lowgrade non-invasive pTa tumors and $100 \%$ of robust over-expression of FGFR3. 
Table 1. miR-100 and FGFR3 expression values.

\begin{tabular}{|c|c|c|}
\hline Cases & miR-100 & FGFR3 \\
\hline 1 & $2.1 \mathrm{E}-08$ & 697.34 \\
\hline 2 & 0.1982 & 274.56 \\
\hline 3 & 0.0831 & 240.35 \\
\hline 4 & 0.0008 & 5556.65 \\
\hline 5 & 0.0006 & 202.95 \\
\hline 6 & 0.0003 & 289.01 \\
\hline 7 & 0.0008 & 313.21 \\
\hline 8 & 0.0086 & 112.59 \\
\hline 9 & $3.4 \mathrm{E}-08$ & 16002.39 \\
\hline 10 & 0.1172 & 3.26 \\
\hline 11 & 0.44 & 19.67 \\
\hline 12 & 0.0726 & 92.34 \\
\hline 13 & 0.0007 & 11.09 \\
\hline 14 & 0.0074 & 64.22 \\
\hline 15 & 0.0011 & 132.33 \\
\hline 16 & $8.9 \mathrm{E}-13$ & - \\
\hline 17 & $1.21 \mathrm{E}-12$ & - \\
\hline 18 & $3.14 \mathrm{E}-11$ & - \\
\hline 19 & 2.87E-09 & - \\
\hline 20 & $6.11 E-10$ & - \\
\hline 21 & $2.85 \mathrm{E}-08$ & - \\
\hline 22 & $1.18 \mathrm{E}-07$ & - \\
\hline 23 & $1.31 \mathrm{E}-08$ & - \\
\hline 24 & $2.03 E-08$ & - \\
\hline 25 & 0.1099 & - \\
\hline 26 & 0.0014 & - \\
\hline 27 & 0.0030 & - \\
\hline 28 & 0.0732 & - \\
\hline 29 & 0.0237 & - \\
\hline 30 & 0.0009 & - \\
\hline
\end{tabular}




\section{EXPRESSION PROFILE OF MICRO RNA-145 IN UROTHELIAL BLADDER}

\section{CANCER}

Nelson Dip ${ }^{1}$, Sabrina T. Reis ${ }^{1}$, Luciana S. Timoszczuk ${ }^{1}$, Nayara I. Viana ${ }^{1}$, Camila

B. Piantino ${ }^{1}$, Denis R. Morais ${ }^{1}$, Caio M. Moura ${ }^{1}$, Daniel K. Abe ${ }^{1,2}$, Miguel Srougi ${ }^{1}$, Marcos F. Dall'Oglio ${ }^{2}$, Katia R. M. Leite ${ }^{1}$

1. Laboratory of Medical Investigation, Urology Department - LIM55, University of Sao Paulo Medical School, Sao Paulo, Brazil

2. Uro-Oncology Group, Urology Department, Sao Paulo Cancer Institute (ICESP), Sao Paulo, Brazil

Corresponding author:

Nelson Gaspar Dip Júnior

Av. Dr. Arnaldo 455, room 2145

01246-903, Sao Paulo, Brazil

Phone/Fax 551130617183

nelson.dip@hotmail.com 


\section{ABSTRACT}

Purpose: Bladder cancer $(\mathrm{BC})$ is the second most common malignancy of the urinary tract, with high mortality. The knowledge of the molecular pathways associated with BC carcinogenesis is crucial to identify new diagnostic and prognostic biomarkers. MicroRNAs (miRNAs) are short non-coding RNA molecules that play important roles in the regulation of gene expression by acting directly on mRNAs. miR-145 has been considered as a tumor suppressor, which targets the c-MYC, MUC-1 and FSCN1 genes. Our aim was to evaluate the expression profile of miR-145 in low-grade non-invasive and high-grade invasive UC, followed over a mean time of 16.1 months.

Materials and Methods: We studied 30 specimens of low-grade, non-invasive pTa and 30 of $\mathrm{pT} 2 / \mathrm{pT} 3$ high-grade invasive UC obtained by transurethral resection or radical cystectomy. Normal controls were represented by five samples of normal bladder biopsy from patients who underwent retropubic prostatectomy to treat $\mathrm{BPH}$. miRNA extraction and cDNA generation were performed using commercial kits. Analysis was performed by qRT-PCR, and miR-145 expression was calculated using the $2^{-\Delta \Delta c t}$ method; we used RNU-43 and RNU-48 as endogenous controls.

Results: miR-145 was under-expressed in $73.3 \%$ and $86.7 \%$ of pTa and pT2/pT3, respectively, with expression means of 1.61 for the former and 0.66 for the last. There were no significant differences in miR-145 expression and histological grade, tumor stage, angiolymphatic neoplastic invasion and tumor recurrence.

Conclusion: miR-145 is under-expressed in low-grade, non-invasive and high-grade invasive urothelial bladder carcinoma and may play an important role in the carcinogenesis pathway, being an interesting candidate diagnostic marker.

Keywords: Micro RNA, miR-145, bladder urothelial carcinoma, diagnostic, prognostic, biomarker. 


\section{INTRODUCTION}

Bladder cancer $(B C)$ is the second most common malignancy of the urinary tract, and approximately 383,300 new cases are estimated to be diagnosed in 2011 (1). Ninety percent of BC are urothelial carcinomas (UC), previously known as transitional cell carcinomas, and the majority are papillary low-grade, non-muscle invasive cancers that recur in up to $80 \%$ of cases but rarely progress to muscle invasion $(2,3)$. In contrast, 10 to $20 \%$ of tumors are muscle invasive at diagnosis, and $50 \%$ of patients die from metastatic disease (4).

The molecular pathways underlying the two main distinct types of UC, lowgrade non-muscle invasive UC and high-grade muscle invasive UC $(2,5)$ have been investigated to identify new potential markers for diagnosis, disease monitoring, prognosis and the development of new targeted therapies $(2,6)$. The most common genetic alteration of $\mathrm{BC}$ associated with low-grade and low-stage is an activating mutation of the fibroblast growth factor receptor 3 (FGFR3) gene $(6,7)$, whereas mutations in p53, retinoblastoma (RB1) and PTEN have been identified as being characteristic of the carcinogenesis pathway for high-grade invasive BC (7-9).

The FGFR3 gene belongs to the growth factor receptor family related to the tyrosine kinase signaling pathway, which plays an important role in embryogenesis, development, angiogenesis, wound healing, tissue homeostasis and tumorigenesis, by regulating the processes of cellular proliferation, migration and apoptosis (7). Mutations are the primary phenomenon related to FGFR3 dysfunction by allowing ligand-independent operation $(7,10)$.

p53, RB1 and PTEN are traditional tumor suppressor genes that work together and trigger BC carcinogenic pathways through several mechanisms, ranging from missense mutation and subsequently loss-of-function (9). Moreover, PTEN gene is another tumor suppressor and play roles in cell proliferation, migrations and invasion trough PI3K/AKT/mTOR carcinogenic pathway $(3,9)$. Despite PTEN is related to development of non-invasive tumors, it is much more associated with promoters pathways and progression of invasive neoplasias. Other events are 
also related to alterations in protein expression, including DNA methylation, histone acetylation and abnormalities in the expression of microRNAs that contribute tothe development and progression of BC.

MicroRNAs (miRNAs) are members of small single-stranded regulatory RNAs (21-25 nucleotides) that can suppress translation or promote degradation of mRNAs, thereby regulating the expression of target genes, including transcription factors, oncogenes and tumor suppressor genes. MicroRNAs have been reported to be differentially expressed in several types of cancers. Currently, there are more than 1400 miRNAs identified in humans, and up to $30 \%$ of genes are thought to be regulated by miRNAs (11). MicroRNAs are involved in cell development, differentiation, apoptosis, tissue homeostasis and several metabolic pathways (1215) and have been related to carcinogenesis by acting as negative regulators of genes related to cancer, as exemplified by the effects of miR15a and miR16-1on BCL2 mRNA, miR-143 and miR-let7c on RAS mRNA as well as miR-21 on p53 mRNA (16-19).

miR-145 is located in chromosome $5 q 32$ and is widely established as a tumor suppressor. Several studies have validated miR-145 as an inhibitor of cellular proliferation, apoptosis, invasiveness and metastasis, as it is down-regulated in an array of cancers including those of the colorectum, lung, breast and prostate (2022). In colorectal cancer, it was firstly demonstrated that down-regulation of miR145 is involved with malignancies where miR-145 may play a role in tumor initiation $(23,24)$. In BC,a Japanese group previously showed under-expression of miR-145 that normally targets the oncogenes KRT-7 and FSCN1 $(25,26)$. However, they have not related miR-145 expression with important prognostic factors orperformed any follow-up. Our aim is to study the expression profile of miR-145 in low-grade, noninvasive and high-grade invasive $\mathrm{BC}$, speculating on its potential role as a prognostic or diagnostic marker. 


\section{MATERIAL AND METHODS}

\section{Patients}

Specimens of 30 low-grade, non-invasive, staged pTa and 30 high-grade invasive, staged $\mathrm{pT} 2 / \mathrm{pT} 3$ urothelial carcinomas obtained from patients who underwent transurethral resection or radical cystectomy were the subject of the study. Seventy-three percent of patients were male, and the mean age was 66.5 years, ranging from 41 to 86 years. As a control, we used normal bladder tissue from five patients who underwent retropubic prostatectomy to treat benign prostatic hyperplasia. All patients provided informed consent, and the study design was approved by the Institutional Board of Ethics,Protocol \#0176/10.

A $1-\mathrm{cm}^{2}$ fragment of tumor tissue was immediately frozen and stored at $80^{\circ} \mathrm{C}$ for molecular studies. The remaining tissue was fixed in $10 \%$ formalin, routinely processed and stained with hematoxylin and eosin for histological examination. Only low-grade, non-invasive pTa and high-grade invasive pT2/pT3 tumors were included in the study. For tumor grading, we used the WHO/ISUP 2004 and for staging AJCC/TNM 2010 classifications. The mean follow-up time was 16.1 months.

\section{miRNA extraction and amplification}

miR-145 was isolated using a mirVana $\mathrm{Kit}^{\circledR}$ (Applied Biosystems, CA, USA) according to the manufacturer's instructions, and the concentration was determined by 260/280 $\mathrm{nm}$ absorbance using a Nanodrop ${ }^{\circledR}$ ND-1000 spectrophotometer (Thermo Scientific). miRNA cDNA was generated using a Taqman MicroRNA Reverse Transcription $\mathrm{Kit}^{\circledR}$ (Applied Biosystems, CA, USA). miRNA reactions were incubated at $16{ }^{\circ} \mathrm{C}$ for $30 \mathrm{~min}, 42{ }^{\circ} \mathrm{C}$ for $30 \mathrm{~min}$ and $85^{\circ} \mathrm{C}$ for 5 min. The CDNA was stored at $-20^{\circ} \mathrm{C}$ until further use. 
For miRNA amplification, a Taqman Reagent Kit ${ }^{\circledR}$ (Applied Biosystems, CA, USA) and the 7500 Fast Real-Time PCR System ${ }^{\circledR}$ (Applied Biosystems, CA, USA) were used.

Expression profiles of miR-145 were obtained by relative quantification determined by the $2^{-\Delta \Delta c t}$ method. The formula includes the following mathematic sentences: $\triangle \Delta C T=\mathrm{dCT}_{1}-\mathrm{dCT}_{2}$, where $\mathrm{dCT}_{1}=\mathrm{CT}$ of miRNA-target, (tumor sample) $\mathrm{CT}$ of mean of endogenous control (tumor sample), and $\mathrm{dCT}_{2}=\mathrm{CT}$ of mean of normal controls (normal bladder samples) - CT of mean of endogenous control (normal bladder samples). The final result is obtained by application of $2^{-\Delta \Delta c t}$ method and findings greater and smaller than 1 are considerate over and under-expressed, respectively.

The reactions were conducted in duplicate, and RNU-43 and RNU-48 were used as endogenous controls. Endogenous RNUs are miRNAs produced by cell machinery and they do not play roles over cellular functions and show a stable behavior. Thus, they were used to stardardize the values in mathematic formula.

\section{Statistical analysis}

Mann-Whitney $U$ tests, ANOVA and $T$ tests were used to compare miR-145 expression levels with tumor grade, stage and angiolymphatic invasion, respectively. The distribution of the expression levels of miR-145 was skewed; therefore, the data were log-transformed for analyses. The results are presented as the geometric means ata $95 \%$ confidence interval $(95 \% \mathrm{Cl})$. The number 1 in logarithmic graphics represent normal bladder samples and the expression levels are represented at times, for overexpression (greater than 1) or underexpression (smaller than 1). 


\section{RESULTS}

miR-145 was under-expressed in $73.3 \%(22 / 30)$ and $86.7 \%(26 / 30)$ of pTa and $\mathrm{pT} 2 / \mathrm{pT} 3$, respectively, as presented in Figure 1 . Although both groups showed miR-145 under-expressed, we can observe that levels of under-expression were more evident in $\mathrm{pT} 2 / \mathrm{pT} 3$ group. Furthermore, when we consider samples overexpressed ( $8 / 30$ for pTa and 4/30 for pT2/pT3), the levels of over-expression were greater in low-grade, non-invasive pTa group, when compared with high-grade invasive $\mathrm{pT} 2 / \mathrm{pT} 3$ tumors.

Expression values of miR-145 in $\mathrm{pTa}, \mathrm{pT} 2 / \mathrm{pT} 3$ and normal bladder controls are represented in Table 2. The mean and median expression of miR-145 was 1.61 and $0.2(0.002-24.07)$ in pTa and 0.66 and $0.13(4.4 \mathrm{E}-05-10.25)$ in pT2/pT3, respectively. We observed no significant differences when we compared miR-145 expression in $\mathrm{pTa}$ and $\mathrm{pT} 2 / \mathrm{pT} 3$ when considering grade $(\mathrm{p}=0.27)$, stage $(\mathrm{p}=0.48)$ and angiolymphatic invasion $(p=0.89)$. Additionally, there was no difference regarding tumor recurrence (Table 1$)$.

\section{DISCUSSION}

Although we did not detect any differences in miR-145 expression between low- and high-grade tumors, our results show that this miRNA is under-expressed in both urothelial carcinomas; the lowest miRNA levels were detected in the second group (86.7\%). In BC, miR-145 can silence a large number of genes and has been involved in bladder carcinogenesis. Ichimi et al. (27) have previously shown miR145 under-expression in BC by microarray and qRT-PCR, but they did not characterize the relationship between miR-145 expression with histological grading, staging or tumor behavior.

miR-145 is located on chromosome $5 q 32$ and is considered a tumor suppressor miRNA because of its negative regulation of target mRNAs involved in 
the control of the cell cycle, apoptosis, invasiveness and metastasis, exerting a fundamental role in cellular and tissue homeostasis $(22-24,29)$.

The first report of miR-145 under-expression was performed by Michael et al. (23) in a study suggesting that these alterations could be involved in the initiation of colorectal cancer. These findings were confirmed by Shi et al. (24) who showed that miR-145 under-expression was associated with malignant tumors.

Accumulating evidence suggest that microRNAs could be key players in the regulation of tumor cell invasion and metastasis. Sachdeva and Mo (27) have shown in breast cancer cells lines that miR-145 targets the Mucin 1 (MUC-1) gene, involved in initiation, invasiveness and tumor dissemination. Another miR-145 target is CMYC (22). miR-145 inhibits c-MYC, a negative regulator of $p 21$, and loss of miR-145 expression could be involved in a failure of c-MYC regulation, lowering levels of p21 and increasing cellular proliferation rate. c-MYC over-expression could also stimulate CDK-4/6 and cyclin D1, promoting RB1 phosphorylation, which would also trigger mitosis and cellular proliferation. The other role of miR-145 is to enhance p53 function by MDM-2 indirect inhibition (6). p53 gene is one of the main indirect targets of miR-145 and is directly related to the high-grade invasive BC carcinogenesis pathway. In 2009, Sachdeva et al. (22) observed that, under physiological conditions, higher levels of p53 due to cellular stress leads to increased levels of miR-145 through the p53 response element (p53RE). p53 can also trigger the enzymatic machinery of microRNAs, mainly the RNase III Drosha, promoting higher expression levels of several microRNAs including miR-145. Loss of p53 function through mutations could generate a lack of production and consequent under-expression of miR-145 (29).

Spizzo et al. (28) demonstrated a tumor suppressor role of miR-145, preventing cell growth and inducing apoptosis through stimulation of p53, by transfecting miR-145 into breast cancer cell lines. This experiment could suggest a therapeutic use of miR-145 in tumors. 
The FSCN1 gene is another target of miR-145. The protein product of this gene is required to form protrusions of the cellular membrane and cytoplasmic movements related to migration. In malignant neoplasms, FSCN1 activity has been correlated to high-grade disease, extensive invasion, metastasis and poor prognosis (30). Chiyomaru et al. (26) concluded that there is an association between FSCN1 oncogene over-expression due to miR-145 under-expression in BC, which leads to a more aggressive phenotype. The authors found a positive correlation between high tumor stage and low levels of miR-145. However, we did not find a relationship between miR-145 expression and tumor grade or stage or angiolymphatic tumor embolization.

We also investigated the levels of miR-145 with tumor recurrence and found no association between both groups. Here, we can make the case that miR-145 is important to tumor carcinogenesis and triggers low-grade, non-invasive pTa tumorigenesis through the lack of control of AKT. We also speculate that miR-145 is involved in our cases of high-grade invasive pT2/pT3 carcinomas through MUC-1, cMYC, p53 and FSCN1 deregulation.

The casuistic was limited, and groups greater than 30 samples are wished. Maybe this fact could really be related to ausence of statistical differences. Another limitation was a short follow-up.

\section{CONCLUSIONS}

miR-145 is a well-characterized tumor suppressor miRNA. We hypothesize that lack of protector role promoted by this miRNA over probable target genes $\mathrm{PI3K} / \mathrm{AKT}, \mathrm{FSCN} 1, \mathrm{MDM} 2, \mathrm{c}-\mathrm{Myc}$ and MUC-1 could be involved in carcinogenic process of low-grade, non-invasive and high-grade invasive urothelial carcinomas, triggering their carcinogenesis. Since we found miR-145 widely under-expressed in both tumor groups, we speculate its use as a possible diagnostic marker. These findings should be tested in experimental models. 


\section{REFERENCES}

1. Jemal A, Bray F, Center MM, Ferlay J, Ward E, Forman D. Global Cancer Statistics 2011. Cancer J Clin 2011;61(2):69-90.

2. Jebar AH, Hurst CD, Tomlinson DC, Johnston C, Taylor CF, Knowles MA. FGFR3 and Ras gene mutations are mutually exclusive genetic events in urothelial cell carcinoma. Oncogene 2005;24(33): 5218-25.

3. McConkey DJ, Lee S, Choi W, Tran M, Majewski T, Lee S et al. Molecular genetics of bladder cancer: Emerging mechanisms of tumor initiation and progression. Urol Oncol 2010;28(4):429-40.

4. Borden LS, Clark PE, Hall MC. Bladder Cancer. Curr Opin Oncol 2005;17(3):275-80.

5. van Rhijn BWG, van der Kwast TH, Vis AN, Kirkels WJ, Boevé ER, Jöbsis $A C$ et al. FGFR3 and P53 Characterize Alternative Genetic Pathways in the Pathogenesis of Urothelial Cell Carcinoma. Cancer Res 2004;64(6):1911-14.

6. Martinez-Torrecuadrada J, Cifuentes G, López-Serra P, Saenz P, Martínez A, Casal JI. Targeting the Extracellular Domain of Fibroblast Growth Factor Receptor 3 with Human Single-Chain Fv Antibodies Inhibits Bladder Carcinoma Cell Line Proliferation. Clin Cancer Res 2005;11(17):6280-90.

7. Castillo-Martin M, Domingo-Domenech J, Karni-Schmidt O, Matos T, CordonCardo C. Molecular pathways of urothelial development and bladder tumorigenesis. Urol Oncol 2010;28(4):401-8.

8. Knowles MA. Molecular pathogenesis of bladder cancer. Int J Clin Oncol 2008; 13(4):287-97.

9. Pandith AA, Shah ZA, Siddiqi MA. Oncogenic role of fibroblastic growth factor receptor 3 in tumorigenesis of urinary bladder cancer. Urol Oncol 2010 (in press). 
10. Bakkar AA, Wallerand H, Radvanyi F, Lahaye JB, Pissard S, Lecerf L et al. FGFR3 and TP53 Gene Mutations Define Two Distinct Pathways in Urothelial Cell Carcinoma of Bladder. Cancer Res 2003;63(23):8108-12.

11. Wu XR. Biology of urothelial tumorigenesis: insights from genetically engineered mice. Cancer Metastasis Rev 2009:28(3-4):281-90.

12. Ornitz DM, Xu J, Colvin JS, McEwen DG, MacArthur CA, Coulier F et al. Receptor Specificity of the Fibroblast Growth Factor Family. J Biol Chem 1996:271(25): 15292-97.

13. Lewis BP, Burge CB, Bartel DP. Conserved Seed Pairing, Often Flanked by Adenosines, Indicates that Thousands of Human Genes are MicroRNA Targets. Cell 2005;120(1):15-20.

14. Ambros V. MicroRNA Pathways in Flies and Worms. Cell 2003;113(6):673-76.

15. Bartel DP. MicroRNAs: Genomics, Biogenesis, Mechanism, and Function. Cell 2004; 116(2):281-97.

16. Croce CM, Calin GA. miRNAs, cancer and stem cell division. Cell 2005;122(1):6-7.

17. Blenkiron C, Miska E. MiRNAs in cancer: approaches, aetiology, diagnostics and therapy. Hum Mol Genet 2007;16(1):106-13.

18. Cimmino A, Calin GA, Fabbri M, lorio MV, Ferracin $M$, Shimizu $M$ et al. miR-15 and miR-16 induce apoptosis by targeting BCL2. PNAS 2005;102(39):13944-49.

19. Lin T, Dong W, Huang J, Pan Q, Fan X, Zhang C et al. MicroRNA-143 as a Tumor Suppressor for Bladder Cancer. J Urol 2009;181(3):1372-80.

20. Johnson SM, Grosshans H, Shingara J, Byrom M, Jarvis R, Cheng A et al. RAS is Regulated by the let-7 MicroRNA Family. Cell 2005;120(5):635-47. 
21. Catto JWF, Miah S, Owen HC, Bryant H, Myers K, Dudziec E et al. Distinct microRNA alterations characterize high and low grade bladder cancer. Cancer Res 2009;69(21):8472-81.

22. Ozen $\mathrm{M}$, Creighton $\mathrm{CJ}$, Ozdemir $\mathrm{M}$, Ittmann $\mathrm{M}$. Widespread deregulation of microRNA expression in human prostate cancer. Oncogene 2008;27(12):178893.

23. Izzoti A, Calin GA, Arrigo P, Steele VE, Croce CM, De Flora S. Downregulation of microRNA expression in the lungs of rats exposed to cigarette smoke. Faseb J 2009; 23(3);806-12.

24. Sachdeva M, Zhu S, Wu F, Wu H, Walia V, Kumar S et al. p53 reppresses c-Myc through induction of the tumor suppressor miR-145. PNAS 2009;106(9): 320712.

25. Michael MZ, O'Connor SM, van Holst Pellekaan NG, Young GP, James RJ. Reduced accumulation of specific microRNA in colorectal neoplasia. Mol Cancer Res 2003;1(12):882-91.

26. Shi B, Sepp-Lorenzino L, Prisco M, Linsley P, deAngelis T, Baserga R. Micro RNA 145 targets the insulin receptor substrate- 1 and inhibits the growth of colon cancer cells. J Biol Chem 2007;282(45):32582-90.

27. Ichimi T, Enokida H, Okuno Y, Kunimoto R, Chiyomaru T, Kawamoto $\mathrm{K}$ et al. Identification of novel microRNA targets based on microRNA signatures in bladder cancer. Int J Cancer 2009;125(2):345-52.

28. Chiyomaru T, Enokida H, Tatarano S, Kawahara K, Uchida Y, Nishiyama K et al. miR-145 and mir-133a function as tumour suppressors and directly regulate FSCN1 expression in bladder cancer. British J Cancer 2010;102(5):883-91.

29. Sachdeva M, Mo Y. miR-145-mediated suppression of cell growth, invasion and metastasis. Am J Transl Res 2010;2(2):170-80. 
30. Spizzo R, Nicoloso MS, Lupini L, Lu Y, Fogarty J, Rossi S et al. miR-145 participates with TP53 in death-promoting regulatory loop and targets estrogen receptor- $\alpha$ in human breast cancer cells. Cell Death and Differentiation 2010; 17(2): 246-54.

31. Suzuki HI, Yamagata K, Sugimoto K, Iwamoto T, Kato S, Miyazono K. Modulation of microRNA processing by p53. Nature 2009;460(7254):529-33, 2009.

32. Vignjevic D, Kojima S, Aratyn Y, Danciu O, Svitkina T, Borisy GG. Role of fascin in filopodial protusion. J Cell Biol 2006;174(6):863-75. 

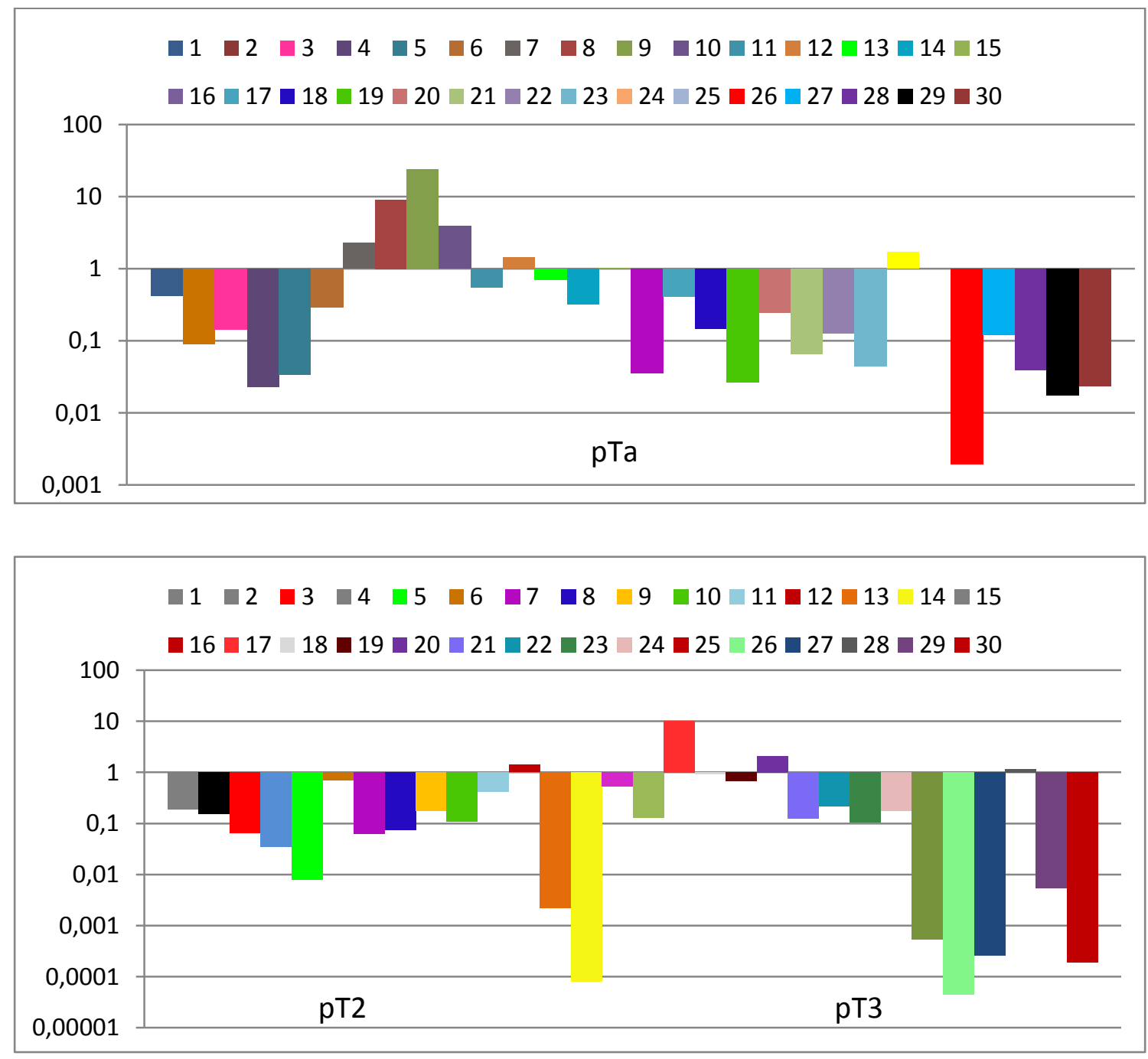

Figure 1. Expression profile of miR-145 in pTa low-grade non-invasive and pT2/pT3 high-grade invasive UC. 
Table 1. miR-145 expression in low-grade non-invasive (pTa) and high-grade invasive (pT2/pT3) UC.

\begin{tabular}{|c|c|c|c|c|c|c|c|c|}
\hline \multirow[b]{2}{*}{ miR-145 } & \multirow{2}{*}{$\begin{array}{c}\text { Low } \\
\text { grade } \\
(30)\end{array}$} & \multirow{2}{*}{$\begin{array}{c}\text { High } \\
\text { grade } \\
(30)\end{array}$} & \multirow[t]{2}{*}{$\begin{array}{l}\text { pTa } \\
(30)\end{array}$} & \multirow[t]{2}{*}{$\begin{array}{l}\text { pT2-3 } \\
(30)\end{array}$} & \multicolumn{2}{|c|}{$\begin{array}{l}\text { Angiolymphatic tumor } \\
\text { embolization }\end{array}$} & \multicolumn{2}{|c|}{ Tumor recurrence } \\
\hline & & & & & Yes & No & Yes & No \\
\hline & & & & & (16) & (44) & (29) & (31) \\
\hline Mean & 1.63 & 0.66 & 1.63 & 0.66 & 0.38 & 1.42 & 0.43 & 1.93 \\
\hline Median & 0.20 & 0.13 & 0.20 & 0.13 & 0.12 & 0.15 & & \\
\hline Min & 0.001 & $4.4^{-5}$ & 0.001 & $4.4^{-5}$ & $4.4^{-5}$ & $8.0^{-5}$ & & \\
\hline Max & 24.06 & 10.20 & 24.06 & 10.20 & 2.08 & 24.06 & & \\
\hline$P$ value & \multicolumn{2}{|c|}{0.27} & \multicolumn{2}{|c|}{0.48} & \multicolumn{2}{|c|}{0.89} & \multicolumn{2}{|c|}{0.44} \\
\hline
\end{tabular}




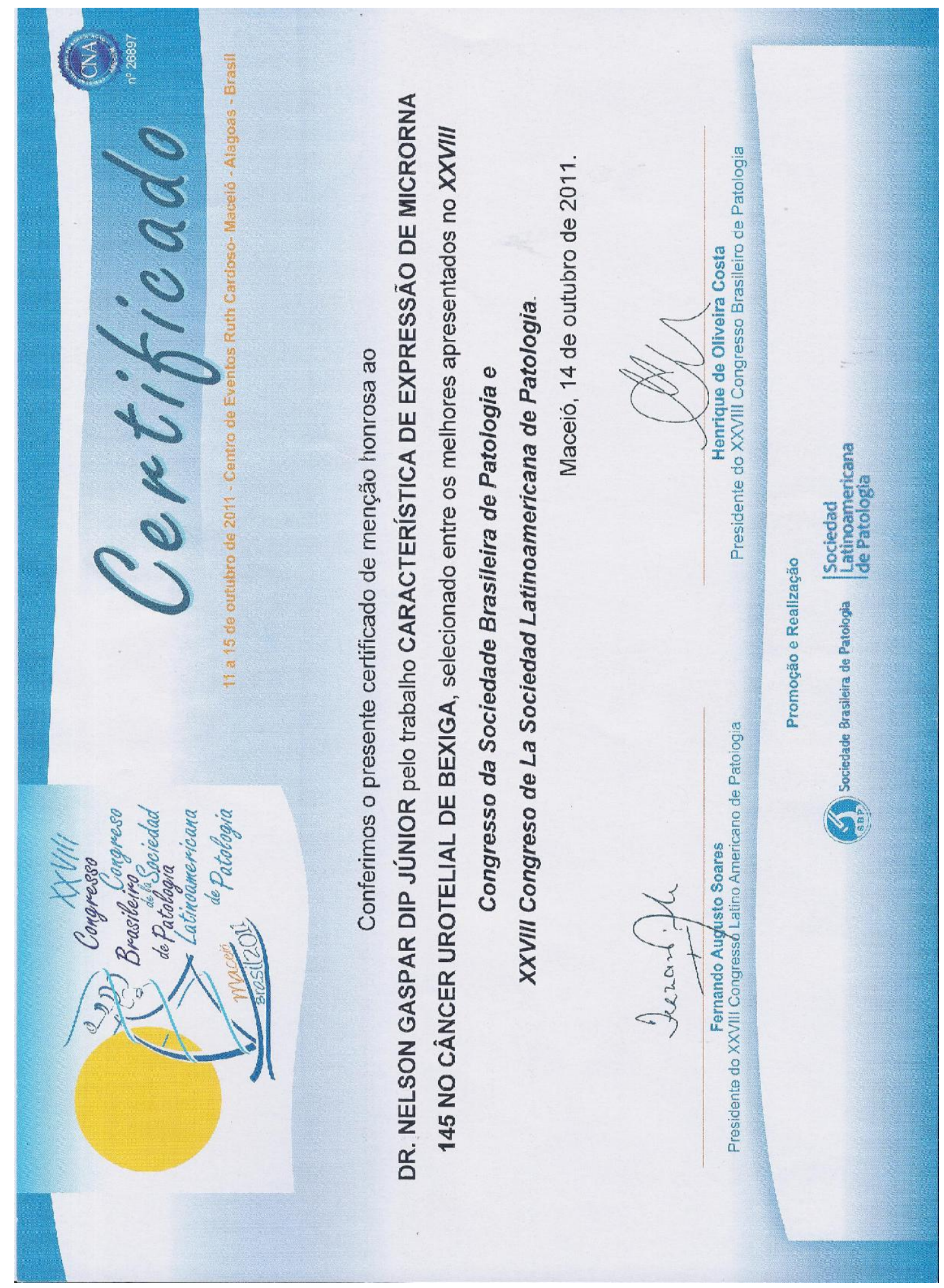




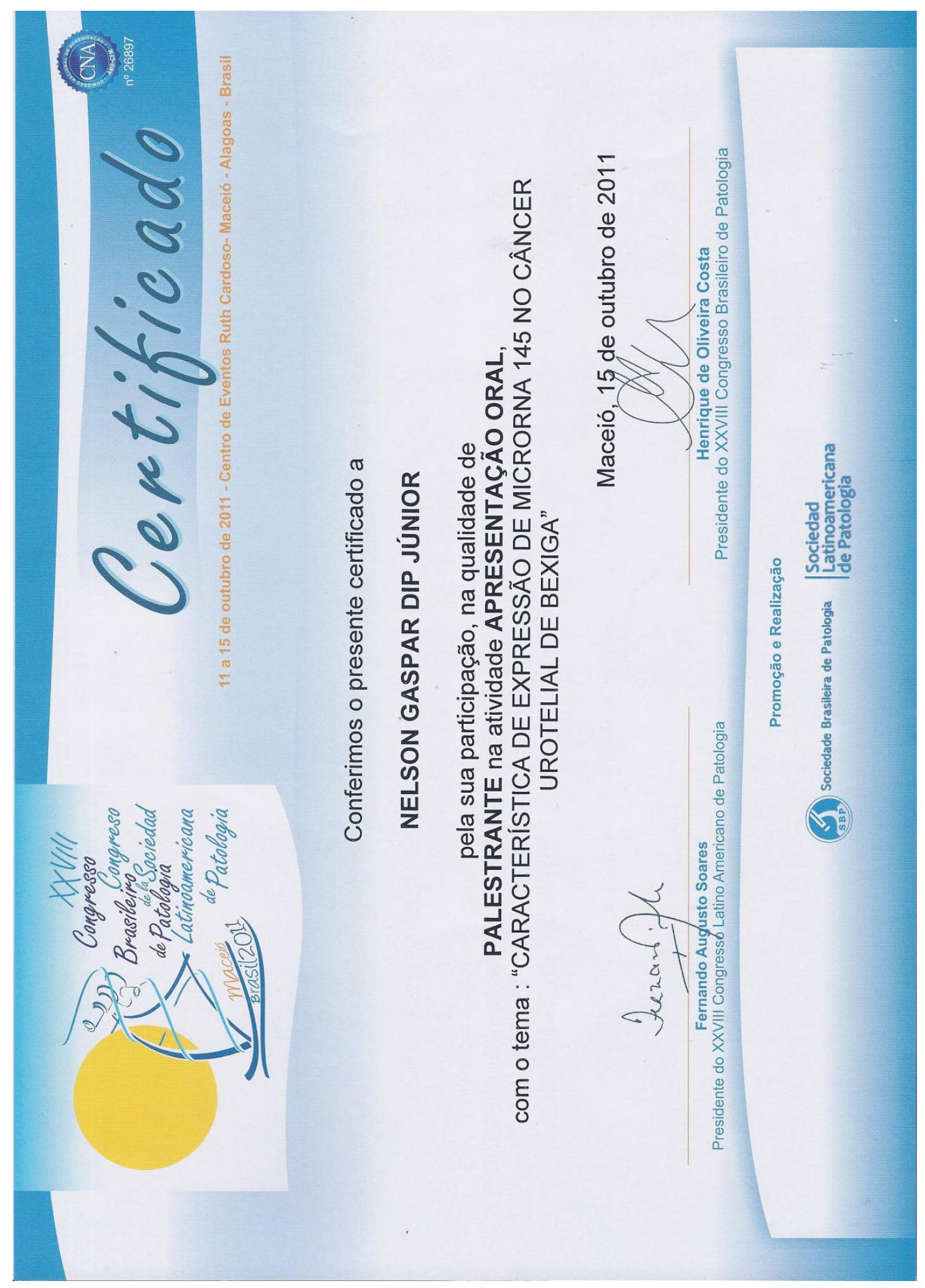



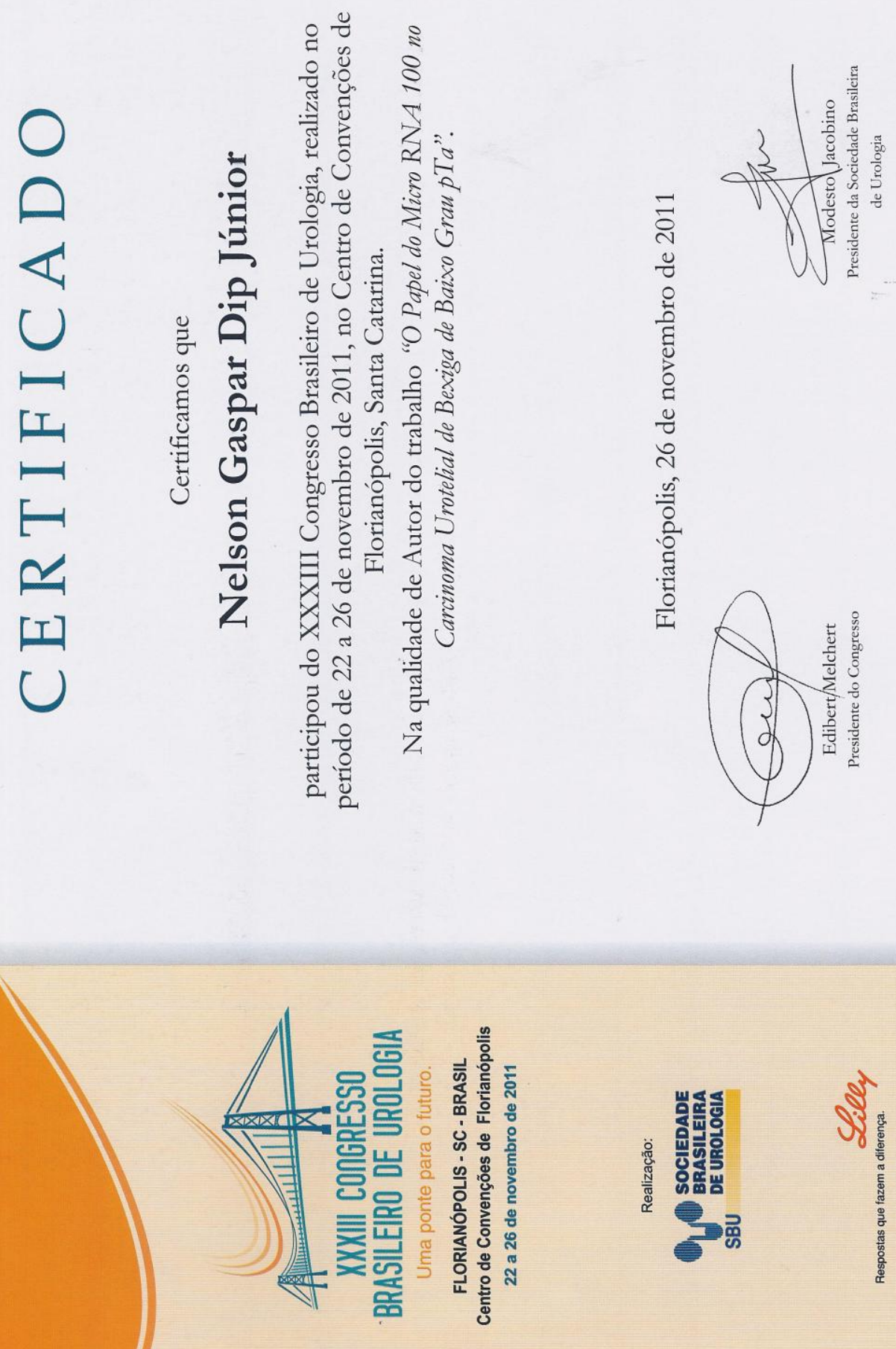


\section{AUA Annual Meeting 2012}

883

Micro RNA profile of superficial and invasive bladder urothelial carcinomas related to disease-free and cancer-specific survival

Nelson Dip*, Sabrina Reis, Daniel Abe, Sao Paulo, Brazil, Marcos Dalloglio, São Paulo, Brazil, Miguel Srougi, Kátia Leite, Sao Paulo, Brazil

INTRODUCTION AND OBJECTIVES: Bladder Cancer $(\mathrm{BC})$ is the second most common tumor of genitourinary tract with 383,000 estimated deaths in 2011. Urothelial carcinomas (UC) represent $95 \%$ of the cases, and the knowledge of molecular pathways associated to BC carcinogenesis is crucial to identify new diagnostic and prognostic biomarkers. Micro RNAs (miRNAs) are short non-coding RNA molecules that play important roles in gene expression regulation, acting over messenger RNA repressing translation. Studies of miRNA in BC are still preliminary and the purpose of this study is to identify an expression profile of miRNA in low-grade non-invasive pTa and high-grade invasive pT2/3 UC, also evaluating their involvement with tumor progression.

METHODS: Expression levels of 14 miRNAs were analyzed by qRT-PCR using TaqMan system in fresh-frozen tumor specimens collected from 60 patients who underwent transurethral resection or radical cystectomy, 30 patients representing pTa low-grade UC and $30 \mathrm{pT} 2 / \mathrm{pT} 3$ high grade UC. Five specimens of normal bladder obtained from patients who underwent transvesical prostatectomy to treat benign prostate hyperplasia were used as controls. For internal control we used two small nucleolar RNA RNU-43 and 48. Also disease-free (DFS) and disease-specific survival (DSS) were evaluated with a mean follow up of 16.1 months

RESULTS: Only four miRNAs showed difference in expression considering pTa and pT2/3 tumors, miR-100, miR-10a, miR-21 and miR-205. The differentially expressed miRNAs in both groups are exposed in table 1. Considering tumor behavior, for pTa UC the overexpression of miR-21 was related to shorter DFS. For pT2/3 UC the overexpression of miR-145 was related to shorter DFS and the underexpression of miR-10a was related to shorter DFS and DSS.

CONCLUSIONS: We have shown that there is a specific profile of miRNAs for pTa and pT2/3 UC and some miRNAs are related to tumor behavior and that could be used to better preview tumor prognosis, which may help in deciding the better treatment for patients with UC.

Source of Funding: FAPESP \#10/50824-1

\begin{tabular}{|c|c|c|c|}
\hline miRNA & $\begin{array}{c}\text { Low grade } \\
\text { pTa } \\
(n=30)\end{array}$ & $\begin{array}{c}\text { High grade } \\
\text { pT2/T3 } \\
\text { (n=30) }\end{array}$ & $p$ \\
\hline 100 & $\begin{array}{c}0,04 \\
0,0008 \\
\left(8,94^{-13}-0,44\right)\end{array}$ & $\begin{array}{c}24,39 \\
1,77 \\
(0,02-526,6)\end{array}$ & $<0,001$ \\
\hline $10 a$ & $\begin{array}{c}46,38 \\
4,88 \\
(0,004-761,2)\end{array}$ & $\begin{array}{c}0,23 \\
0,06 \\
(0,001-1,75)\end{array}$ & $<0,001$ \\
\hline 21 & $\begin{array}{c}1,08 \\
0,4 \\
(0,002-11,14)\end{array}$ & $\begin{array}{c}18,17 \\
0,65 \\
(0,03-407,99)\end{array}$ & 0,03 \\
\hline 205 & $\begin{array}{c}0,07 \\
0,04 \\
(0,002-0,35)\end{array}$ & $\begin{array}{c}6,91 \\
0,65 \\
(0,009-97,84)\end{array}$ & $<0,001$ \\
\hline
\end{tabular}

